\title{
The Determinants of International Student Demand in New Zealand and the OECD
}

By

Logan Sinclair Page

A thesis

submitted to the Victoria University of Wellington in fulfilment of the requirements for the degree of Master of Commerce

Victoria University of Wellington 


\begin{abstract}
Tertiary education, once a purely domestic affair, has become an increasingly globalised industry over previous decades. Whilst the international sector has grown to being New Zealand's fourth largest export market (Ministry of Education, 2016), there is a lack of credible research on the demand of international students.
\end{abstract}

This thesis aims to provide a greater understanding of the determinants of international student demand, both in New Zealand and internationally. I firstly provide a descriptive analysis of the trends in the international student market for New Zealand and 27 OECD countries. Secondly, I use a fixedeffects approach to analyse the demand of international students within New Zealand, using fees data at the course-by-university level. Thirdly, I then generalise this approach to the international market to provide an analysis of the demand for international students travelling to the OECD.

The findings from these analyses imply that the demand for international university education is relatively inelastic. The impact of a marginal increase in fees decreases the number of EFTS/students at a proportion of less than one. Furthermore, this effect is generally not statistically distinguishable from zero. 


\section{Acknowledgements}

Thanks firstly, to Bob Buckle and the Enabling Asia Pacific Trading Nation Steering Group for providing the scholarship that allowed me to undertake this research. Thanks are also due to Colin Smithies, for his helpful advice and comments, as well as pointing me towards the Ministry of Education data cubes. I would also like to thank the Victoria Business Intelligence Group and Victoria International for helpful comments.

Thanks to Dr. Paul Calcott for running the administrative side of the degree and putting me forward for the Bernard Edward Murphy Memorial Scholarship which allowed me to focus full-time on my studies.

Finally, many thanks to Dr. Harold Cuffe for his patient guidance in supervising my research. I could not ask for a better supervisor. 


\section{Contents}

1 Introduction 4

2 Literature $\quad 6$

2.1 Background . . . . . . . . . . . . . . 6

2.2 International Mobility/Migration Literature . . . . . . . . 7

2.3 Economics of Education Literature . . . . . . . . . . . . 10

2.3.1 Aid programs as variation in fees . . . . . . . . . 11

2.3.2 Political Changes . . . . . . . . . . . . . . . . 12

3 Data $\quad 15$

3.1 New Zealand Data . . . . . . . . . . . . . . . . . . . 15

3.1.1 Students . . . . . . . . . . . . . . . 15

3.1 .2 Fees . . . . . . . . . . . . . . . 16

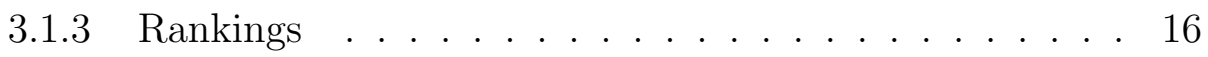

3.1.4 Exchange Rates . . . . . . . . . . . . . . . 16

3.2 Global Data . . . . . . . . . . . . . . . . . 16

3.2.1 Students . . . . . . . . . . . . . . . 17

3.2 .2 Fees . . . . . . . . . . . . . . . . . . . . . . . . . . . . . 17

3.2.3 Exchange Rates . . . . . . . . . . . . . . 18

4 Descriptive Evidence and Trends $\quad 19$

4.1 New Zealand Market . . . . . . . . . . . . . . . . . . . . . . . 20

4.1 .1 EFTS ........................ 20

4.1 .2 Fees . . . . . . . . . . . . . . . . 24

4.1.3 Change in Fees versus Change in EFTS . . . . . . . . . 28

4.1.4 Ranking . . . . . . . . . . . . . . . . . 30

4.1.5 Exchange rates . . . . . . . . . . . . . 31

4.2 Overseas Market . . . . . . . . . . . . . . . . . 32

4.2.1 Number of Students . . . . . . . . . . . . . . 32

4.2 .2 Fees . . . . . . . . . . . . . . . . 35

4.2.3 Exchange Rates . . . . . . . . . . . . . . 38 
5 Empirical Strategy and Methodology 39

5.1 Observable Covariates and Unobservable Confounders . . . . . 39

5.1 .1 Omitted Variables Bias . . . . . . . . . . . . . . . . 40

5.1 .2 Simultaneity Bias . . . . . . . . . . . . . . . . 40

5.2 Fixed Effects Model . . . . . . . . . . . . . . . . . . . . . . . 41

5.2 .1 Motivation . . . . . . . . . . . . . . . . . . 41

5.2 .2 Zero values . . . . . . . . . . . . . . . . . . . . 42

5.2 .3 Log-transformation . . . . . . . . . . . . . . . . . 42

5.2 .4 Clustering . . . . . . . . . . . . . . . . . . 43

6 Results 44

6.1 New Zealand Model . . . . . . . . . . . . . . . . . . . . . 44

6.1.1 University Level Model . . . . . . . . . . . . . . . . . . 44

6.1.2 Subject Level Model . . . . . . . . . . . . . . . . . . 48

6.1.3 Country by Subject Level Model . . . . . . . . . . . 51

6.2 All Countries Model . . . . . . . . . . . . . . . . . . . 54

6.2.1 Domestic Fees Model . . . . . . . . . . . . . . . . . . 54

6.2.2 Domestic Fees Model: Fees $=0$ Dropped . . . . . . 58

7 Discussion $\quad 61$

7.1 Optimal Pricing . . . . . . . . . . . . . . . . 61

7.1.1 Heterogeneity . . . . . . . . . . . . . . . . . . . . 61

7.1.2 Capacity Constraints . . . . . . . . . . . . . . 63

7.1 .3 Equity Concerns . . . . . . . . . . . . . . . . . . 64

7.1.4 Information . . . . . . . . . . . . . . . 64

7.2 Limitations and Avenues for Future Work . . . . . . . . . . 64

7.3 Final Remarks . . . . . . . . . . . . . . . . . . 66

$\begin{array}{ll}\text { References } & 68\end{array}$

$\begin{array}{ll}\text { Appendices } & 73\end{array}$

A New Zealand Model $\quad \mathbf{7 4}$

A.1 International EFTS by Country, (All Countries) . . . . . . . 74

A.2 EFTS by University for Selected Courses . . . . . . . . . 75

A.3 University Fees by Course . . . . . . . . . . . . . . . . . 79

B OECD Model 82

B.1 Foreign Fees Assumptions . . . . . . . . . . . . . . . 82

B.2 Sending-Country International Students . . . . . . . . 84 


\section{Chapter 1}

\section{Introduction}

The internationalisation of domestic education systems has been an ongoing process throughout the last fifty years. International education is now New Zealand's fourth largest export market (Ministry of Education, 2016), with New Zealand having the highest number of international students per capita in the OECD (Wilkinson, 2010). Universities only host around $16 \%$ of international students who come to New Zealand, but charge much higher fees than primary and secondary schools (Education NZ, 2016b), and make up $27.9 \%$ of the sectors' contribution to GDP (Education NZ, 2016a).

In New Zealand, international students in university can expect to pay upwards of five times the average fee for a domestic student. This would imply that international students who choose to come to New Zealand might be less price-sensitive than domestic students. However, to what degree these level differences imply a difference in price-sensitivity in elasticity, or changes in price is not well understood in New Zealand, or indeed, internationally.

Academic research on the burgeoning international education market has not kept up with the rising importance of this industry. This is partly due to empirical issues. The two issues of major concern are simultaneity bias and omitted-variable bias. Prices are often set in conjunction with demand and we might expect demand to determine prices to some degree. In addition, the demand for a given university's education will depend on other factors such as prestige, living conditions and marketing, which are not always measurable.

This thesis attempts to provide a greater understanding of the demand of international students. I provide two models of the demand of international students. The first model, focuses on the price response of New Zealand 
international students, using a fixed-effects approach. The second model extends this fixed-effects approach to the global market providing an analysis of the elasticity of demand of 17 OECD countries.

The rest of this thesis proceeds as follows: Chapter 2 presents a review of the current body of research on international students, focusing on the economics of education, and the economics of migration literature. Chapter 3 provides an overview of the sources of data for my empirical analyses. Chapter 4 provides a descriptive background of the New Zealand international students market. Chapter 5 discusses the empirical concerns surrounding my research, and how my empirical approaches aim to account for these. Chapter 6 provides the results from my analyses. Chapter 7 concludes with a discussion of these findings, covering evidence of heterogeneity, implications for optimal pricing of university places, and avenues for future research. 


\section{Chapter 2}

\section{Literature}

\subsection{Background}

The number of international students in New Zealand has grown from 2,000 in 1993 (Butcher, 2004), across all levels, to 114,312 in 2015-2016 (Education NZ, 2017). The majority of these students are of Indian and Chinese descent, ${ }^{1}$ from wealthier backgrounds and end up primarily in Auckland (Education NZ, 2017). Survey evidence suggests that students are often attracted to New Zealand by the lower cost of NZ education compared to other Anglosphere countries, the quality of English instruction and permanent migration opportunities (Wilkinson, 2010).

With the growth in the number of students, the importance and contribution of the sector to the national economy has increased proportionally. In 1999 the contribution of the international education sector to New Zealand's GDP was estimated at $\$ 545$ million, by 2004 this had grown to $\$ 2.2$ billion (Infometrics, 2008). This slumped heavily over the 2007-2009 period due to global pressures including the Global Financial Crisis, with a $25 \%$ decrease in enrolments from 2004 to 2008 (Ministry of Education, 2011). The sector has recovered quite strongly however, with an increase in GDP contribution from $\$ 2.4$ billion in $2012 / 2013$ to $\$ 4.0$ billion in 2015 (Education NZ, 2016a).

Whilst the majority of this growth has been in the primary/secondary and private training establishment sectors, universities continue to punch above their weight financially, serving only $16 \%$ of students but making up $27.9 \%$ of the GDP contribution of the sector (Education NZ, 2016a). In addition to this, post-graduate international students contribute to NZ research, teach-

\footnotetext{
${ }^{1} 25 \%$ and $27 \%$ of all international students respectively.
} 
ing and innovation (Mclnnis et al., 2006). University students are less likely to permanently migrate to New Zealand than polytechnics and PTE's, and are more sensitive to quality concerns (Wilkinson, 2010).

New Zealand universities have placed a high importance on attracting foreign students. Universities are able to charge full fees for international students, whereas tuition fees for domestic students are lower and highly regulated by the government. These fees are often up to 4-5 times as much as fees charged to domestic students.

As an example, in 2017, a domestic university student at Victoria University of Wellington studying a full course-load of Humanities and Social Sciences could expect to pay $\$ 5,360.40$ per annum, whereas his international counterpart could expect to pay $\$ 25,110.00$ for the same course of study. ${ }^{2}$ The marginal revenue from attracting an additional international student is therefore quite high, whilst the marginal cost of adding an extra student can be minimal, subject to class sizes/capacity.

The only previous piece of research that has covered the price-elasticity of demand of international students in New Zealand institutions is surveybased. Baxter (2012) conducted a survey with 334 students in undertaking two 100-level papers at Victoria University of Wellington, only 76 of these were international students. They found that when presented with a hypothetical $100 \%$ increase in the cost of tuition, $46 \%$ of international students (as compared to $26 \%$ of domestic students) would discontinue studies.

\subsection{International Mobility/Migration Litera- ture}

Over time, around $31 \%^{3}$ of fee-paying international students will transition to work or permanent residence in New Zealand after their study is complete. International student mobility makes up a large and growing part of the broader migratory flows, both in New Zealand and internationally. Until quite recently, the international migration literature has not concerned itself with student migration (King, Findlay, \& Ahrens, 2010), but there is a grow-

\footnotetext{
${ }^{2}$ From the Victoria University of Wellington website.

${ }^{3}$ This number masks quite large heterogeneity of stay-rates by student's country of origin - $72 \%$ of Indian students and $43 \%$ of Chinese students will remain after finishing their studies (Wilkinson, 2010).
} 
ing body of research that deserves attention here.

Beine, Noel, and Ragot (2014) use data collected by the OECD on the number of international students in thirteen OECD countries (including New Zealand) from 2004 to 2007. They construct a theoretical model which captures the main motivations of international student migration. This model includes destination-specific variables such as the average tertiary tuition, population and destination skill prices. It also includes dyadic cost variables which are dependent on the interaction between destination and sending country such as a common language, the distance between the countries and the presence of a colonial link.

They attempt to identify these factors using a fixed effects model controlling for host-country and sending-country fixed effects. They then relax these host-country fixed effects in order to identify some destination-specific covariates such as local skill price and domestic tuition fees. ${ }^{4}$ Their most significant finding is the presence of strong network effects in student mobility decisions, i.e. higher number of residents from one country will pull more students from that destination.

In addition to this, they find that while living costs have a strong impact on the demand for international education, tuition fees have a small but statistically significant positive impact on the number of students. This finding may be due to fees acting as a proxy for prestige, or some other omitted variable bias. On the other hand, it may be due to reverse causality/simultaneity in that countries/universities with high demand are able to set tuition fees higher than those with low demand. In a simple cross-sectional comparison this simultaneity will bias comparisons along the price/number of students margin.

In order to avoid these issues, Beine et al. (2014) instrument for fees by using the share of private sector expenditures in the destination's higher education system in a Generalized Method of Moments procedure. This ratio is correlated with the average amount of fees (relevance), but is possibly uncorrelated with total number of students when holding fees constant (excludability). When this instrument is used fees become an insignificant predictor in the model. Suggesting that fees are both endogenous to the model, and not an important factor to predicting demand.

\footnotetext{
${ }^{4}$ Fee data is only collected for one year (2004), so they are unable to find the timevarying effect of tuition fees and this drops out of a fixed effect model.
} 
However, it should be noted that this instrument (percentage of private sector expenditures) may be reasonably weak, and the authors do not provide results from the first-stage regression. If there is any correlation between the instrument and student numbers through non-excludable avenues (one potential would be political climates affecting ease of immigration and public tertiary expenditure) the estimate will still be biased. This may mean that the fees dimension in this model deserves more attention.

Rosenzweig (2007) and Rosenzweig (2008) find that students become internationally mobile for many of the same reasons that more traditional migrants do, such as distance, opportunities and cultural similarities. In Rosenzweig (2007) he uses Occupational Wages around the World (OWW) and New Immigrant Survey NIS-P data on international occupational wages to construct skilled wage premia for major sending nations. He finds using the NIS-P data that a doubling of the skill price relative to another country would lower the number of student visas by 36 percent (95 percent for OWW). This implies that relative skill price is a very important component of international student mobility and deserves more attention. This could be an interesting consideration in the New Zealand context, where the skill price or return to education is quite low compared to other OECD nations (Zuccollo, Maani, Kaye-Blake, Zeng, \& others, 2013).

A piece of research that is in some respects similar to the research methodology of this thesis is Dreher and Poutvaara (2005). They firstly estimate a cross-sectional regression using 9 OECD host countries and 36 sending countries for the years 1999-2000 using the OECD education database. ${ }^{5}$ Regressing the number of migrants as the dependent variable on the ratio of foreign students to host country population, they find that this ratio is a highly significant predictor of immigration.

They then extend this analysis to a panel data set of immigration and international student migration to the United States from 76 source countries. Using a random and then, fixed effects model they find again that the ratio of international students to population is highly significant, confirming the cross-sectional results. They do not however, include tuition or exchange rates as a covariate in either of their regressions.

\footnotetext{
${ }^{5}$ This database is also used to construct the Education at a Glance Indicators which I use (OECD, 2017).
} 
Whereas there are some similarities in methodology and data sources between the research in this thesis and Dreher and Poutvaara (2005), it should be made clear that we are asking fundamentally different questions. I am interested in international student migration as an end, in and of itself, and the effect of tuition fees on this migration. On the other hand, they are interested in the degree to which student migration predicts broader migratory flows. In addition to this, similar to Beine et al. (2014), when they turn their attention to their OECD model instead of the standalone U.S model, they rely on cross-sectional identification, whereas I use panel data methods.

\subsection{Economics of Education Literature}

The economics of education literature has been concerned with the demand for college education for some time (Campbell \& Siegel, 1967). However, the majority of papers in this area are concerned with the decision of whether to go to university at all, and focus on domestic students. To what degree these determinants generalize to the international student case remains to be seen, but the following papers certainly present an interesting reference regardless.

As a starting point, Leslie and Brinkman (1987) provide a meta-analysis of twenty-five papers which provide results on the student price elasticity to tuition in higher education. They find overall that a $\$ 100$ change in the price of tuition is associated with a drop in enrolment of $0.6 \%$. It is questioned whether this estimate should be interpreted causally, given the lack of research design in the component studies. For example, the AASCU studies which are the only experimentally (natural or controlled) designed studies contain no control group. Even if these result were credible in an internal sense, the age of these results have lessened their relevance. As Heller (1997) notes, college tuitions continued to rise in real terms throughout the 90's with no sign of a slowdown in enrollees, perhaps due to an increasing college-wage premium.

The largest problem with a cross-sectional model with enrolment as the dependent variable and tuition as the independent is one of endogeneity. It may be the case that a higher tuition is correlated with some unobserved or omitted variable, such as quality of teaching/employer perception, which is correlated positively with student numbers. Leaving this factor out of the model will bias my estimates upwards. Another possibility is that students choosing which university to enrol in are price-insensitive but look at 
the nominal fee as a signal for prestige, with higher fees indicating a more prestigious institution and attracting more students (Mixon \& Hsing, 1994). These empirical issues may explain why many studies present a horizontal or positively sloped demand curve. It is therefore important to control for endogeneity through the use of exogenous variation (a natural experiment) or through the use of panel data methods.

\subsubsection{Aid programs as variation in fees}

One way that researchers have tried to recover the demand for college education, is by using plausibly exogenous variations in the implementation of aid programs. Variations in the generosity of aid programmes can be a source of variation in the real cost of tuition while avoiding the simultaneity/endogeneity biases in actual tuition fee setting. This is because aid programmes are often implemented for political/equity reasons rather than being as closely related to demand as tuition-setting. An increase in the level of aid available decreases the real cost of education for students who receive it, and conversely, a decrease in the level of aid increases it. The evidence from papers using variation in aid programs as a natural experiment consistently show that an increase in the real cost of education decreases demand for college education.

Dynarski (2003) analyses the effect of the dissolution of the Social Security Student Benefit Program in the U.S in 1982. This program granted aid to 18-to-22 year old children of deceased, disable or retired Social Security beneficiaries. The average yearly payment for this program was $\$ 2000$ in 1982 dollar or $\$ 6700$ in 2003 dollars. This payment nearly met completely the average tuition fees at a public college. The elimination of this program was done for plausibly exogenous reasons, being a political decision, and provides a natural control group between those who were receiving the benefit prior to 1982 (around 12\% of university students) and those who were not. They employ a difference-in-differences approach which compares benefit-receiving students to non-benefit-receiving students before and after the elimination of the programme. They find a significant increase in the likelihood of attending college of about $21 \%$ before the elimination, implying a $3.6 \%$ increase in college attendance for every $\$ 1000$ decrease in fees.

Similarly, Abraham and Clark (2006) analyses the effect of the introduction of the the District of Colombia Tuition Assistance Grant Program in Washington, D.C 1999. This program introduced a subsidy for students to 
attend out-of-state institutions at in-state prices. The benefit is subject to a $\$ 10,000$ cap annually and a $\$ 50,000$ cap over a student's lifetime. Using a difference-in-differences approach they compare how many students enrol in out-of-state institutions in Washington compared to the control cities (Baltimore, Philadelphia, Norfolk) before and after the introduction of the grant. They find that compared to the control, the introduction of the program increased enrolments of high school students by $8.9 \%$. Using the average savings from the program $(\$ 2,472)$ they calculate that the average increase from a $\$ 1000$ decrease in fees is again $3.6 \%$.

\subsubsection{Political Changes}

Another source of plausibly exogenous variation in the cost of a university education is national/regional changes in political conditions or government policies towards tertiary education. Tertiary education is often a contentions political issues in New Zealand and other countries (Baxter, 2012). Government bodies can regulate fees, abolish fees and also impact the issuing of student visas. Changes in these policies is plausibly exogenous to demand and may be related to other factors such as changes in the relative power of political parties.

Neill (2009) uses the Canadian Labour Force Survey, which contains information on enrolments and tuition fees of Canadian universities to apply an instrumental variable approach to get around these endogeneity issues. She uses the fact that different political parties on a provincial level tend to enact different fees policies, to exogenously vary tuition fees across provinces. ${ }^{6}$ In a model without the use of instrumental variables, she finds that tuition has no impact on enrolments. However using the instrumental variables approach outlined above she finds a strong negative impact of an increase on fees on enrolment though not statistically significant in all specifications. The estimates here imply that a $\$ 1000$ dollar increase in tuition fees reduce enrolments by 2-3 percentage points.

Hubner (2012) uses the introduction of tuition in seven of the sixteen German states in 2007 as part of the policy platform of the conservative majorities in those states to determine the effect of the introduction of these fees (which were almost uniformly 1000 Euros annually) on enrolment. Using

\footnotetext{
${ }^{6}$ Whilst it might seem as if changes in which political party holds power in each provinces would be a weak instrument, post-secondary education falls under provincial jurisdiction in Canada and the majority of institutions are public, meaning that political decision-making has real impacts on tuition fees.
} 
a difference-in-differences estimation strategy he finds that the introduction of fees caused enrolment to drop 2.7 percentage points, compared to the counter-factual no-fee university. The obvious issue with this is that the counter-factual may be a direct substitute for the tuition paying universities i.e with the introduction of fees at one university, the student may decide to attend a university which did not. This may bias the estimate to some degree, making it smaller than the true population effect.

Dwenger, Storck, and Wrohlich (2012) uses the same natural experiment as Hubner (2012) focusing of the introduction of tuition fees in seven German states. However, they focus specifically on the student mobility factor, i.e how likely were students to move to a out-of-state university following the introduction of fees in their home states. Using a difference-in-differences approach, they find that students in a fee-paying state after the introduction in fees (the treatment group) were 5 percentage points less likely to apply for an in-state university. They also find that students with higher grades are less responsive to the treatment i.e more likely to stay in their home state following the treatment.

This has an interesting implication, namely that a change in the price of tuition for a certain university, can change the composition of students who apply for that university. Weighting a potential drop in students from an increase in price (Hubner, 2012) versus an increase in average students quality (Dwenger et al., 2012) may be an interesting consideration given that student quality and peer effects are an important determinant of tertiary demand in their own right (Epple, Romano, \& Sieg, 2006).

Sa (2014) uses two natural experiments in Britain, the removal of tuition fees in Scotland in 2001 and the increase of the tuition fee cap in England from $£ 3000$ to $£ 9000$ in 2012 . They first present a theoretical model where potential students maximise their lifetime utility function through making a choice between the NPV of not going to university versus the NPV of not attending. They predict that an increase in fees causes less people to attend university, and this increase is mainly driven through credit constrained students. Using a difference-in-differences model they find that the Scottish removal of fees (equivalent to $£ 3000$ ) increased applications by 21.4 log points, while the increase in fees $(£ 6000)$ decreased applications by 25 log points with both of these being statistically significant at the $1 \%$ level. These estimates imply an elasticity of around -0.14 to -0.26 .

In total, the economics of education literature clearly shows that in the 
absence of confounding factors, an increase in fees significantly decreases the number of students who choose to attend university, implying a traditionally downward-sloped demand curve. Purely descriptive or cross-sectional studies, on the other hand have shown horizontal or upward sloped demand curves. This implies that endogeneity issues are of concern in the study of student demand. What is missing however, is a study of international students instead of domestic students. It is likely that the demands of these two sub-populations are quite different, especially in New Zealand and other Anglosphere nations, where international students pay five times as much as domestic students, incur temporary or permanent migration costs and face different labour markets in their home countries. 


\section{Chapter 3}

\section{Data}

This research collates data from a number of sources. This chapter describes these sources of data.

The New Zealand fixed effects model uses data on the number of students from the New Zealand Ministry of Education, and is discussed first in Section 3.1. The OECD country fixed effects model, primarily uses publicly available data from the OECD and is discussed separately in Section 3.2.

\subsection{New Zealand Data}

New Zealand data has been collected on the number of international students at the universities, the fees they pay, the ranking of each university and exchange rates. This section describes the sources of this New Zealand data.

\subsubsection{Students}

The source for the number of students at each university is The Ministry of Education data warehouse $\mathrm{OLAP}^{1}$ cube. This database collects the number of students, both domestic and international at each university, as well as the sum of course fees, EFTS ${ }^{2}$ and EFTS funding from each record in the database. The information for this database is collated from each of the

\footnotetext{
${ }^{1}$ Online analytic processing

${ }^{2}$ EFTS or Equivalent Full-Time Students measures the number of students at a tertiary institution, by the amount of courses they take. Typically, 0.125 EFTS is equivalent to one course or 15 points at a university. The average amount of courses taken by a student at university is 8 annually, giving 1 EFTS. This EFTS number is also used in a variety of funding decision for tertiary institutes, by the Ministry of Education.
} 
universities yearly. The available years for this data set is from 2000 to 2016 , however, I restrict the sample to 2009-2016 due to availability of other data, in particular rankings and fee data.

\subsubsection{Fees}

Whilst the Ministry of Education data cubes have the sum of course fees data available, this part of the database appears to be unreliable. Instead, I collect historical fees data from the Universities NZ website. Universities NZ is a representative body of the eight New Zealand universities, who are represented on this board by their Vice-Chancellors, they also conduct research on issues affecting the university sector as a whole. Their International Unit, publishes historical fee data, by university, by field of study. This fee data is collected for both international students and domestic students, on an annual basis for a full course load.

\subsubsection{Rankings}

Historical ranking data is collected from the QS World University Rankings published annually by Quacquarelli Symonds. Whilst rankings have been criticised to some extent, they do appear to be important in student marketing, and potentially a reasonable proxy for quality/prestige (Smart, 2014).

\subsubsection{Exchange Rates}

Exchange rate data is collected from the Reserve Bank, "Exchange Rates and TWI - B1" publication. This is a monthly time-series of NZ exchange rates from 1999 to 2017. Data for 17 currencies are available. This means that I restrict my analysis to these major trading partners for which exchange rate data is available in those models which have exchange rate as a covariate.

\subsection{Global Data}

I collect international data on the number of international students in each country. Unfortunately, to my knowledge there is no data available on the amount of students at each university within a country so this model is restricted to analysing competition in the international student market across countries. 


\subsubsection{Students}

The UNESCO institute of statistics collects a variety of statistics for their Education Indicator dataset. This includes a dataset of the number of internationally mobile students, both inbound and outbound, by continent and country of origin, from 1999 to 2016. I use the inbound indicator from the years 2004-2014 due to availability of fees data.

This dataset is surprisingly extensive with information on the number of outbound students from countries such as The Holy See and The Democratic People's Republic of Korea, and allows me to use flexible econometrics methods, as well as providing descriptive trends from an international perspective.

\section{International Students Definition}

There are two definitions of internationally-mobile students commonly used in the literature. Firstly, there are foreign students who are not citizens of the country they are being educated in. This definition includes students who have travelled to another country for other reasons such as family migration, economic migration, etc., as well as students who have lived in the country for quite some time but have not applied for citizenship. Whilst this measure is easy to collect, it is too broad a category for my purposes and may be misleading as different countries have different policies concerning the naturalisation of foreign-born students.

I instead use the UNESCO definition of international students which is as follows: "Students who have crossed a national or territorial border for the purpose of education and are now enrolled outside their country of origin." This has the advantage of focusing on students who make the choice to become international students and can be seen as the pool of students that countries (and universities within those countries) can try to attract through their tertiary policies.

\subsubsection{Fees}

I restrict my attention to OECD host countries whilst maintaining the full sample of sending countries. I merge the inbound student data on international to fee data provided by the OECD in their Education at a Glance Series (OECD, 2016, 2014, 2012, 2009, 2008). This data is only presented for intermittent years $(2004,2006,2008,2010,2013)$ so I restrict the student data to years for which fee data is available. 
Unfortunately, data is only collected for international fees in 2013 and 2015 , whilst the rest of the data is only available for domestic students. Furthermore, the 2015 data appears to be missing data for many countries. This data also includes an indicator for whether an OECD country charges different fees for international students, with about half of the countries having fee differentials. All fee data is converted to USD by purchasing power parities (PPP), based on the average fee for a full-time student completing a bachelors degree at public institutions. ${ }^{3}$

For those countries that do have fee differentials I use the same strategy as Beine et al. (2014) and collect data on the fees paid by native students. Whereas they collect data paid by students in the 2003-2004 academic year, I collect data for many years.

This strategy relies on two assumptions. Firstly, as in Beine et al. (2014) that fees paid by domestic fees are a good proxy for foreign fees in a crosssectional sense (i.e countries with higher domestic fees generally have higher international fees). The second assumption is that changes in domestic fees are positively correlated with changes in international fees, over time. This is violated if countries substitute international student fees for domestic student fees i.e they raise international fees in order to make domestic fees cheaper.

I provide evidence for these assumptions pictorially in Section 4.2 and through regression analysis in Appendix B.1.

\subsubsection{Exchange Rates}

As stated previously, all fees for this model are converted by the OECD to American dollars by PPP. However, exchange rates can also influence the relative attractiveness of countries through other avenues such as cost of living and remittances (Keita, 2016).

In order to be able to control for this, I collect data from the OECD on the exchange rate of the currencies of the host-countries to USD for each year in my sample-period. These are included as time-varying covariates

\footnotetext{
${ }^{3}$ UK Fees are taken from government-dependent institution category as there are no publicly owned universities in the UK
} 


\section{Chapter 4}

\section{Descriptive Evidence and Trends}

The international education market has expanded rapidly in terms of size and scope, both in New Zealand and globally. This increase in size and scope has also made it more complex. This chapter presents a series of descriptive graphs to help contextualise and explore the market for international students.

Section 4.1 explores the New Zealand market for international students. I cover trends in the number of EFTS, fees, QS university rankings and exchange rates.

Section 4.2 turns to cover the global market for international education amongst OECD nations. I cover the number of students, fees and exchange rates. 


\subsection{New Zealand Market}

\subsubsection{EFTS}

Figure 4.1: International EFTS in Total, by Year

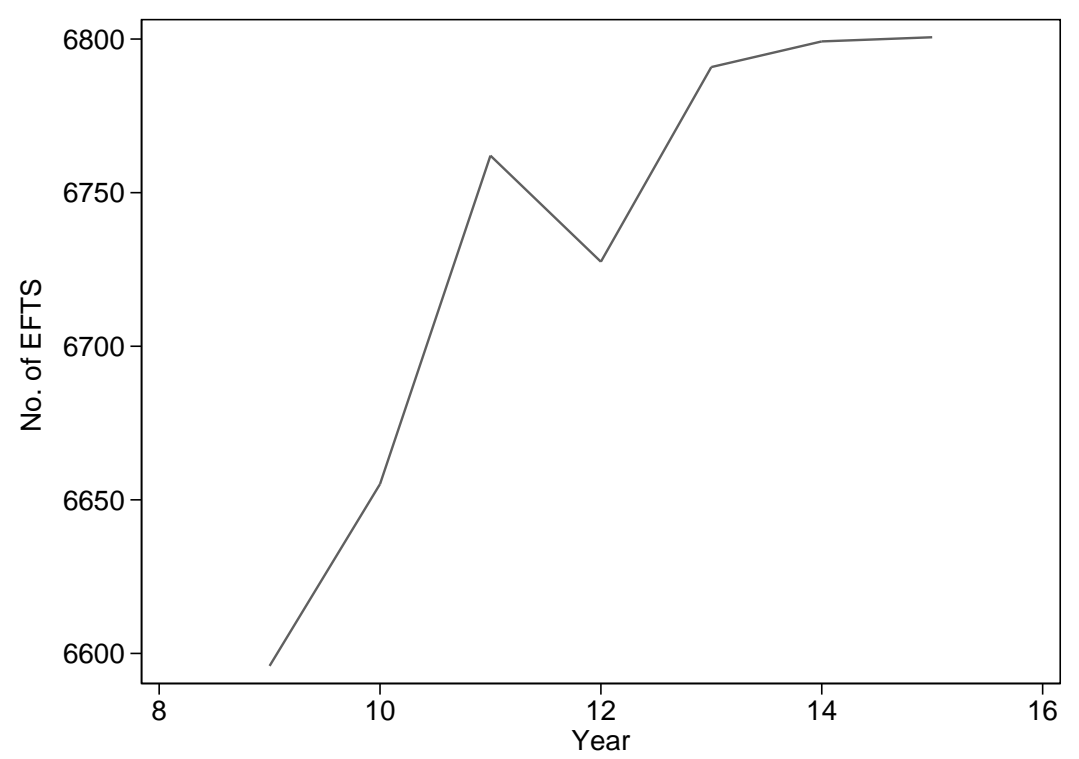

Figure 4.1 presents the total amount of EFTS (Equivalent Full-time Students) taken by international students at all universities in New Zealand. It is clear that the overall trend is upwards, from around 6600 EFTS in 2009 to 6800 EFTS in 2015.

There was a small decrease in 2012 but this only appears to be 50 or so EFTS. Overall, whilst there is certainly an upwards trend in the number of EFTS, it is quite a small trend in absolute terms, with only an increase of 200 EFTS in total or $3 \%$, over 5 years. 
Figure 4.2: International EFTS by Country (Major Trading Partners)
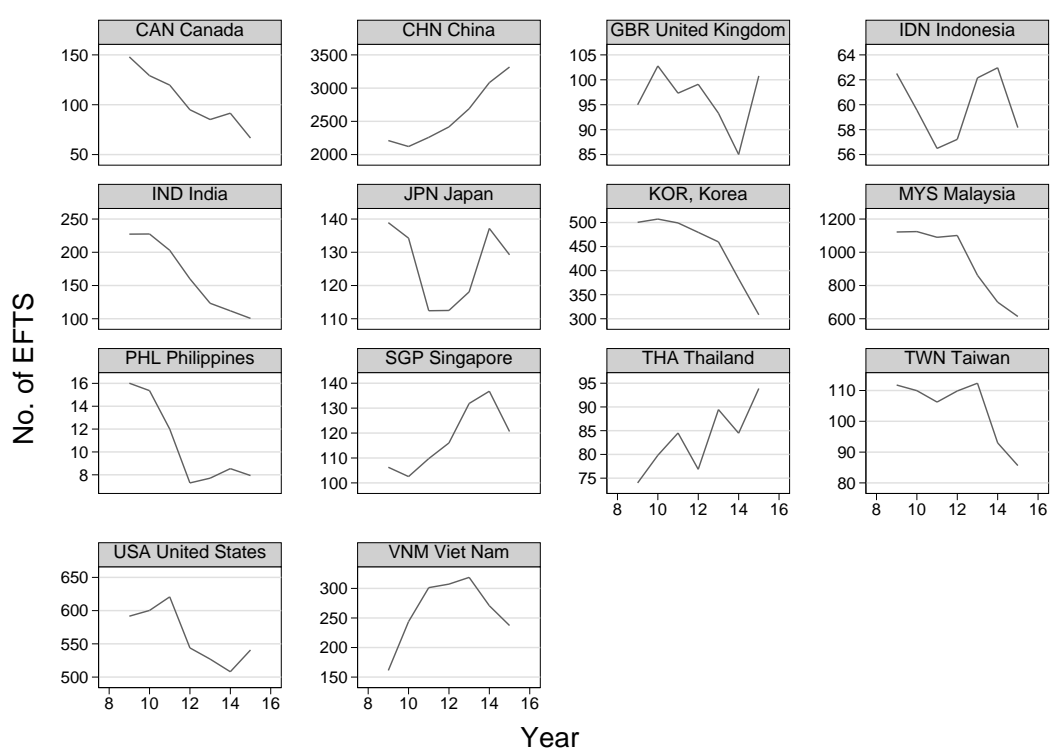

Figure 4.2 presents the number of international student EFTS over the sample period from New Zealand's major trading partners ${ }^{1}$ (2009-2015). Figures for all sending countries are available in Appendix A.1. This figure is quite interesting when compared to Figure 4.1. Whilst there did not appear to be a lot of variation in total EFTS taken across all universities, there is quite a lot of variation in the trend across countries. It appears that the majority of countries are trending downwards, but some notable exceptions such as China, Japan and Singapore.

Asia predominates, with the top three sending countries being China, Malaysia, and the U.S.A. China sends the most students to the New Zealand university sector by almost a factor of five.

It is notable that whist Indian students make up the second highest proportion of students in the New Zealand international education sector (Education NZ, 2016a), they are not part of the top three nationalities in NZ universities. It appears that Indian students are much more likely to attend private training establishments and polytechnics instead (Ministry of Education, 2016).

\footnotetext{
${ }^{1}$ Note that New Zealand's largest trading partner, Australia is missing from the sample. Australian students are treated as domestic students for funding purposes, pay domestic fees, and thus are not included in my analysis.
} 
Given the large differences in student levels across-countries and acrosstime, within a country, I would expect that sending-country specific factors drive a large proportion of international student demand. Unfortunately from a domestic perspective, these factors are often outside of policymakers' control.

Figure 4.3: International EFTS by University
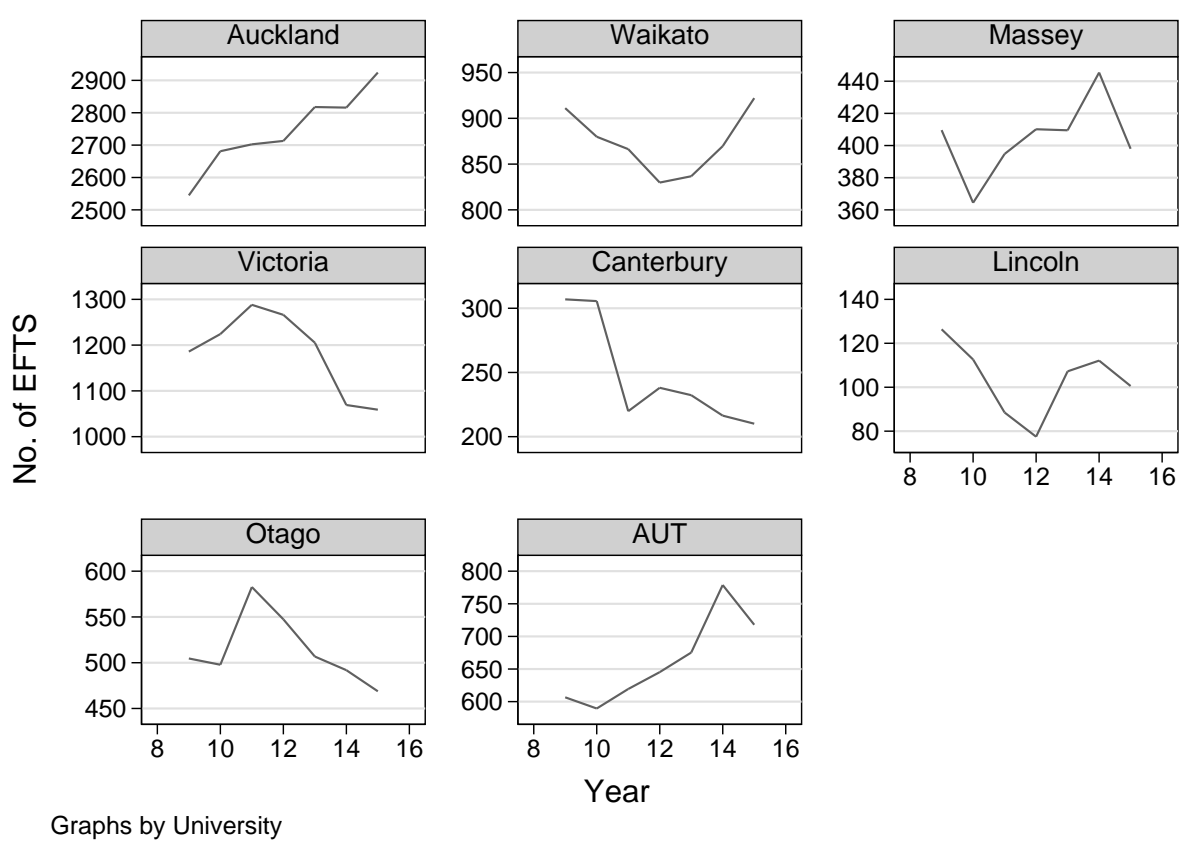

Figure 4.3 shows the number of international EFTS across all courses in each university per year. It is clear that Auckland University, VUW, and AUT dominate in terms of international student EFTS. The general trend in student EFTS also varies in direction across universities with UOA and AUT showing a consistent increase over the sample period, whereas VUW and UOC end up with fewer students in 2015 than in 2009. 
Figure 4.4: International EFTS by Subject
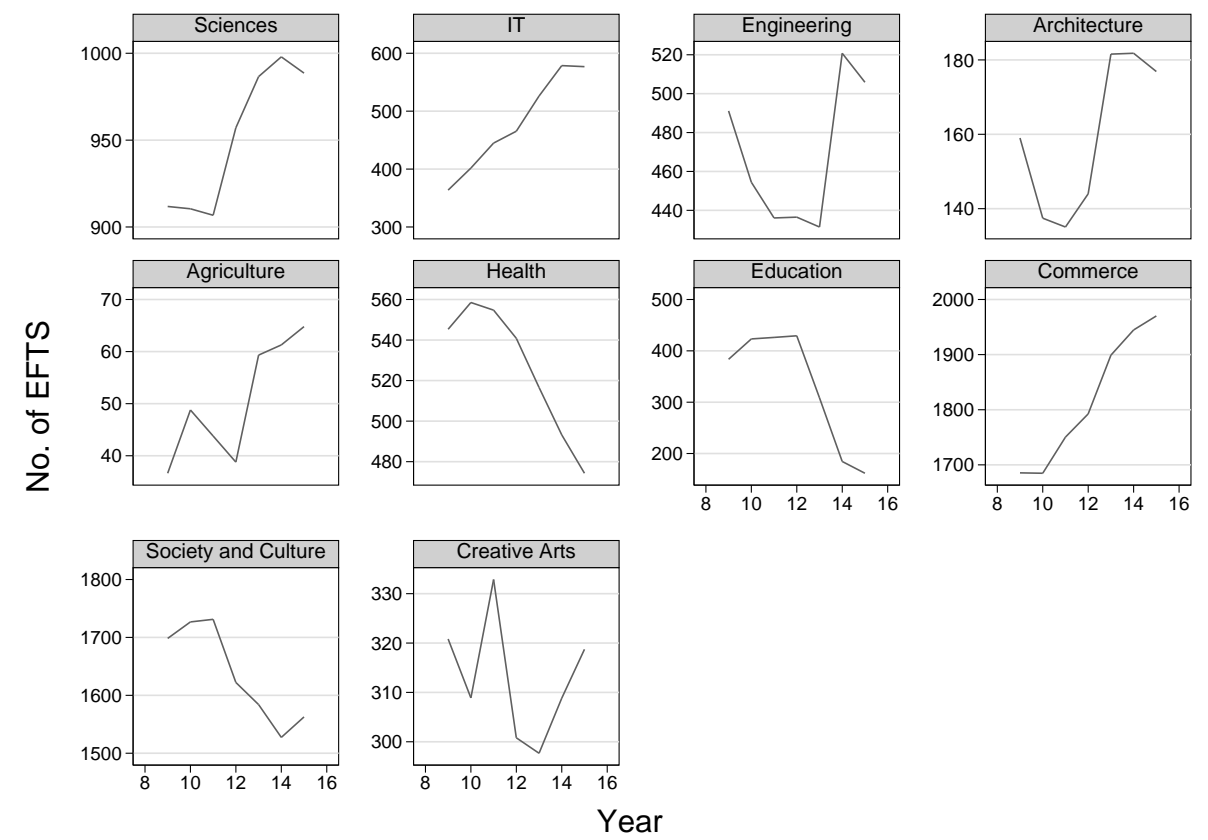

Figure 4.4 presents the number of EFTS taken by international students, across all universities, broken up by NZCED field of study. It is clear that there is large variation in both the levels and the trends in what subjects International students choose to take.

The most popular subjects are Commerce, Society and Culture, and Sciences. These subjects account for the vast majority of EFTS. However, whilst Commerce and Sciences have both been steadily trending upwards, Society and Culture has lost around 200 students over the sample period consistent with the international decline in the humanities generally (Lewin, 2013).

Interestingly, both Engineering and Architecture appear to have faced a reasonably large drop around 2011, but have both recovered with more students at the end of the sample period than at the start. Information technology on the other hand, has showed a consistent increase over the entirety of the sample period. Two subjects that appear to have shown reasonably consistent decreases are Health and Education.

These graphs imply that factors within and across subjects may be an important determinant of student demand. In addition to this the interaction 
between a subject and a university may be important. I include a breakdown of EFTS, for selected subjects, by university in Appendix A.2.

\subsubsection{Fees}

Figure 4.5: Average University Fee by Year

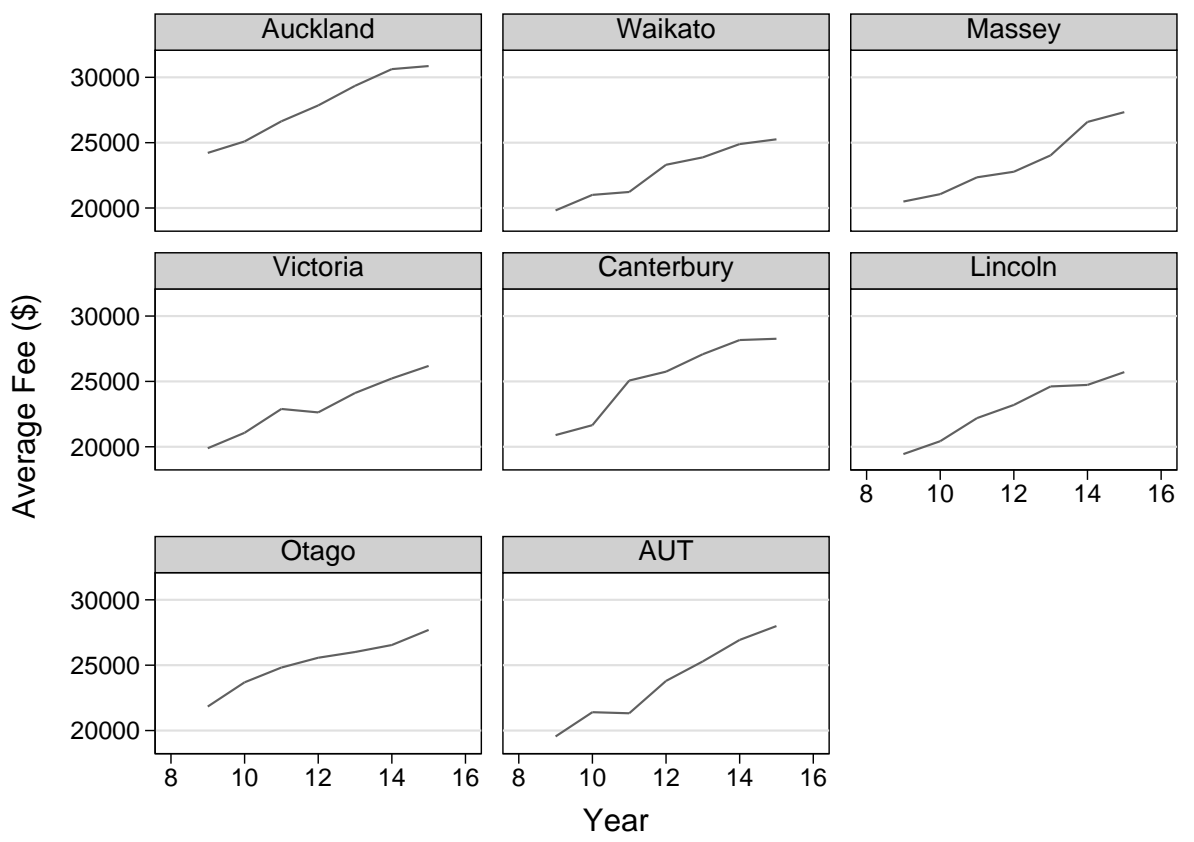

Figure 4.5 shows the average annual fee for international students, by university. As one of the largest expenses incurred in travelling for education, fees could be an important part of the international student mobility decision.

We can see that every university shows an increase in fees over the sample period. It is clear that the University of Auckland has the highest average fee over the entire sample period. This is followed by the University of Canterbury, with the lowest fees being from Lincoln University, Waikato University and Victoria University of Wellington.

It is clear that a naive analysis of international student demand in this context might provide misleading results, as Auckland has the highest amount of students but also the highest fees, whereas universities with lower fees such as Lincoln, will also have a lower number of students. This would give us 
a positive estimate on any cross-sectional regression, implying that raising prices would increase student numbers when this is most likely not the case. It is more likely that there are other factors influencing the higher demand for Auckland University tuition when compared to other universities.

One candidate is the large size of migrant networks in Auckland when compared to other regions in New Zealand (Infometrics, 2008). Beine et al. (2014) finds that the size of established migrant networks from the sending country is a significant predictor of international student mobility to a location. Another candidate is differences in perceived quality between universities, Auckland University consistently ranks higher than other universities in QS and Times rankings. Leveraging within-university variation with a fixedeffects model will control for any time-invariant across-university differences which would confound my estimates.

Figure 4.6: Change in Average University Fee from Previous Year (\%)

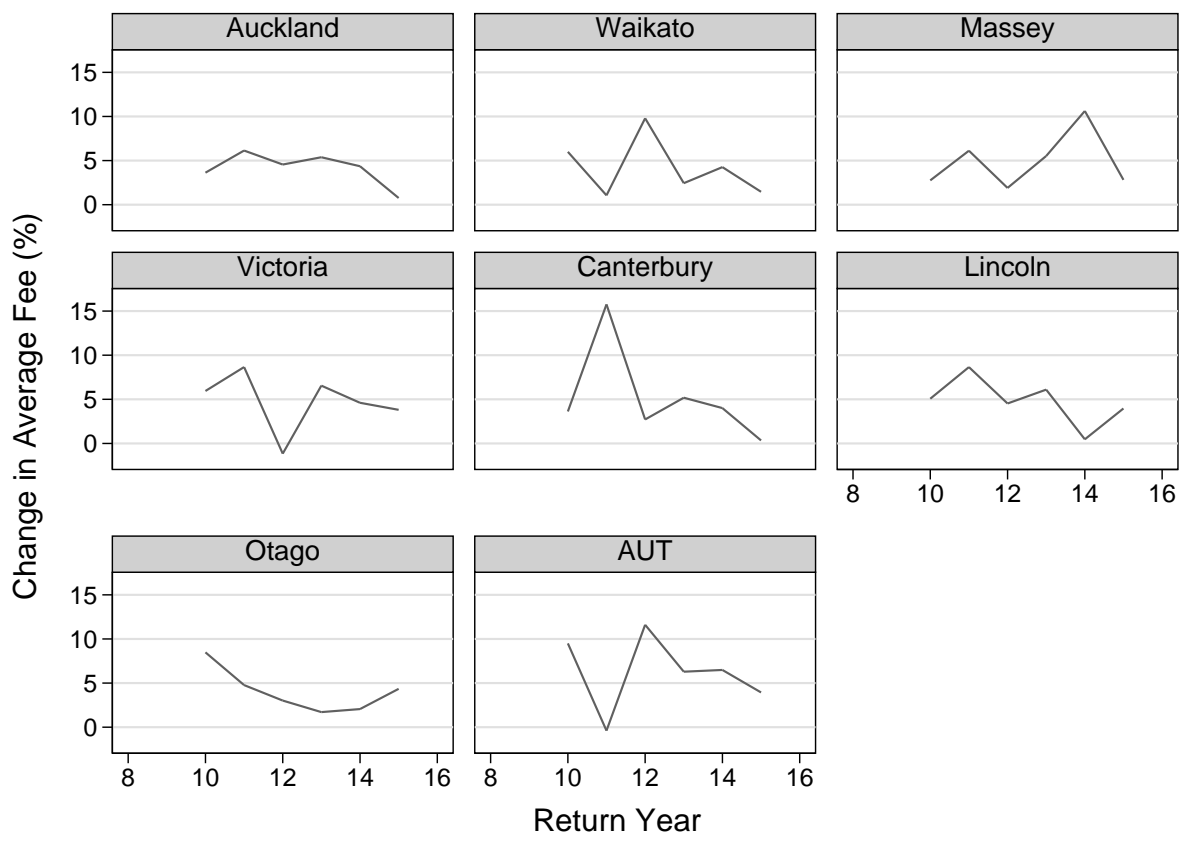

Figure 4.6 plots the change in average international tuition fee from the previous year in percentage terms, by university.

We can see that the average fee change for international fees is around $4.8 \%$. This is higher than the maximum fee increase regulated for domestic 
students by (4\%) and the change is occasionally much higher than this.

Figure 4.7: Average University Fee (Weighted By Number of EFTS) by Year

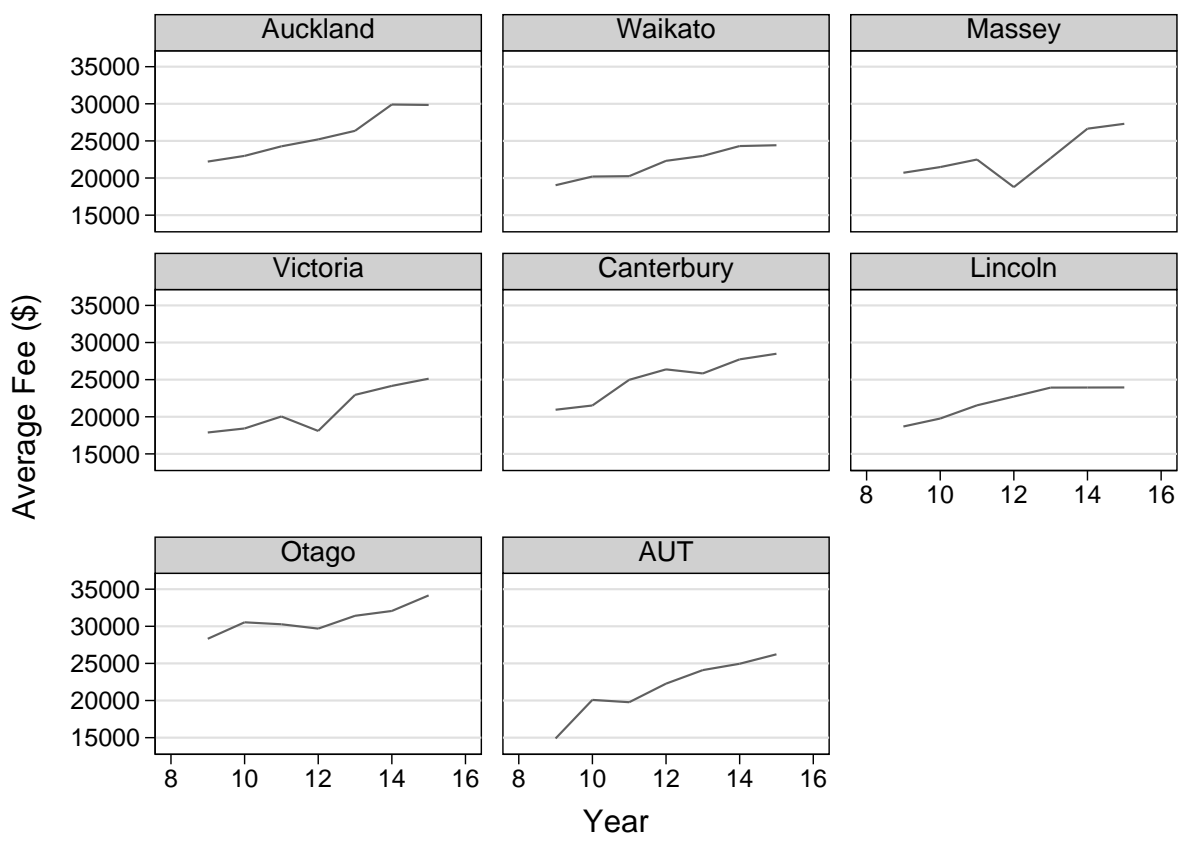

Figure 4.7 presents the same estimate of the average fee as in Figure 4.5, but is now weighted by the number of students in each subject per year when I take the average. Instead of each subject being given an equal weight in the fee average, subjects with a higher number of international students are now given a higher weighting.

In Figure 4.5 the interpretation is the average fee on offer, with each subject being given an equal weight. The interpretation of average fee in Figure 4.7 however, is the average fee that the average international student actually faces.

In this case the differences between high-demand universities and lowdemand universities are even larger. It appears that potentially low-demand universities such as Lincoln and VUW have a higher proportion of student in low-fee courses, whereas student at the University of Otago and the University of Auckland appear to be more likely to take higher-fee courses. This is likely to do with students travelling to Auckland and Otago in order to undertake high cost medical and health degrees. 
In some cases such as VUW in 2012 and Massey in 2012 the weighted fee actually falls, this is either because more students have chosen to take lower-fee courses or a high-population course decreases it's fees.

Figure 4.8: Average Fee by Course

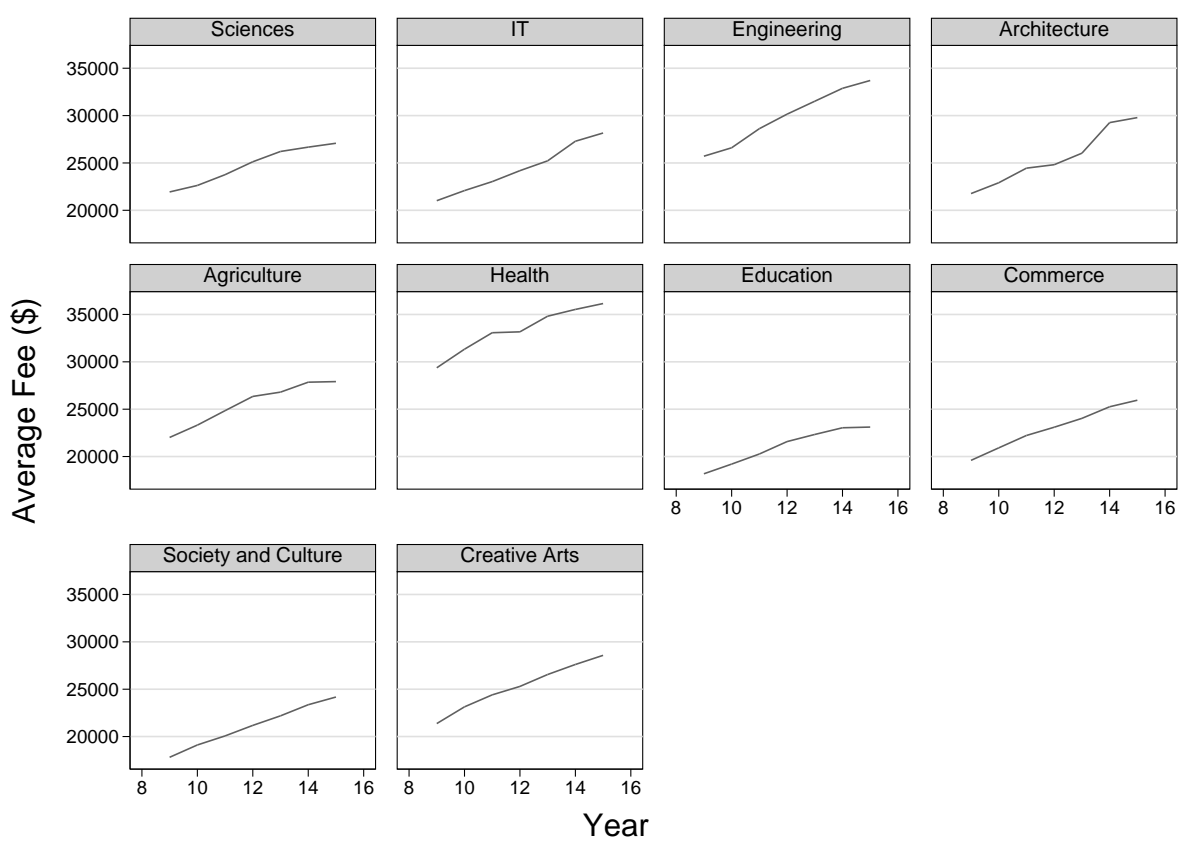

This figure shows the average fee in each course across all universities. All subjects are trending upwards, but it is clear that there are also large level differences in the price of a certain subject/qualification. Whereas Engineering and Health subjects are quite expensive, costing around $\$ 30,000$ per year, Society and Culture and Education are closer to $\$ 20,000$. Given a 4 -year degree, this implies a $\$ 40,000$ difference in a full course of study. ${ }^{2}$

There are also subtle differences in change in fees from year to year, across subjects. Whereas the slope of the line for Society and Culture is very flat, there are kinks in the line for Architecture and Building. This is more clear, when breaking down subjects by university. I include Commerce, Health, Society and Culture, and Science degrees, by university in Appendix A.3

\footnotetext{
${ }^{2}$ There are also large differences in the length of courses. A typical Medical degree takes around 7 years to complete whereas an English Literature degree will take around 3 years, on average.
} 


\subsubsection{Change in Fees versus Change in EFTS}

Figure 4.9: Change in International EFTS versus Change in Fees

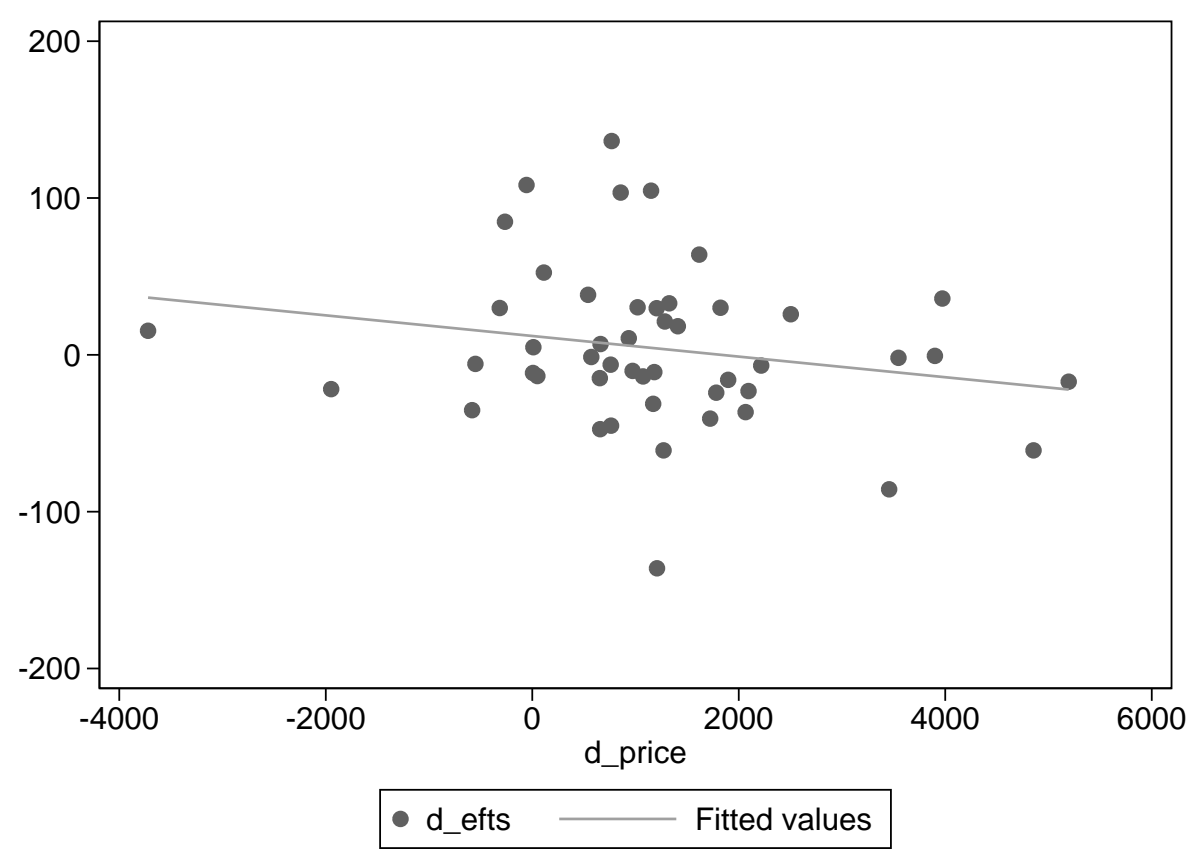

Figure 4.9 takes the average fee in each university (weighted by the number of students in each course as in Figure 4.7), and derives the change in this fee from the previous year, for each university. This is then plotted on the $\mathrm{x}$-axis. I then plot, on the y-axis, the change in the number of students in each university from the previous year.

The line of best fit on this figure shows a moderate negative relationship, i.e an increase in fees is associated with a decrease in the number of EFTS taken by International students, but the magnitude of this effect is quite small. This suggests that international students have a relatively inelastic demand. 
Figure 4.10: Change in International EFTS versus Change in Fees, by University
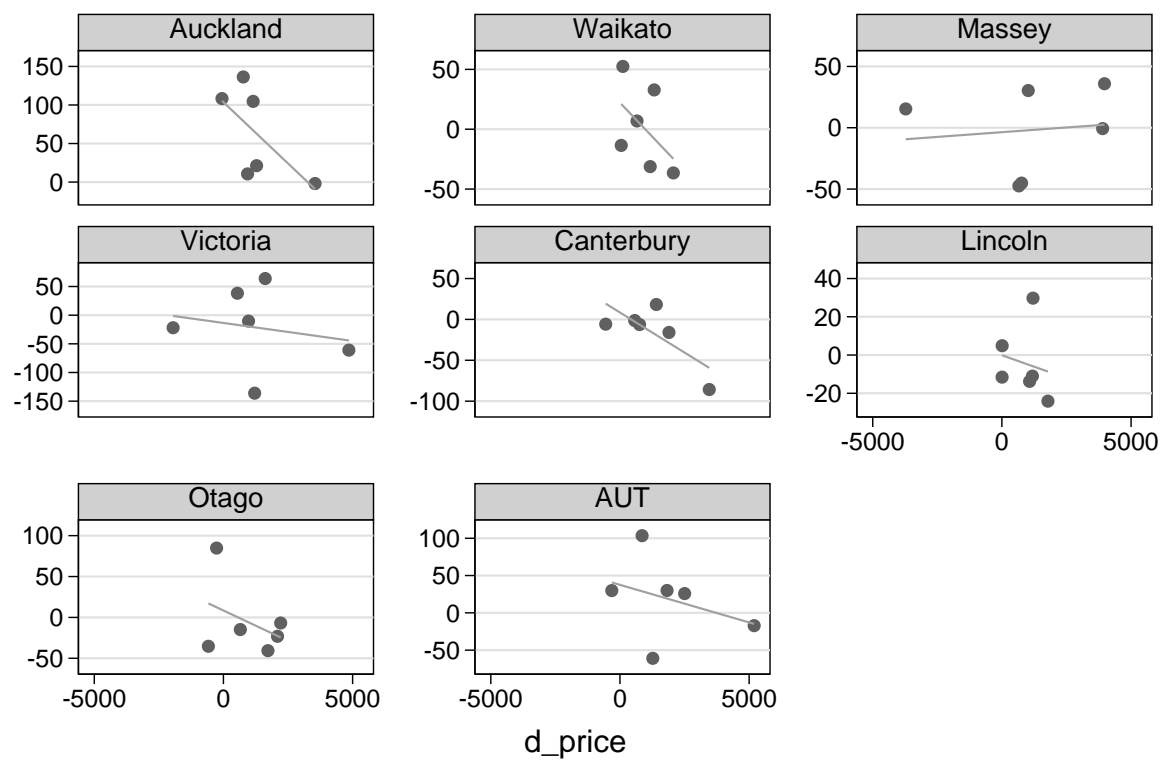

- d_efts

Fitted values

Figure 4.10 presents the same data as in Figure 4.9, but broken up by university. All universities appear to have a negative association between change in fees and change in EFTS individually, with the exception of Massey University. 


\subsubsection{Ranking}

Figure 4.11: University QS Ranking by Year
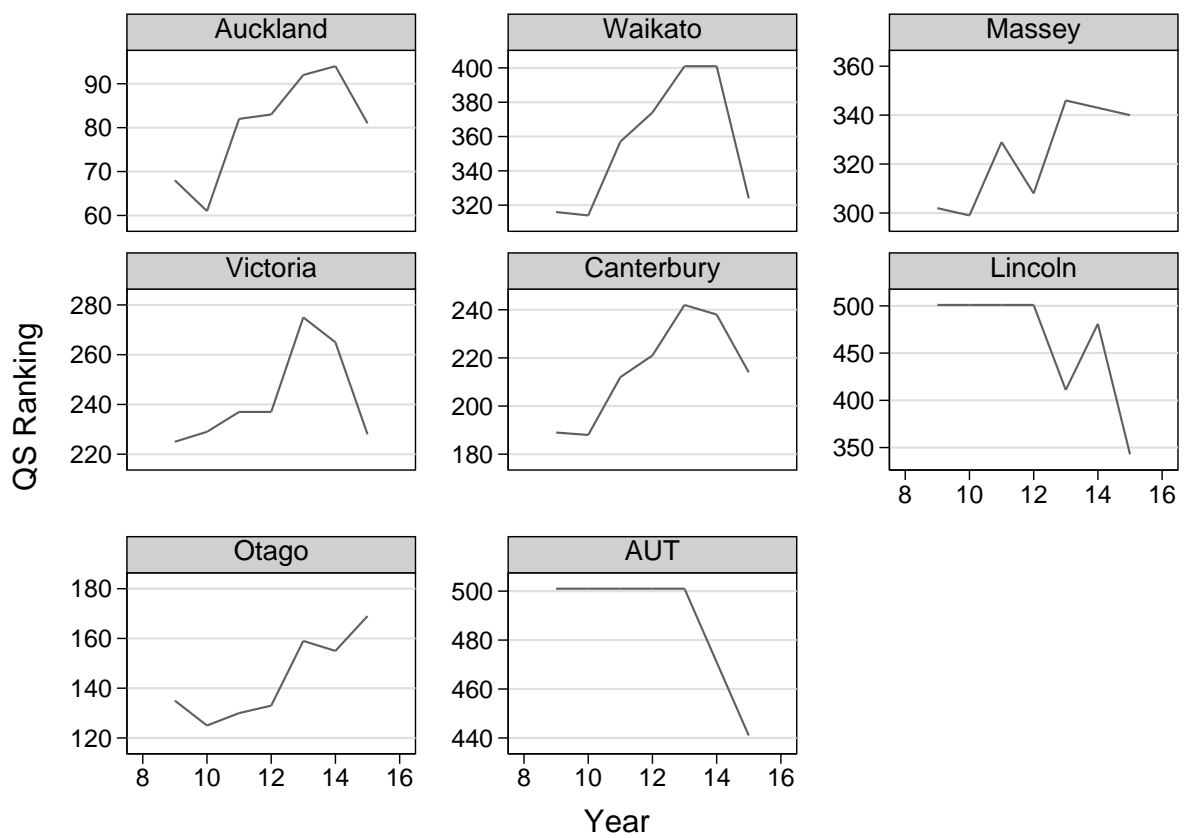

Figure 4.11 presents each universities QS World University Ranking over time. Note that a lower number means that a university is higher in ranking, i.e rank 1 is the top university and rank 10 is better than 20 .

Interestingly, the majority of universities have slipped from their 2009 ranking ending up at a lower ranking in 2016. The exceptions to this are Lincoln and AUT that have slipped into the ranking tables. Previously, these universities were ranked at 501+ instead of having an individual ranking. 


\subsubsection{Exchange rates}

Figure 4.12: Foreign Currency Exchange Rate (Major Trading Partners)
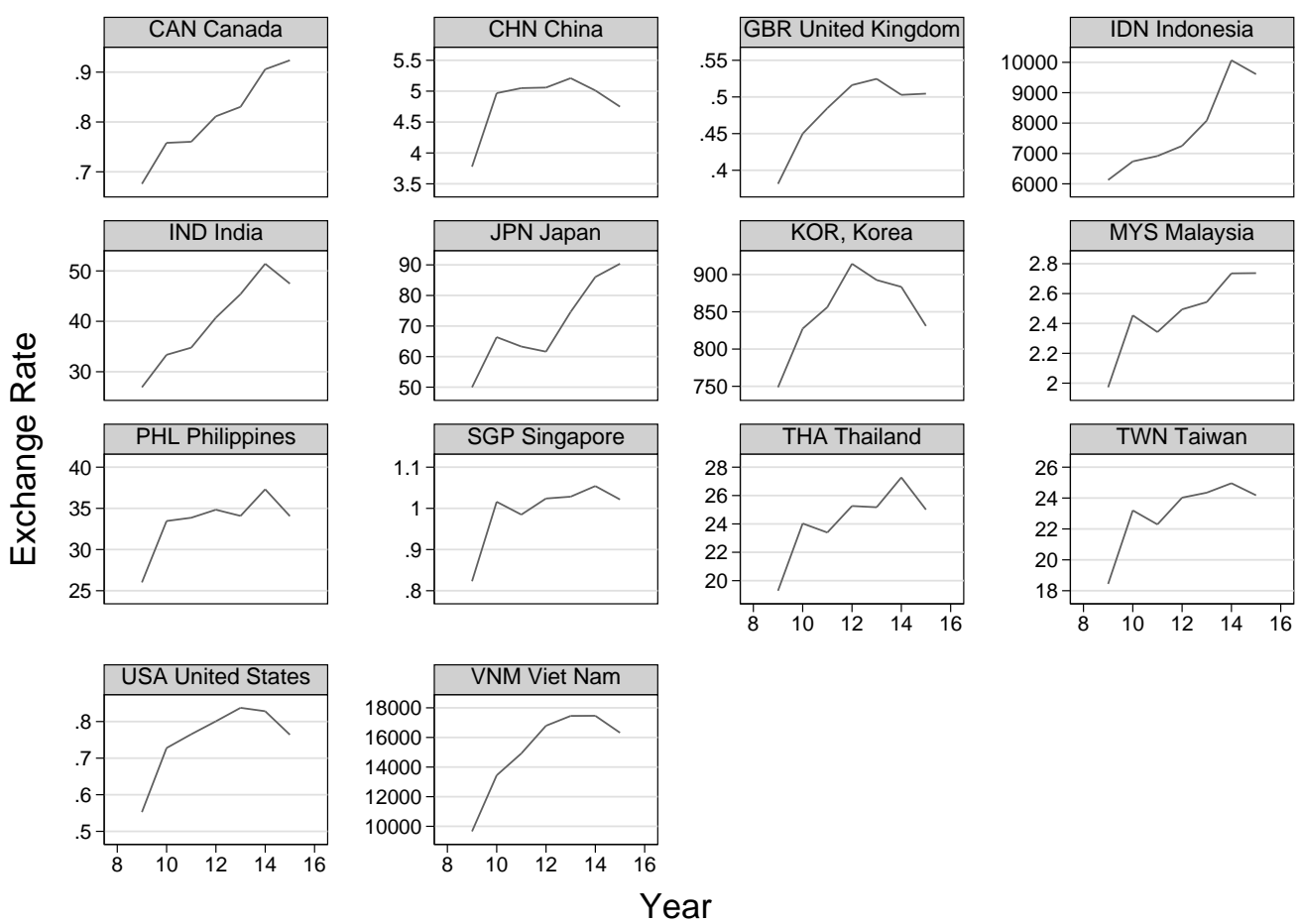

Figure 4.12 plots major trading partners' exchange rate to NZD, over the sample period (2009-2015). The New Zealand dollar has generally been quite strong over the period with quite large appreciations against almost every country. There appears to be a slight down-tick in 2015 for the majority of countries.

These changes in exchange rates can alter the real cost of education for many students whilst also affecting broader migratory influences in general such as cost of living and the real value of remittances. (Keita, 2016; Nguyen \& Duncan, 2017). 


\subsection{Overseas Market}

\subsubsection{Number of Students}

Figure 4.13: Number of International Students at OECD Universities, by Year

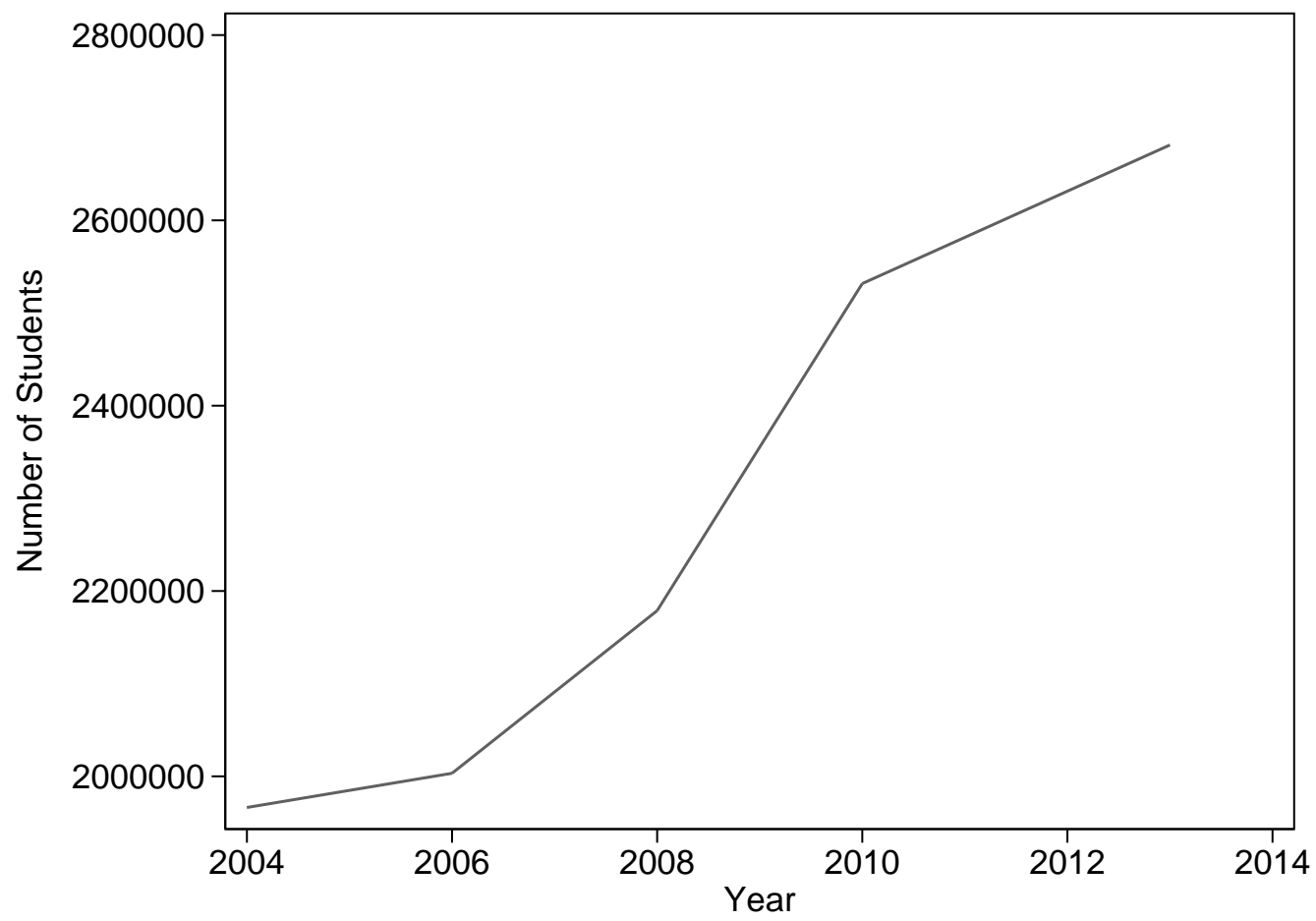

Figure 4.13 shows the total number of students at OECD universities, over time.

The number of students is quite large starting at 2 Million in 2005 and reaching around 2.7 Million at its peak in 2013. Furthermore, the number of students is increasing over the entire sample period.

It is interesting to note that the Global Financial Crisis appears to not have cause a large dip in the number of international students. 
Figure 4.14: Number of International Students by OECD Host-Country

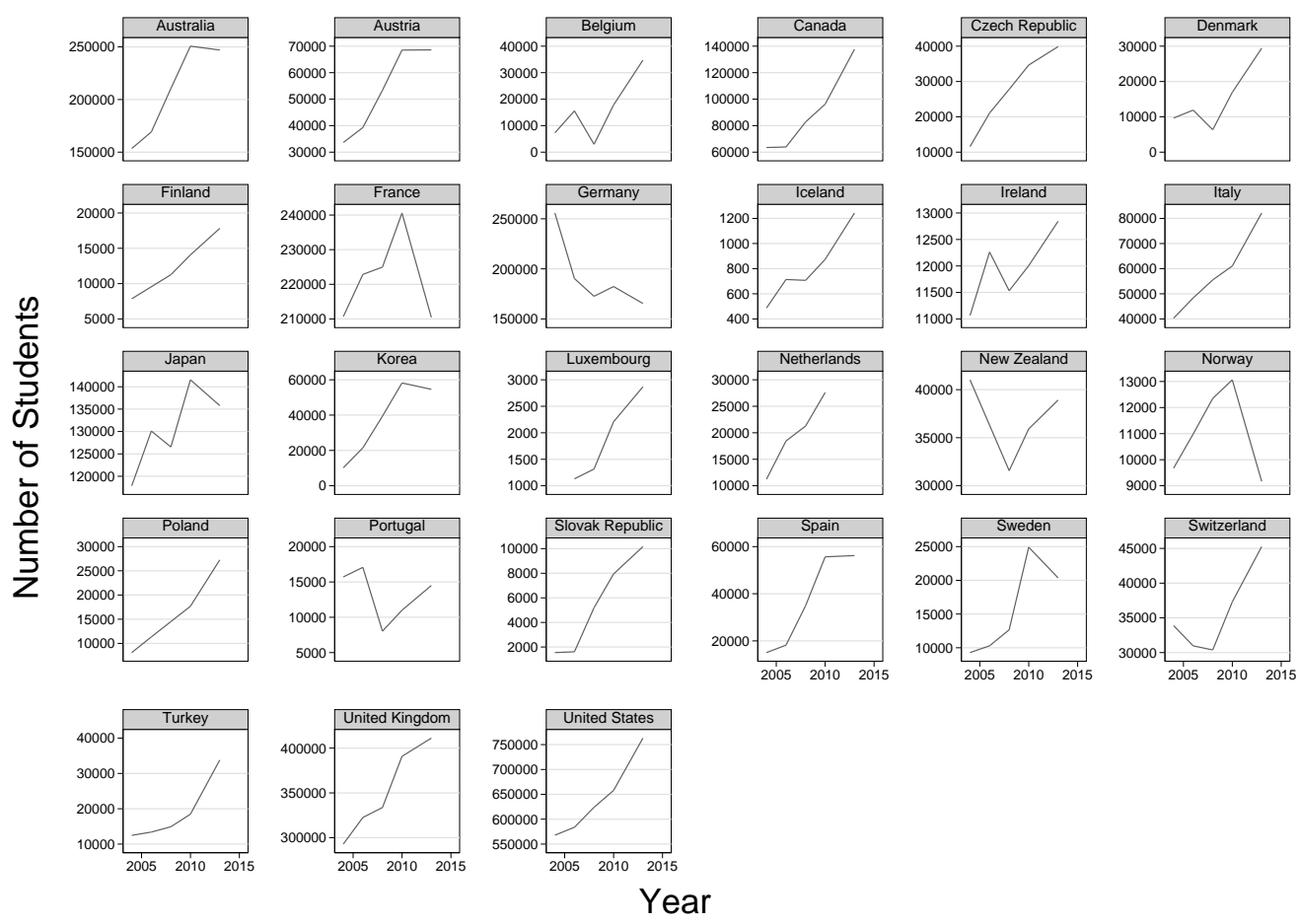

Figure 4.14 shows the number of international students at OECD Universities over time, broken up by host-country.

The OECD country with the largest number of international student is clearly the United States which has twice a large an international student population as the second largest; the United Kingdom. The third largest country is either France or Germany, depending on the year. It is interesting to note that Germany is one of the only host countries to show a clear downward trend over time.

For the majority of countries however, the trend is clearly upwards, with many countries such as Canada and The Netherlands doubling their international students populations over the sample period.

Whereas in the New Zealand Model I was only able to control for sendingcountry effects, it will be important to control for host-country effects in this model as there are large differences here as well. 
Figure 4.15: Number of International Students at OECD Universities, by Sending Region

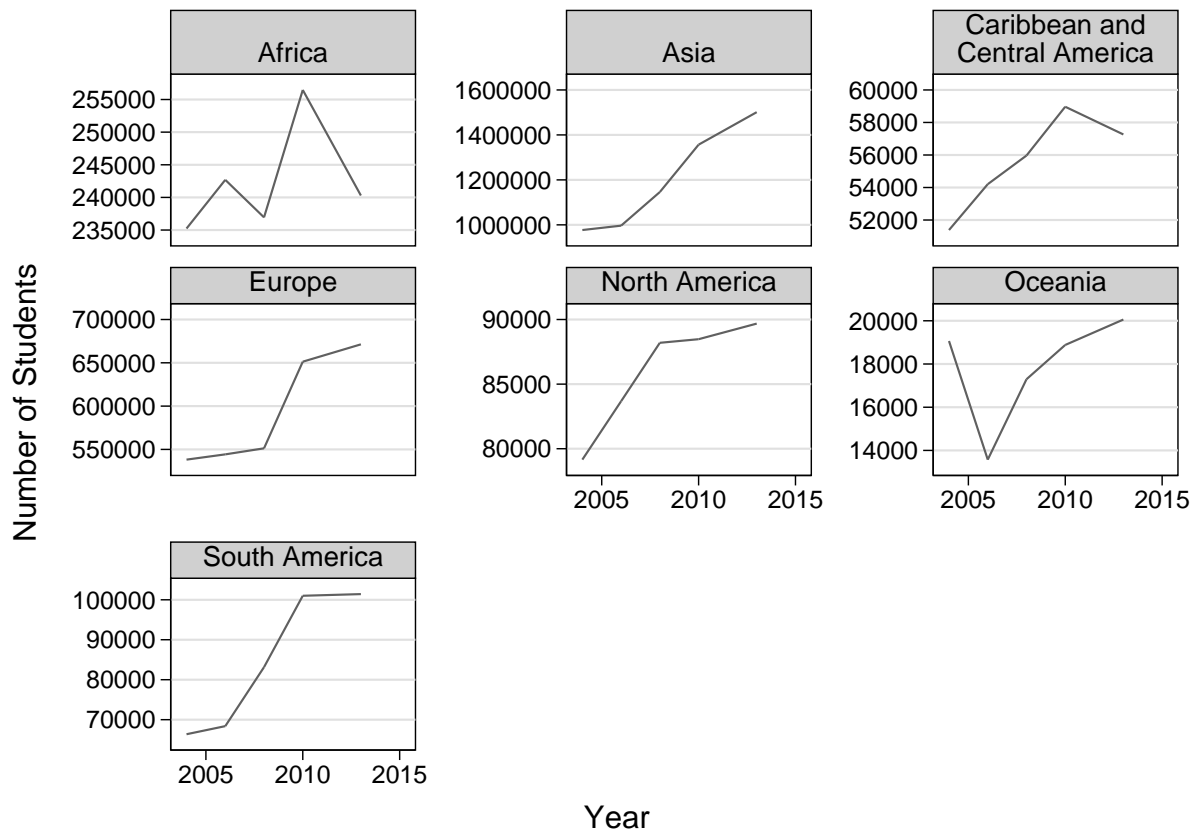

Figure 4.15 shows the number of international students at OECD universities. Due to the high number of sending-countries, I split the data by sending-region.

The largest sending-region by far is Asia with over a million students enrolled outside of their country of origin. The second largest sending region is Europe with 550,000 to just over 666, 000 enrolled students over the sample period, this is likely due to the Erasmus program operates exchange programmes for European Union Students and had enrolled almost 270, 000 students in 2012-2013 (European Commision, 2014).

Most regions are trending upwards. There also appears to be some variation within some regions conditional on this trend. Africa in particular is not flat, with quite a lot of variation from year to year, and Oceania appears to have had a large dip in 2006.

I present this data broken up by all sending countries in Appendix B.2. 


\subsubsection{Fees}

Figure 4.16: Domestic University Fees of OECD Countries
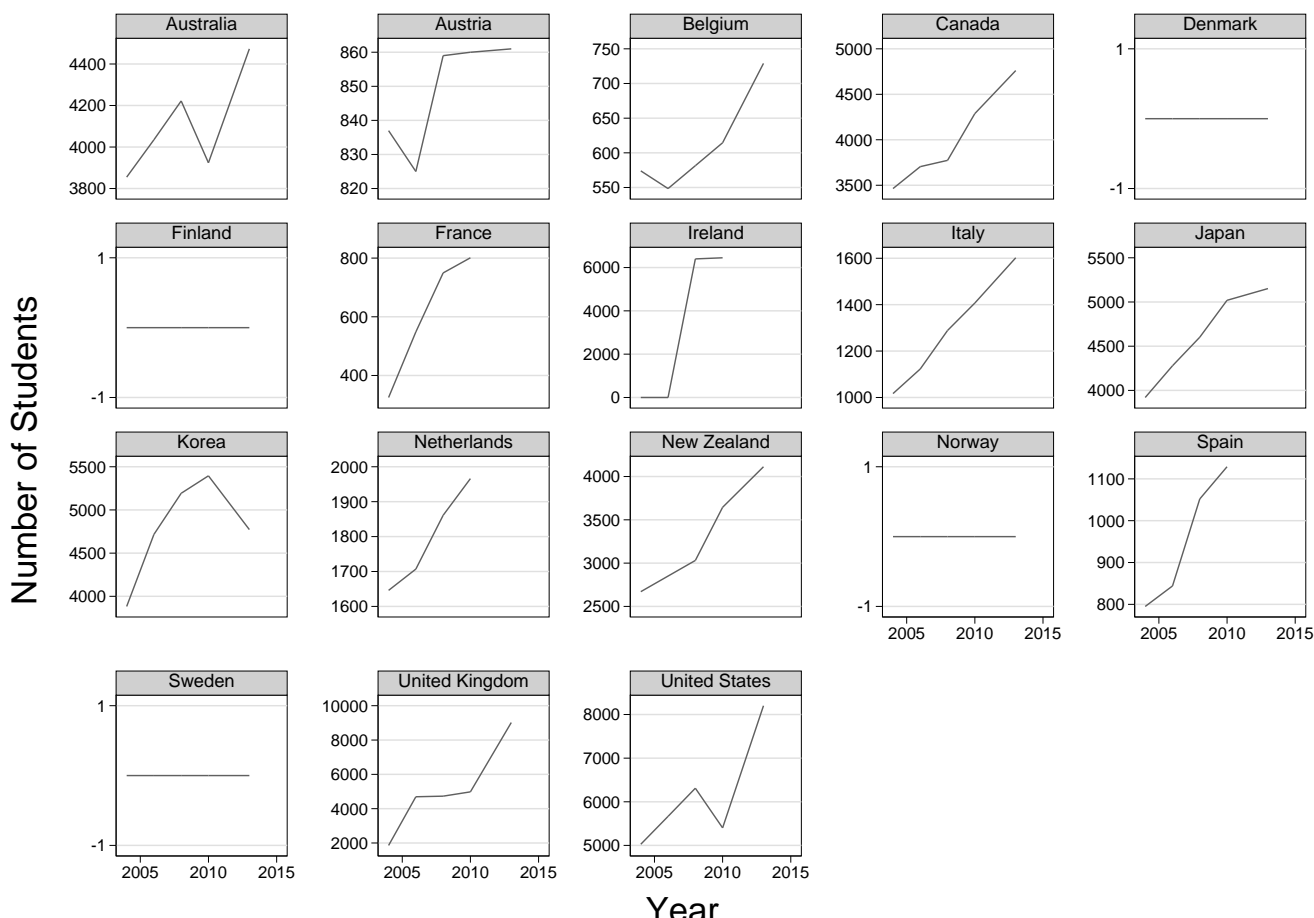

Figure 4.16 plots the change in domestic fees for the sample of OECD countries. As stated previously, foreign fees are unavailable for years that are not 2013 and 2015. Therefore following Beine et al. (2014), I use domestic fees as a proxy for international fees. I would expect domestic fees to be correlated with international fees, cross-sectionally and potentially over time. Evidence in favour of these assumptions is provided pictorially in Figure 4.17 and Figure 4.18, whilst regression evidence is provided in Appendix B.1.

I would also expect international fees to be generally higher than domestic fees (for example, New Zealand international fees are generally 4-5 times domestic fees). There is still however, quite a large amount of variation in domestic fees, both across countries and over time. The United Kingdom in particular has huge variation, starting as one of the lower fee countries and following the massive increase in tuition fee caps in $2012 \mathrm{Sa}$ (2014), ends up as the most expensive country. 
In general, European countries (Excluding the UK and Ireland) tend to be cheaper, and have had less drastic changes in tuition. Anglosphere countries such as Canada, Australia and New Zealand tend to be more expensive and have had larger increases in tuition fees over the sample period.

Figure 4.17: International Fees Versus Domestic Fees of OECD Countries

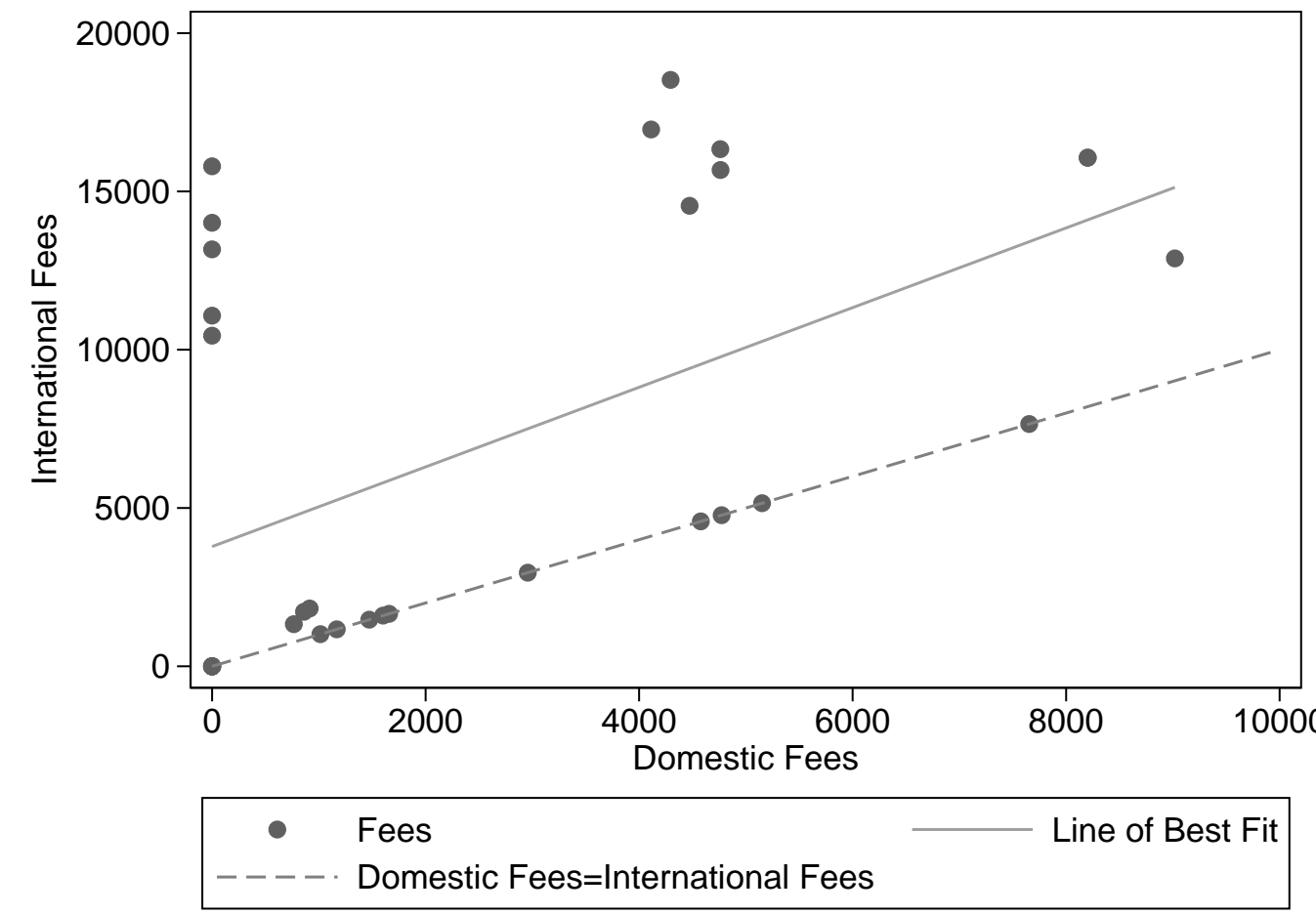

Figure 4.17 plots the International fees of OECD countries versus the Domestic fees for the years $2013 / 2015$. This tests the cross-sectional assumption that domestic fees are correlated with international fees. It is clear that this assumption is true for these years, as the line of best fit is strongly positively sloped. This implies that those countries with higher domestic fees tend to have higher international fees.

It is also important to note that almost no countries charge zero domestic fees and zero international fees, with the exception of Finland and Norway. Therefore, countries which have zero domestic fees may not be a good proxy for international student demand. 
Figure 4.18: Change in International Fees Versus Change in Domestic Fees of OECD Countries

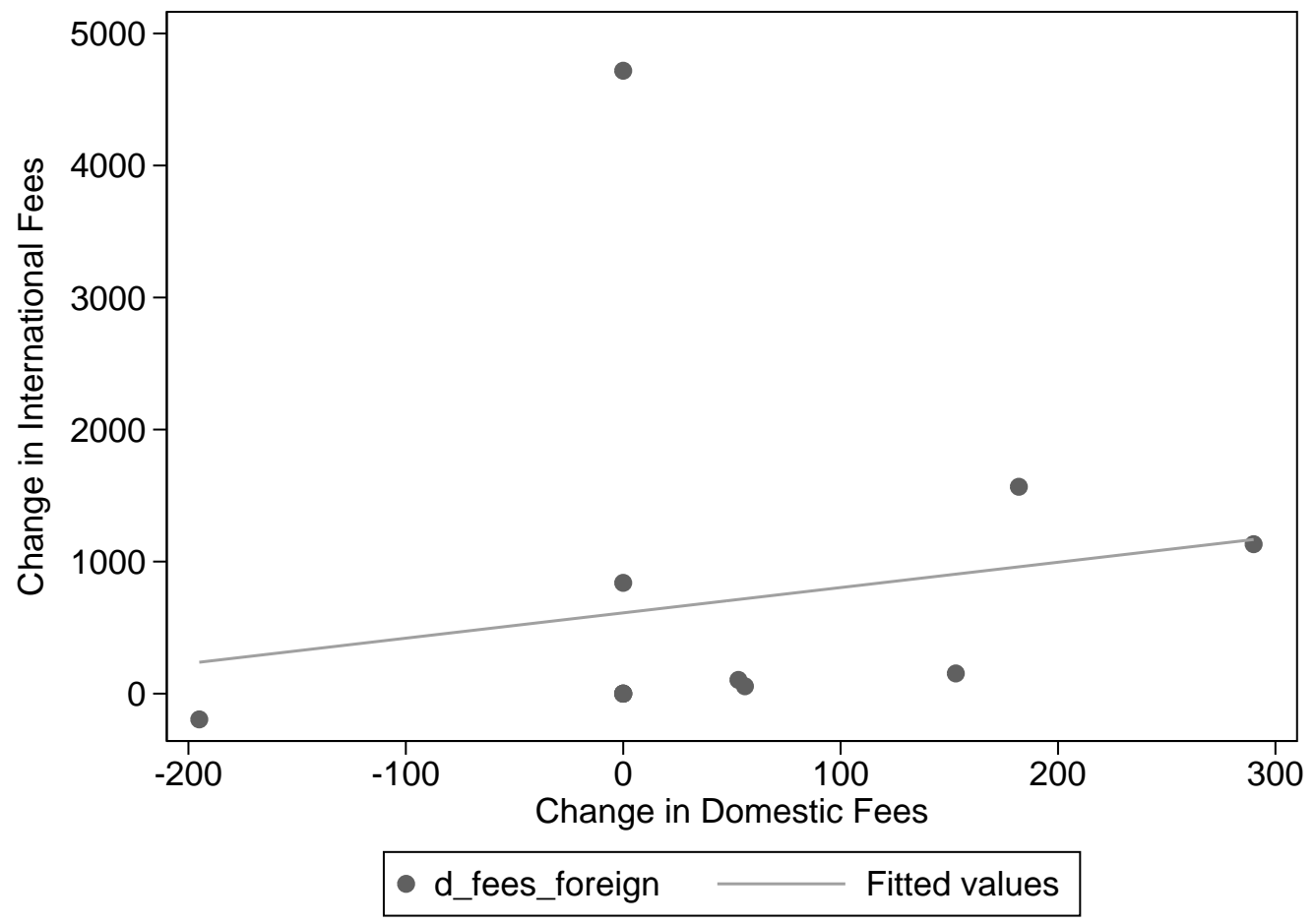

Figure 4.18 tests the assumption that changes in domestic fees are a proxy for changes in international fees. Again, the line of best fit is upwards sloping so it does appear that an increase in domestic fees is correlated with an increase in international fees. For regression analysis of these assumptions see Appendix B.1. 


\subsubsection{Exchange Rates}

Figure 4.19: Exchange Rate of OECD Countries to USD

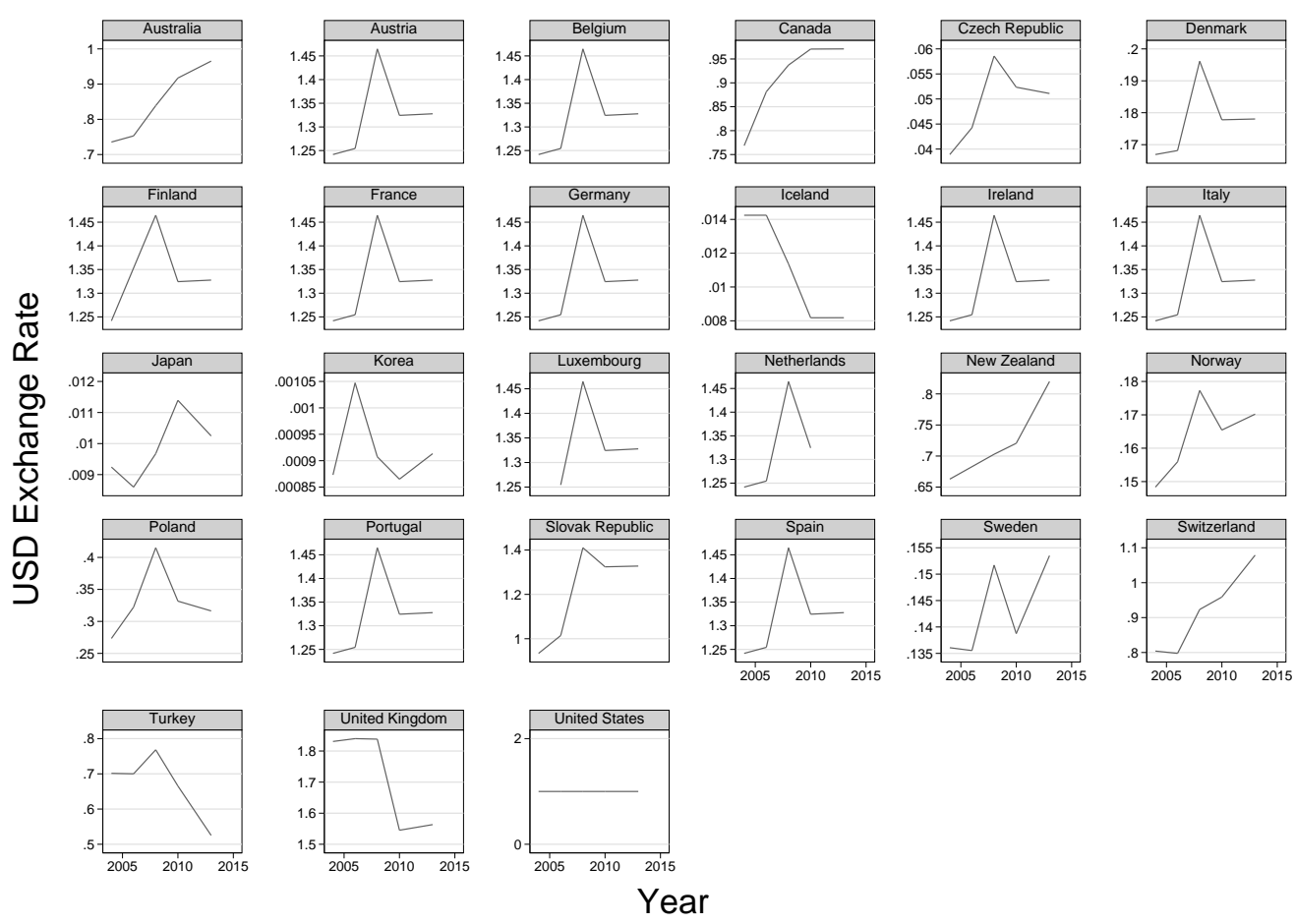

Figure 4.19 shows the exchange rate of OECD countries from the United States Dollar (i.e 1 Australian Dollar bought around .73 US cents in 2004). The USD is the cross-rate for countries that do not have their own bilateral exchange rates as well many currencies being pegged to the USD in some form, it is therefore a decent approximation of appreciations and depreciations of a given country.

For the majority of countries, the USD has been depreciating with a large upward spike in 2009 due to a large proportion of OECD countries using the Euro. Notable exceptions to this trend include the United Kingdom and Turkey. 


\section{Chapter 5}

\section{Empirical Strategy and Methodology}

This chapter introduces my empirical strategy and methodology for analysing international student demand.

I begin in Section 5.1 by introducing a simple cross-sectional model of (international) student demand such as those used in many of the studies in Leslie and Brinkman (1987) and Heller (1997) in meta-analyses of (domestic) student demand and the more recent study by Wei (2013) on the determinants of international student mobility. I then explain the various biases that such a model may have that would confound the 'true' relationship between tuition fees and student demand.

In Section 5.2 I outline the motivation behind using a fixed effects model in order to control for these biases. I end by outlining three data-specific issues that have arisen in my research, and how I deal with these: zero values, logarithmic transformations, and clustered standard errors.

\subsection{Observable Covariates and Unobservable Confounders}

This section discusses a range of possible sources of endogeneity and biases that need to be taken into account when analysing the relationship between international student demand and my independent variables. The majority of these biases can be broadly classified into two types: omitted variable bias and simultaneity bias. 


\subsubsection{Omitted Variables Bias}

Consider a simple cross-sectional model of international student demand at the New Zealand university level with EFTS as the dependent variable and fees and university ranking as the independent variables:

$$
\ln \left(\mathrm{EFTS}_{i t}\right)=\beta_{0}+\beta_{1} \ln \left(\mathrm{FEE}_{i t}\right)+\mathrm{RANK}_{i t}+\epsilon_{i t}
$$

Where EFTS $_{i t}$ denotes the number of international EFTS taken at institution $i$ in year $t . \mathrm{FEE}_{i t}$ denotes the average fee at an institution over time and $\mathrm{RANK}_{i t}$ denotes the QS university ranking of an institution over time.

This may be subject to various omitted variable biases. This occurs when a model incorrectly leaves out or 'omits' an important explanatory variable in the estimating equation. If these omitted variables are correlated with the independent variables, then this will bias the coefficient estimates. (Wooldridge, 2010).

There are many factors left out of Equation (5.1) that we might expect to fulfil the omitted variable conditions. As a starting point, Beine, Noel, and Ragot (2012) develop a small theoretical model to identify the major determinants of international student mobility. These factors include migration costs, the skill premium at the destination country, and living costs. These variables are likely to be correlated with either the fees variable or the rank of the university.

\subsubsection{Simultaneity Bias}

A second source of endogeneity that is concerning and relevant to my models of demand is simultaneity bias or reverse causality. This occurs when the dependent variable and one or more of the independent variables are jointly determined together.

The classic example of this is the estimation of demand and supply equations, the prediction of quantity demanded is endogenous as quantity demanded is determined by price, consumers, whereas the price producers charge is determined by demand. This is the same context that I find myself in.

However, it has often been assumed that in the tertiary education market, price is exogenous to demand as the supply of university places is perfectly elastic (Kane, 2003; Bound \& Turner, 2007). This is assumed to be the 
case as the marginal cost to the university of adding another student is very close to zero. However Neill (2009) notes that this assumption is basically untested. Furthermore, the literature on cohort crowding (Bound \& Turner, 2007) suggest that larger cohorts tend to receive significantly less university resources than smaller cohorts. This may imply that the assumption that supply is perfectly elastic may not be justified.

If this exogenous price assumption is not true, then we have a potential source of endogeneity that will bias my estimates of the relationship between price and number of EFTS. This may not be solved by the use of a fixedeffects model.

\subsection{Fixed Effects Model}

This section describes the fixed effects approach I employ to try and recover the true relationship between tuition fees and international student demand and how my approaches account for the biases explained in Section 5.1.

\subsubsection{Motivation}

A well known advantage of panel data is that fixed effects models allow one to control for the impact of omitted variables in estimating relationships (Hsiao, 2005; Wooldridge, 2010; Verbeek, 2008). The presence of unobservable effects in the demand estimating equation such as quality of institution (as opposed to proxies such as QS ranking), or local cultural conditions (whether at the university/city/country level) will tend to bias cross-sectional estimates. By creating a level-fixed-effect I am able to remove the effect of these omissions on the regression.

As an example consider the New Zealand university-level model that will be discussed in further detail in Subsection 6.1.1. This model regresses the total number of international EFTS in each university over the sample period (2009-2015) against the average fee each university offers (weighted by the number of students in each subject) as well as QS ranking.

Suppose the true model is:

$$
\ln \left(Y_{i t}\right)=\beta_{0}+\beta_{1} \ln \left(\mathrm{FEE}_{i t}\right)+\beta_{2} \mathrm{RANK}_{i t}+\beta_{3} \mathrm{OMIT}_{i}+\epsilon_{i t}
$$


Where $Y_{i t}$ gives the number of international EFTS at institution $i$ in year $t$. FEE gives the annual weighted tuition, RANK gives a given universities QS ranking and $\mathrm{OMIT}_{i}$ is one of the time-invariant omitted variables discussed in Subsection 5.1.1.

If this $\mathrm{OMIT}_{i}$ variable is observable, it should be included in the regression, if not and it is correlated with any of the other regressors the equation will be biased.

In a cross-sectional model this omitted factor goes into the error term:

$$
\ln \left(Y_{i t}\right)=\beta_{0}+\beta_{1} \ln \left(\mathrm{FEE}_{i t}\right)+\beta_{2} \mathrm{RANK}_{i t}+\nu_{i t}
$$

Where $\nu_{i t}=\beta_{3} \mathrm{OMIT}_{i}+\epsilon_{i t}$ In order for this to not bias the estimating equation we need that $E\left(\nu_{i t} \mid \mathrm{FEE}_{i t}, \mathrm{RANK}_{i t}=0\right)$ but we might expect some of the unobservable traits of institutions such as teaching quality, prestige, quality of life, etc. to be correlated with the fee and the university ranking. This will bias my estimates.

A fixed-effect model will handle this unobserved source of endogeneity by creating an institution-specific fixed effect:

$$
\ln \left(Y_{i t}\right)=\alpha_{i}+\beta_{0}+\beta_{1} \ln \left(\mathrm{FEE}_{i t}\right)+\beta_{2} \mathrm{RANK}_{i t}+\epsilon_{i t}
$$

This $\alpha_{i}$ term will soak up the effect of $\mathrm{OMIT}_{i}$ on the estimating equation and is allowed to be correlated with the other regressors. Exogeneity of the error term is still required, but we have effectively solved the omitted variable problem for time-invariant effects.

\subsubsection{Zero values}

In the full panel model (Equation (6.3)) there are a high proportion of zero or near-zero EFTS values. This may mean that I give undue weight to very small observations. For this reason, I probability weight the regression by the number of EFTS in a country by subject by university group in the midpoint year of 2012. This weighting scheme will counter this issue by giving more weight to larger groups.

\subsubsection{Log-transformation}

As we will see in the summary statistics in Tables $6.1,6.4$ and 6.7 of the NZ model, the data appears to be quite right-skewed. For example in Table 6.7 the mean number of EFTS is 8.552, the median is 1.385, and the maximum number of EFTS is 402.4. This is even more of a problem in the OECD data 
with a median number of students of just 8 and a maximum of 225,474 in a host-sending-country pair.

This makes interpreting a linear-linear model quite problematic. For example if the coefficient of fees showed that a $\$ 100$ decrease in fees lead to a 8 student increase in numbers. For the largest OECD host-sending-country pair $(225,474)$ this would be a $0.0035 \%$ increase in the number of students. For the median pair (8) on the other hand, this would be a $100 \%$ increase. Interpreting this result would be quite problematic as we would expect pairs with a larger number of students to lose a proportionate amount to smaller pairs.

For these reasons I take a log-transformation of my dependent and independent variables (EFTS, count, fees, exchange rate). This would more aptly be called the log-plus-one-transformation, due to the presence of zero values i.e:

$$
\log \text { fees }_{i t}=\ln \left(\text { fees }_{i t}+1\right)
$$

An additional advantage of doing this, in terms of interpretability, is that I can now interpret the coefficients as an elasticity, i.e, a $1 \%$ increase in fees leads to a $\beta \%$ change in EFTS, count.

\subsubsection{Clustering}

I apply cluster-robust inference to all regression results in Chapter 6 . In the New Zealand model I cluster the standard errors at the highest level of observation (a university), following the advice in Cameron and Miller (2015). This makes the inference robust to intra-cluster correlation within a university under some assumptions. (Wooldridge, 2010; Rogers, 1994).

In the OECD model I apply a two-way clustering routine (Schaffer, 2015), this is robust to clustering at the host-country level and the sending-country level. The intra-cluster correlations within a sending-country appears to be negative as the standard errors are smaller than regular standard errors. On the other hand, host-country intra-cluster correlations appear to be positive. 


\section{Chapter 6}

\section{Results}

This chapter presents the specifications and the results for my regression analyses.

Section 6.1 presents the results from my New Zealand panel regressions. I produce three models for these analyses, each adding a different part of the picture towards understanding the market.

Section 6.2 provides two analyses of the OECD panel data set.

\subsection{New Zealand Model}

\subsubsection{University Level Model}

\section{Specification}

Firstly I estimate a model at the university by year level. The unit of observation is a given New Zealand university in a given year. The preferred specification of this model is then:

$$
\ln \left(Y_{i t}\right)=\alpha_{i}+\theta_{t}+\beta_{1} \ln \left(\mathrm{FEE}_{i t}\right)+\beta_{2} \mathrm{RANK}_{i t}+\epsilon_{i t}
$$

Where $Y_{i t}$ denotes the number of international EFTS at a given institution $i$ in year $t . \alpha_{i}$ denotes a university-specific fixed effect, $\theta_{t}$ denotes a year fixed effect. $\mathrm{FEE}_{i t}$ denotes the average fee at a university (weighted by number of students ${ }^{1}$ ) and $\mathrm{RANK}_{i t}$ denotes the QS ranking of a given university.

\footnotetext{
${ }^{1}$ This is the same weighting process as in Figure 4.7
} 


\section{Summary Statistics}

Table 6.1: University Model: Summary Statistics

\begin{tabular}{lccccc}
\hline & $(1)$ & $(2)$ & $(3)$ & $(4)$ & $(5)$ \\
VARIABLES & mean & sd & min & $\max$ & p50 \\
\hline & & & & & \\
fees & 24,751 & 3,789 & 19,033 & 34,404 & 24,474 \\
efts & 841.6 & 797.0 & 77.50 & 2,924 & 586.1 \\
rank & 288.9 & 140.2 & 61 & 501 & 287 \\
log_efts & 6.331 & 0.945 & 4.363 & 7.981 & 6.375 \\
log_fees & 10.11 & 0.150 & 9.854 & 10.45 & 10.11 \\
& & & & & \\
\hline
\end{tabular}

Table 6.1 presents summary statistics from the variables in the university level model (Equation (6.1)). The unit of observation in this model is university by year.

The average international fee (weighted by number of EFTS in each course) at New Zealand universities is $\$ 24,751$ there is quite a lot of variation in this fee, with the minimum and maximum being around fifteen-thousand dollars apart. However, most universities have a fee within $\$ 3789$ of this.

There is an even larger variation in the number of international EFTS per year with a maximum of 2,924 (University of Auckland) and a minimum of just 77.50 (Lincoln University). The average number of EFTS is 841.60 with a standard deviation of 797 .

The EFTS variable appears to be slightly right skewed with a slightly longer right tail, the median is significantly lower than the mean and the maximum value is quite far from both the median and the mean. Because of this possible right-skew and the convenience of interpreting the results as an elasticity, I take a log-transformation of fees and EFTS ${ }^{2}$. The logtransformation centres the data.

\footnotetext{
${ }^{2}$ More precisely, I take the $\ln +1$ transformation of these variables for consistency with later models where zero-values will become a problem. See Subsection 5.2.2
} 


\section{Results}

Table 6.2: University Model: Fixed Effects

\begin{tabular}{|c|c|c|c|}
\hline VARIABLES & $\begin{array}{c}(1) \\
\text { Log. EFTS }\end{array}$ & $\begin{array}{c}(2) \\
\text { Log. EFTS }\end{array}$ & $\begin{array}{c}(3) \\
\text { Log. EFTS }\end{array}$ \\
\hline log_fees & $\begin{array}{l}-1.386940 \\
(0.938060)\end{array}$ & $\begin{array}{c}-0.147515 \\
(0.304928)\end{array}$ & $\begin{array}{l}-0.649237 \\
(0.788029)\end{array}$ \\
\hline rank & $\begin{array}{l}-0.004246 \\
(0.002571)\end{array}$ & $\begin{array}{l}-0.000761 \\
(0.000525)\end{array}$ & $\begin{array}{l}-0.001115 \\
(0.000836)\end{array}$ \\
\hline Observations & 56 & 56 & 56 \\
\hline Mean No. of EFTS & 841.63 & 841.63 & 841.63 \\
\hline UNI FE & NO & YES & YES \\
\hline YEAR FE & $\mathrm{NO}$ & $\mathrm{NO}$ & YES \\
\hline
\end{tabular}

Table 6.2 presents the regression results from the university level model.

Column (1) presents the model without university or year fixed effects. Here the effect of fees on EFTS is quite large. The point estimates here imply a $1 \%$ increase in fees is associated with a $1.38 \%$ decrease in international EFTS. The point estimates of ranking imply that a one place fall in ranking (i.e going from the top 20th place to top 21st) decrease the number of EFTS taken by $0.4 \%$.

It is worth noting that Column (1) is the purely cross-sectional model discussed in Section 5 and is subject to problems with endogeneity and should be interpreted with caution, if at all.

I introduce year fixed effects in Column (2). It appears that controlling for these across-time effects significantly diminished the relationship between the dependent an independent variables.

My preferred specification for this model is Column (3), which includes both year and university fixed effects. This implies that we are looking at the variation within a university whilst controlling for year effects constant across universities and university effects constant across time. The coefficients here implies that a $1 \%$ increase in fees leads to a $0.64 \%$ decrease in the 
number of international EFTS, and a one place fall in ranking is leads to a $0.1 \%$ decrease in EFTS.

In all columns the effect of logged fees and rank are not statistically significant. This may be because of the low number of clusters (Cameron \& Miller, 2015), the effect of throwing out the between variation in fees or a weak relationship (although the magnitude of the estimate is large in economic terms). It is worthwhile therefore, to look at the confidence intervals from my preferred specification.

\section{Confidence Intervals}

Table 6.3: University Model: Confidence Intervals

(1)

\begin{tabular}{lc} 
VARIABLES & Log. EFTS \\
\hline log_fees & {$[-2.512630-1.214155]$} \\
rank & {$[-0.003092-0.000863]$} \\
& \\
\hline & \\
& $* * * \mathrm{p}<0.01,{ }^{* *} \mathrm{p}<0.05,{ }^{*} \mathrm{p}<0.1$
\end{tabular}

Table 6.3 presents the confidence intervals for the preferred specification (Column 3 in Table 6.2). We can see that the possible range for logged fees is quite high, it could be as large as a $1 \%$ leading to a $2.51 \%$ decrease in EFTS, or conversely a $1.214 \%$ increase in EFTS. The rank coefficient has a much smaller range with a one place fall in rank being associated with as large as a $2 \%$ fall in number of EFTS, or as small as a $0.6 \%$ increase in the number of EFTS.

Overall, the demand for EFTS at a university level seems relatively inelastic in terms of these coefficients. The elasticity here is less than 1, and is fact statistically indistinguishable from 0 (though this may be due to a lack of statistical power). This implies that the average university could increase the average price of EFTS and increase revenue by marginally increasing fees. 


\subsubsection{Subject Level Model}

\section{Specification}

Another way that we can have variation in fees, within a university, is by breaking up the data by field of study. Students in NZ pay fees by paper, and there is significant variation in course fees across subjects ${ }^{3}$. This implies that the relevant cost for students is more likely to be subject-specific. This is a somewhat richer level of observation, as I can leverage both competition across universities, and profit maximisation within a university, across subjects.

The preferred specification for this model is:

$$
\ln \left(Y_{i s t}\right)=\alpha_{i s}+\theta_{t}+\beta_{0}+\beta_{1} \ln \left(\mathrm{FEE}_{i s t}\right)+\beta_{2} \mathrm{RANK}_{i t}+\epsilon_{i s t}
$$

Where $Y_{\text {ist }}$ denotes the number of international EFTS in a given subject $s$ within a given university $i$ at time $t$. $\alpha_{i s}$ denotes a university by subject fixed effect and $\theta_{t}$ denotes a year fixed effect. $\mathrm{FEE}_{i s t}$ denotes the subject-specific, university-specific annual fee. RANK Rt $_{i t}$ denotes the university's QS ranking as in (6.1).

\section{Summary Statistics}

Table 6.4: Subject Model: Summary Statistics

\begin{tabular}{lccccc}
\hline & $(1)$ & $(2)$ & $(3)$ & $(4)$ & $(5)$ \\
VARIABLES & mean & sd & min & $\max$ & p50 \\
\hline fees & & & & & \\
efts & 24,595 & 4,681 & 16,200 & 44,847 & 24,112 \\
rank & 92.23 & 142.1 & 0.125 & 785.9 & 40.21 \\
log_efts & 282.6 & 137.1 & 61 & 501 & 275 \\
log_fees & 3.539 & 1.523 & 0.118 & 6.668 & 3.719 \\
& 10.09 & 0.178 & 9.693 & 10.71 & 10.09
\end{tabular}

Table 6.4 presents summary statistics from the regression analysis that accompanies specification (6.2).

\footnotetext{
${ }^{3}$ See Chapter 4, Figure 4.8
} 
It is clear that whilst the mean and standard deviation are reasonably similar to Table 6.1, however, the minimum and maximum fee are much smaller and larger. This implies larger variation in the fees variable.

In addition there are also large differences in the EFTS variable. Whereas the mean number of EFTS per-uni in Table 6.1 was 841.6, the mean here is 92.23. The standard deviation is also much smaller. The difference between the minimum and the maximum values is quite concerning here with a minimum value of just 0.125 and a maximum of 785.9 . This appears to be even more right-skewed than in the university summary statistics (Table 6.1).

To control for this, I again take the log-transformation of EFTS and fees, this appears to be a decent job of centring the data.

\section{Results}

Table 6.5: Subject Model: Fixed Effects

\begin{tabular}{|c|c|c|c|}
\hline VARIABLES & $\begin{array}{c}(1) \\
\text { Log. EFTS }\end{array}$ & $\begin{array}{c}(2) \\
\text { Log. EFTS }\end{array}$ & $\begin{array}{c}(3) \\
\text { Log. EFTS }\end{array}$ \\
\hline log_fees & $\begin{array}{c}0.310190 \\
(0.828439)\end{array}$ & $\begin{array}{l}-0.196588 \\
(0.217667)\end{array}$ & $\begin{array}{l}-0.133180 \\
(0.367452)\end{array}$ \\
\hline rank & $\begin{array}{l}-0.003168 \\
(0.001872)\end{array}$ & $\begin{array}{c}-0.000221 \\
(0.000517)\end{array}$ & $\begin{array}{l}-0.000511 \\
(0.000738)\end{array}$ \\
\hline Observations & 449 & 449 & 449 \\
\hline Mean No. of EFTS & 92.23 & 92.23 & 92.23 \\
\hline SUBJECT-BY-UNI FE & $\mathrm{NO}$ & YES & YES \\
\hline YEAR FE & $\mathrm{NO}$ & $\mathrm{NO}$ & YES \\
\hline
\end{tabular}

Table 6.5 presents the results from regression equation (6.2). I begin with a model with no fixed effects in Column (1), we can see that the effect of logged fees is slightly positive while the effect of rank is slightly negative. Column (2) introduces a course-by-university fixed effect which changes the sign on logged fees to negative as we would expect. 
Introducing a year fixed effect in Column (3) decreases the size of the effect whilst maintaining the negative sign. The point estimates here imply that a $1 \%$ increase in fees is associated with a $0.13 \%$ decrease in international EFTS. A one place fall in rank is associated with a 0.05 percent decrease in EFTS.

These estimates are smaller than those in the university level model (Table 6.2), perhaps reflecting the differing source of variation and different unit of observations. Whereas before I looked for variation within a university over time, I now look for variation within a university-subject pair.

Furthermore, whereas the fees variable in the previous model reflected the average price of a given university, the fees variable now reflects the price of a subject within that university. It may be the case that an appreciation of the average price of a university causes a small amount of substitution, but changes in the price of a certain subject cause almost no substitution. This makes intuitive sense as students can often transfer credits from previous universities, whereas they will generally have to start from the beginning for a new subject, extending the length of their degree.

\section{Confidence Intervals}

Table 6.6: Subject Model: Confidence Intervals

(1)

\begin{tabular}{lc} 
VARIABLES & Log. EFTS \\
\hline $\log _{\text {_fees }}$ & {$[-1.002065-0.735704]$} \\
rank & {$[-0.002255-0.001234]$} \\
& \\
\hline & ${ }^{* * *} \mathrm{p}<0.01,{ }^{* *} \mathrm{p}<0.05,{ }^{*} \mathrm{p}<0.1$
\end{tabular}

Table 6.6 presents confidence intervals from the regression in Table 6.5. We can see that the interval for the price elasticity is quite large in this case ranging from basically unitary $E_{d}=-1$, implying a change in price will not affect revenue, to perfectly inelastic and even positive. On the balance of probabilities these results imply that the universities could increase prices on the margin without losing revenue. 


\subsubsection{Country by Subject Level Model}

\section{Specification}

I now introduce my final NZ model, which uses the full panel data set with observations at the country by course by university level.

The advantage to using a model at this level when compared to previous models is that I can now leverage the fact that I have observations within a country-year to include country-by-year fixed effects. Country by year fixed effects control for effects that are common across all students from a country, with a time period.

This is of special importance because previous research (Beine et al., 2014) have found that the one of the largest predictors of international student flows is the stock of migrants from that sending country in the host-country, and this stock will change over time. There is also a concern that economic shocks common to a country, such as a recession or changes in the return-to-skill in a country may drive some of my results thus far.

Here I can use unweighted fees, but because of the high presence of zero values in the observations (see Table 6.7) which give undue weight to smaller courses, I weight the data by number of students as discussed in Subsection 5.2.2.

The unit of observation here is a given sending country, within a subject, within a university, for a given year. The preferred specification for this approach is:

$$
\ln \left(Y_{i c s t}\right)=\alpha_{i s}+\left[\theta_{t} \times \gamma_{c}\right]+\beta_{1} \ln \left(\mathrm{FEE}_{i s t}\right)+\beta_{2} \mathrm{RANK}_{i t}+\epsilon_{i c s t}
$$

Where $Y_{\text {icst }}$ denotes the number of international EFTS at a given institution $i$, in a given subject $s$,from a given country, $c$ at time $t$. $\alpha_{i s}$ denotes a university by subject fixed effect, $\left[\theta_{t} \times \gamma_{c}\right]$ denotes a country by year effect $\mathrm{FEE}_{\text {ist }}$ denotes the average fee of a subject within a university and RANK denotes the QS ranking of a given university over time. 


\section{Summary Statistics}

Table 6.7: Full Panel: Summary Statistics

\begin{tabular}{lccccc}
\hline & $(1)$ & $(2)$ & $(3)$ & $(4)$ & $(5)$ \\
VARIABLES & mean & sd & $\min$ & $\max$ & $\mathrm{p} 50$ \\
\hline efts & & & & & \\
fees & 8.552 & 27.84 & 0 & 402.4 & 1.385 \\
exchangerate & 24,706 & 4,983 & 16,200 & 44,847 & 24,060 \\
rank & 1,488 & 4,069 & 0.382 & 17,463 & 5.210 \\
log_efts & 269.3 & 139.2 & 61 & 501 & 242 \\
log_fees & 1.250 & 1.116 & 0 & 6.000 & 0.869 \\
log_exchangerate & 10.10 & 0.187 & 9.693 & 10.71 & 10.09 \\
& 3.175 & 2.880 & 0.323 & 9.768 & 1.826
\end{tabular}

Table 6.7 presents the summary statistics from the full panel regression model (6.3).

We can see that the average number of EFTS is much smaller in this model than the previous (8.552). Here, we have a minimum number of EFTS of 0, many country by course by university sets have no students in a given year. This is the motivation for probability-weighting the regression by number of EFTS (in 2012) in order to avoid giving undue weight to smaller observations.

The other variables are similar to previous models. We have the same level of variation in fees as in the course level model (6.2), the same level of exchange rate variation as in the country level model and the same-level of rank variation as in the university level model (6.1). I also include a term for the effect of the exchange rate in Column (1) of Table 6.8.

As in previous models, I take the log-transformation of all variables well to control for skewed data and to help with interpretability. 


\section{Results}

Table 6.8: Full Panel: Fixed-Effects

\begin{tabular}{|c|c|c|c|}
\hline VARIABLES & $\begin{array}{c}(1) \\
\text { Log. EFTS }\end{array}$ & $\begin{array}{c}(2) \\
\text { Log. EFTS }\end{array}$ & $\begin{array}{c}(3) \\
\text { Log. EFTS }\end{array}$ \\
\hline log_fees & $\begin{array}{l}-0.317595 \\
(0.994101)\end{array}$ & $\begin{array}{c}-0.615478 \\
(1.293498)\end{array}$ & $\begin{array}{l}-0.401849 \\
(0.267199)\end{array}$ \\
\hline log_exchangerate & $\begin{array}{c}-0.148533^{* * *} \\
(0.036151)\end{array}$ & & \\
\hline rank & $\begin{array}{l}-0.000314 \\
(0.002116)\end{array}$ & $\begin{array}{l}-0.001867 \\
(0.001064)\end{array}$ & $\begin{array}{c}-0.002058^{*} \\
(0.001067)\end{array}$ \\
\hline Observations & 4,225 & 4,225 & 4,225 \\
\hline Mean No. of EFTS & 8.55 & 8.55 & 8.55 \\
\hline COUNTRY-BY-YEAR FE & NO & YES & YES \\
\hline UNI FE & YES & YES & - \\
\hline UNI-BY-SUBJECT FE & $\mathrm{NO}$ & $\mathrm{NO}$ & YES \\
\hline
\end{tabular}

Table 6.8 presents the results from the empirical specification (6.3).

I begin with a regression in Column(1) which includes a term for the logged exchange rate instead of a country by year effect. The signs are mainly what we would expect with the an fee elasticity of EFTS of -0.318. The estimated elasticity of exchange rates is -0.1485 and this effect is significant at the $1 \%$ level. The effect of rank is statistically significant here with the estimates implying a one place fall in rank leading to a $0.3 \%$ decrease in EFTS.

In Column (2) I include a country by year fixed effect following the motivation in Subsection 6.1.3. The exchange rate coefficient is subsumed under these fixed effects, but I can now control for other time-varying sendingcountry effects. The inclusion of a country-by-year fixed effect increases the magnitude of the fee elasticity to -0.615 , which is almost twice as large as the coefficient in Column (1). This implies that students demand is more elastic with respect to fees when controlling for home-country conditions.

Finally, in Column (3) I include a course by university fixed effect. The point estimates here imply that a $1 \%$ increase in fees leads to a $0.4 \%$ decrease 
in the number of international EFTS, but this is not statistically significant. The marginal effect of a one place fall in rank is a $0.2 \%$ decrease in the number of EFTS and this is statistically significant at the $10 \%$ level. These results are reasonably similar to the results in Table 6.2 as well as being quite similar to the survey results in Baxter (2012).

\section{Confidence Intervals}

\begin{tabular}{lc} 
Table 6.9: Full Panel: & Confidence Intervals \\
VARIABLES & Log. EFTS \\
\hline $\begin{array}{l}\text { log_fees } \\
\text { rank }\end{array}$ & {$[-1.033675-0.229977]$} \\
& {$[-0.004582-0.000465]^{*}$} \\
\hline & \\
\hline
\end{tabular}

Table 6.9 presents $95 \%$ confidence intervals for the logged fee and rank variables.

We can see that the range of estimates for the elasticity of logged fees range from very slightly elastic $E_{f}<-1$ to very inelastic/positive $E_{f}>0$. At the lowest value this would imply that an increase in fees would cause a small drop in revenue, at the highest value this would imply that an increase in fees would increase revenue.

\subsection{All Countries Model}

\subsubsection{Domestic Fees Model}

\section{Specification}

I now present a model which uses the OECD data discussed in Section 3.2. This dataset contains data on the number of students in 27 host-countries from all sending-countries in the world for the years 2004, 2006, 2008, 2010 and 2013. I employ the same fixed effects approach as in Section 6.1.

As there is no available international fees for this data, I use domestic fees as a proxy variable as in Beine et al. (2014). The assumption that domestic 
fees are a reasonable proxy for international fees is explored pictorially in Subsection 4.2.2 and empirically in Appendix B.1.

In my preferred specification I use host-country by sending-country fixed effects. This accounts for common unobservables in host-countries such as the quality of education and living costs, as well as sending-country variables such as the local skill price and local quality of education. It also captures what Beine et al. (2014) terms 'dyadic' factors that are only present between countries, such as the existence of a colonial link, the size of the present sending-county migrant network in a host-country and shared languages.

The preferred empirical specification is then:

$$
\ln \left(Y_{h s t}\right)=\alpha_{h s}+\theta_{t}+\beta_{1} \ln \left(\mathrm{FEE}_{h t}\right)+\beta_{2} \ln \left(\mathrm{EXCHANGE}_{h t}\right)+\epsilon_{h s t}
$$

Where $Y_{h s}$ denotes the number of students at a given host-country $h$ from a given sending-country $s$ at time $t$. $\alpha_{h s}$ denotes a host-country by sending-country specific fixed effect, $\mathrm{FEE}_{h t}$ denotes the average domestic fee within a host-country over time, and EXCHANGE $h t$ denotes a host-country's exchange rate from USD.

\section{Summary Statistics}

Table 6.10: All Countries: Summary Statistics

\begin{tabular}{lccccc}
\hline & $(1)$ & $(2)$ & $(3)$ & $(4)$ & $(5)$ \\
VARIABLES & mean & sd & min & $\max$ & p50 \\
\hline fees & & & & & \\
count & 2,044 & 2,222 & 0 & 9,019 & 1,015 \\
exchangerate_host & 451.1 & 3,683 & 0 & 225,474 & 8 \\
log_fees & 0.847 & 0.566 & 0.000865 & 1.840 & 1 \\
log_count & 5.318 & 3.598 & 0 & 9.107 & 6.924 \\
log_exchangerate & 2.615 & 2.472 & 0 & 12.33 & 2.197 \\
& 0.559 & 0.343 & 0.000865 & 1.044 & 0.693
\end{tabular}

Table 6.10 presents the summary statistics from the empirical specification (6.4). 
The fees variable here denotes the average domestic fee from a given country for public institutions, converted to USD. There is quite a lot of variation in domestic fees across countries with some countries having no fees and others (the U.K. and the U.S.A) having quite high average fees.

The count of students has extremely high variation with some sendinghost country pair having 0 students and the largest pair (China-US) having 225,474 students. This variable is very right-skewed with a mean of 451.1 and a median of just 8 students.

Because of the presence of right-skewness in all three variables, interpretability of the estimates and consistency with the New Zealand model 6.1 I take the log-transformation of these variables.

\section{Results}

Table 6.11: All Countries: Fixed Effects Model

\begin{tabular}{|c|c|c|c|c|}
\hline VARIABLES & $\begin{array}{c}(1) \\
\log _{-} \text {count } \\
\end{array}$ & $\begin{array}{c}(2) \\
\log _{-} \text {count }\end{array}$ & $\begin{array}{c}(3) \\
\log _{-} \text {count } \\
\end{array}$ & $\begin{array}{c}(4) \\
\log \text { _count }\end{array}$ \\
\hline $\log$ fees & $\begin{array}{c}-0.019650 \\
(0.025696)\end{array}$ & $\begin{array}{c}-0.016508 \\
(0.016461)\end{array}$ & $\begin{array}{c}-0.018029 \\
(0.016966)\end{array}$ & $\begin{array}{l}-0.017097 \\
(0.016789)\end{array}$ \\
\hline log_exchangerate & $\begin{array}{c}1.151349 \\
(0.954445)\end{array}$ & $\begin{array}{l}-0.474961 \\
(0.994902)\end{array}$ & $\begin{array}{c}-0.576402 \\
(1.048367)\end{array}$ & $\begin{array}{c}-0.507304 \\
(1.040934)\end{array}$ \\
\hline Observations & 21,611 & 21,611 & 21,611 & 20,744 \\
\hline Host-Country FE & YES & YES & YES & - \\
\hline Year FE & NO & YES & YES & YES \\
\hline Sending-Country FE & $\mathrm{NO}$ & NO & YES & - \\
\hline Host-by-Sending Country FE & NO & NO & NO & YES \\
\hline
\end{tabular}

Table 6.11 presents the regression results from the specification in (6.4).

I begin with the most parsimonious regression in Column (1) with only a host-country fixed effect the results here imply that a $1 \%$ increase in average fees leads to a $0.0196 \%$ decrease in the number of students choosing to attend a university within a given host-country. The effect of a $1 \%$ appreciation in the host countries exchange rate to the USD is a $1.151 \%$ increase in 
the number of students. Because of the lack of a year fixed effects this coefficient should be interpreted with caution as it may be proxying a time trend.

In Column (2) and (3) I include a year fixed effect and then a sendingcountry fixed effect, to account for omitted variables that are common to all countries, within a year, and unobservable covariates that are common within a sending-country, across time. The results for the logged fee variable are substantively the same, but the sign on the exchange rate reverses, becoming negative. The coefficient in Column (3) for example implies that a $1 \%$ appreciation in the host-country's exchange rate leads to a $0.576 \%$ decrease in the number of students, this would make sense as the students home-country currency reserves are now less valuable in their host-country.

Finally in Column (4) I present the results from my preferred specification which account for 'dyadic cost' variables (Beine et al., 2014) by using a sending-host pair fixed effect. The results here are quite similar to Column (3) and Column (4) with a fee elasticity of demand of (-0.017) and an exchange rate elasticity of demand of $(-0.507)$.

However as none of these results are statistically significant I now turn to confidence interval estimates:

\begin{tabular}{|c|c|}
\hline Table 6.12: & $\begin{array}{r}\text { (1) Countries: CI } \\
\text { log_count }\end{array}$ \\
\hline log_fees & {$[-0.050003-0.015809]$} \\
\hline log_exchangerate & [-2.547497 - 1.532889] \\
\hline
\end{tabular}

Table 6.12 presents the $95 \%$ confidence intervals from the regression in Table 6.11, Column (4). We can see that the fee elasticity of demand ranges from quite inelastic to slightly positive. This implies that tuition fees are not necessarily an important predictor in this model.

The exchange rate elasticity of demand varies widely ranging from quite elastic (-2.547) to quite positive. To a degree this makes some sense as an appreciation of the host-country currency implies that a students foreigncountry currency reserves are less valuable, but it also implies the host- 
country has a relatively stronger economy and may be able to attract more students (Beine, Docquier, \& Rapoport, 2008).

\subsubsection{Domestic Fees Model: Fees = 0 Dropped}

Very few countries charge zero dollars for their international tuition fee. ${ }^{4}$ The overwhelming majority of countries charge some sort of fee for their international students' tuition. ${ }^{5}$ This fact may bias my estimates to be smaller in magnitude as I will see a change in students from countries, where in reality there is a change in international fees, but domestic fees remain zero throughout the sample period.

Because of this potential bias, I now present a model where all hostcountries with zero fees are dropped, this model uses the same specification as in (6.4)

\section{Summary Statistics}

Table 6.13: Dropped Observations Model: Summary Statistics

\begin{tabular}{lccccc}
\hline & $(1)$ & $(2)$ & $(3)$ & $(4)$ & $(5)$ \\
VARIABLES & mean & sd & min & $\max$ & p50 \\
\hline fees & & & & & \\
count & 2,939 & 2,113 & 276 & 9,019 & 2,707 \\
exchangerate_host & 622.1 & 4,398 & 0 & 225,474 & 14 \\
log_fees & 7.009 & 0.500 & 0.000865 & 1.840 & 1.242 \\
log_count & 3.005 & 2.583 & 0 & 12.33 & 2.708 \\
log_exchangerate & 0.658 & 0.302 & 0.000865 & 1.044 & 0.807 \\
& & & & &
\end{tabular}

The summary statistics here are very similar to Table 6.10 , the major difference (as I would expect) is that the minimum fee is no longer 0 , it is now $\$ 276$.

\footnotetext{
${ }^{4}$ See Figure 4.17

${ }^{5}$ An exception to this is countries in the EU which often charge zero fees for other EU nationals while charging a fee for students who are not from the EU.
} 


\section{Results}

Table 6.14: Dropped Observations Model: Fixed Effects

\begin{tabular}{|c|c|c|c|c|}
\hline VARIABLES & $\begin{array}{c}(1) \\
\log \_c o u n t\end{array}$ & $\begin{array}{c}(2) \\
\log \_c o u n t\end{array}$ & $\begin{array}{c}(3) \\
\log \_ \text {count }\end{array}$ & $\begin{array}{c}(4) \\
\log \_ \text {count }\end{array}$ \\
\hline log_fees & $\begin{array}{c}0.508466^{* *} \\
(0.251781)\end{array}$ & $\begin{array}{c}-0.446636^{* *} \\
(0.204899)\end{array}$ & $\begin{array}{c}-0.444754^{* *} \\
(0.197788)\end{array}$ & $\begin{array}{c}-0.419986^{* *} \\
(0.199522)\end{array}$ \\
\hline log_exchangerate & $\begin{array}{c}1.214412 \\
(0.817585)\end{array}$ & $\begin{array}{c}-0.676614 \\
(1.127759)\end{array}$ & $\begin{array}{l}-0.763565 \\
(1.149179)\end{array}$ & $\begin{array}{c}-0.681387 \\
(1.156423)\end{array}$ \\
\hline Observations & 15,029 & 15,029 & 15,029 & 14,784 \\
\hline Host-Country FE & YES & YES & YES & - \\
\hline Year FE & $\mathrm{NO}$ & YES & YES & YES \\
\hline Sending-Country FE & $\mathrm{NO}$ & NO & YES & - \\
\hline Host-by-Sending Country FE & $\mathrm{NO}$ & $\mathrm{NO}$ & NO & YES \\
\hline
\end{tabular}

From the outset, we can see that dropping the zero fees countries, which make up around 6000 observations, has a major effect on the estimating equation.

The parsimonious regression in Column (1) with only a host-country fixed effect, is counterintuitive. The results here imply that an increase in fees increases the number of international students and and an appreciation of the host-country exchange rate also increases the number of international students. This is most likely due to the lack of a year fixed effect.

When adding year and sending-country fixed effects in Column (2) and (3) the sign on both of these variable flips implying that an increase in fees and an appreciation of host-country exchange rate leads to a decrease in the number of students. The size of the coefficients of logged fees here are much larger than in Table 6.11, as well as both being statistically significant at the $5 \%$ level.

Column (4) presents the results from my preferred specification with a host-by-sending country fixed effect. The coefficients here imply that a $1 \%$ increase in the average domestic fee of a country leads to a $0.42 \%$ decrease in the number of international students in that country and this effect is statistically significant at the $5 \%$ level. Similarly, a $1 \%$ appreciation of a host-country's exchange rate leads to $0.68 \%$ decrease in the number of stu- 
dents, although this effect is not statistically significant.

It appears as if domestic fees for these countries are a reasonable proxy for international fees given the strength of this relationship. I would expect domestic fees to not necessarily affect international student demand except through it's relationship to international fees. Furthermore, the results here are quite similar in magnitude to the results in the New Zealand model Table 6.3 which is reasonably comforting.

Table 6.15: Dropped Observations Model: CI

$(1)$

\begin{tabular}{lc} 
VARIABLES & log_count \\
\hline$l_{\text {log_fees }}$ & {$[-0.811041--0.028930]^{* *}$} \\
log_exchangerate & {$[-2.947934-1.585161]$} \\
& \\
\hline & \\
& \\
&
\end{tabular}

Table 6.15 presents the confidence intervals from the preferred specification Table 6.14, Column (4). The fee elasticity of demand ranges from -0.811 to -0.029 implying that demand is relatively inelastic. The exchange rate elasticity is very variable, implying on the lower end that demand is quite elastic, to being slightly positive with respect to the host-country exchange rate. 


\section{Chapter 7}

\section{Discussion}

This chapter provides a discussion of the results in Chapter 6. I begin in Section 7.1 with a discussion of heterogeneity and its impact on optimal pricing and institutional policy-making. In Section 7.2 I discuss the limitations of this research and avenues for further research to combat and address these limitations. I conclude in Section 7.3 with some final remarks.

\subsection{Optimal Pricing}

\subsubsection{Heterogeneity}

The results from the previous chapter (Section 6.1) actually mask a substantial amount of heterogeneity in price elasticities across New Zealand universities that have important implications for optimal pricing. 
Table 7.1: Full Panel Model: Heterogeneity Across Institutions

\begin{tabular}{|c|c|}
\hline & $\begin{array}{c}(1) \\
\text { log_efts }\end{array}$ \\
\hline University of Auckland*log_fees & $\begin{array}{c}0.173 \\
(0.303)\end{array}$ \\
\hline University of Waikato*log_fees & $\begin{array}{l}-1.548^{*} \\
(0.511)\end{array}$ \\
\hline Massey University*log_fees & $\begin{array}{l}-0.225 \\
(0.340)\end{array}$ \\
\hline Victoria University of Wellington*log_fees & $\begin{array}{l}-0.768^{*} \\
(0.282)\end{array}$ \\
\hline University of Canterbury*log_fees & $\begin{array}{c}-1.055^{\text {*** }} \\
(0.171)\end{array}$ \\
\hline Lincoln University*log_fees & $\begin{array}{c}-2.132^{* *} \\
(0.418)\end{array}$ \\
\hline University of Otago*log_fees & $\begin{array}{l}0.603^{*} \\
(0.187)\end{array}$ \\
\hline Auckland University of Technology* ${ }^{*} \log _{\text {ffees }}$ & $\begin{array}{l}-0.202 \\
(0.361)\end{array}$ \\
\hline rank & $\begin{array}{c}-0.00188^{* *} \\
(0.000416)\end{array}$ \\
\hline Observations & 4225 \\
\hline
\end{tabular}

Table 7.1 shows the NZ Model full panel specification (Table 6.8, Column 3) with the logged fees variable interacted with a dummy for each university. This shows the effect of logged fees specific to a university, or equivalently, their individual fee elasticities of demand.

It is clear that these elasticities vary widely across institutions, and the majority of these elasticities are now statistically significant. Specifically The University of Auckland and The University of Otago appear to have positive fee elasticities of demand, Massey, AUT and Victoria appear to have relatively inelastic demands $\left(E_{F}>-1\right)$ and Canterbury, Waikato and Lincoln have relatively elastic demands $\left(E_{F}<-1\right)$. 
This implies that Auckland and Otago Universities can increase revenues and profit by marginally raising their prices, and perhaps even see an increase in the number of students. This may be because as New Zealand's most highly-ranked universities, an increase in price is seen as a signal for global prestige.

Victoria University of Wellington, Massey University, and AUT appear to have inelastic demands $\left(E_{F}>-1\right)$ and can afford to increase their prices a small amount.

Canterbury, Waikato and Lincoln however have elastic demands (Canterbury, very slightly). The results here imply that the revenue maximising decision is to decrease prices.

However, when we look at the unweighted fee graphs in Chapter 4 (Figure 4.5 and Figure 4.6) it seems as if the universities are increasing their fees at around the same rate as their compatriots, Whilst there are certainly level differences, the average rate of increase appears to be reasonably similar across universities. This is quite interesting, given that the elasticity estimates for Canterbury, Waikato and Lincoln imply decreases in prices would be revenue maximising. Conversely, for Otago and Auckland, the estimates imply that even larger price increases would be revenue maximising.

Why then, are universities not differentiating prices? Two candidates are capacity constraints for elastic universities, and fee caps for inelastic universities. A third factor that would affect both of these categories equally may be equity concerns tying international fees to domestic fees. I discuss each of these concerns forthwith.

\subsubsection{Capacity Constraints}

We generally assume following the literature (Neill, 2009; Bound \& Turner, 2007) that the cost of a given of a university has a very low marginal cost compared to the marginal revenue of an additional student. This is because accommodating an additional student within existing infrastructure is quite low. The difference in cost between a lecturer teaching 20 students versus 21 will be small.

However, there exists significant fixed costs in running a university, the cost of maintaining buildings, lecturers, etc. Furthermore, if a university is 
running at current capacity, the marginal cost of accommodating an additional student will be very high as it will involve expanding current infrastructure, which may be prohibitively expensive.

It may be the case therefore, that these universities price to the revenue maximising-point within capacity constraints. In addition, it is likely that the biggest concern in regards to capacity constraints are domestic students instead of international students.

\subsubsection{Equity Concerns}

New Zealand university domestic fees have been constrained to $4 \%$ as part of the Annual Maximum Fee Movement (AMFM) (Baxter, 2012) although this fee increase has been reduced to 2\% for 2018 (New Zealand Gazette, 2017), this fee constraint has typically been binding.

It may be the case that even though Waikato and Lincoln could increase revenue by decreasing international students prices, they do not want to be seen cutting prices for international students whilst raising the prices for domestic students.

\subsubsection{Information}

Another more simple explanation is that the universities simply do not understand their relevant demand conditions. To my knowledge, this thesis is the first empirical analysis of the demand for New Zealand university places. It may be the case that the universities do not currently know their optimal pricing or elasticities of demand.

\subsection{Limitations and Avenues for Future Work}

One of the biggest limitations facing this research is the lack of exogenous variation in prices. Unfortunately, tuition fees are set in conjunction with student demand and are not necessarily exogenous with respect to the estimating equations in Section 6 (See Subsection 5.1.2).

Whilst my fixed effects and exchange rates approach should control for all time-invariant omitted variable biases, it can not necessarily solve this simultaneity problem. This is plausibly not a huge issue, if we assume that the supply of university places is perfectly elastic. This has generally been 
the assumption in the literature (Neill, 2009), but is an untested assumption that my estimation strategy unfortunately relies on.

There have been a multitude of so-called 'natural' experiments in relation to the relationship between domestic demand and domestic student demand, utilizing plausibly exogenous changes in things like aid programmes and political changes (See Section 2.3). Unfortunately, international student fees are typically less regulated, and international students are much less likely to be eligible for aid programmes. Education for domestic students will typically be quite important in determining the future of a country, whereas it is hard to argue that international students who in the majority, return to their home countries (Wilkinson, 2010).

One candidate for a natural experiment approach that has not been explored to date is the removal of international fees for $\mathrm{PhD}$ programmes in New Zealand. Prior to 2006, international students were required to pay the typical international students of 4-5 times the domestic rate. In 2006 however, the government introduced a policy whereupon international $\mathrm{PhD}$ students were only required to pay domestic fees (Education NZ, 2016a). This was quite a large, plausibly exogenous change in the tuition fees for $\mathrm{PhD}$ students and deserves further investigation.

However, to what degree the results from this experiment would generalize to the undergraduate international student body is unclear. It may be the case that the $\mathrm{PhD}$ internationals students are a fundamentally different population than undergraduates. Furthermore, the policy relevance to university decision-makers is unclear as the majority of fee changes will be much smaller than the 4-5 factor decrease in $\mathrm{PhD}$ fees.

Ultimately, there is a tension in the final analysis of this market between descriptive research, which is generally applicable to current decision-making work, and natural experiments, which may only identify a local treatment effect. This debate has continued on in domestic student research for quite time, but is heightened in the international student market by a lack of plausible natural experiments.

In regards to the OECD model the most obvious issue is the use of domestic fees as a proxy for international fees. Luckily, new releases of the Education at a Glance Indicators (OECD, 2017, 2016) have actually included the average international tuition fee as the importance of this market has increased. Currently, data is available for about half of the countries in 2015 
and the majority of countries in 2013. As time goes on, the availability of this data will increase and a natural extension would be to use these fees instead of a domestic fees.

A final avenue for research is the extension of my fixed effects approach to other countries at a sub-national, across-university level. Whilst I include a wide range of countries in my OECD model (Section 6.2), the data analysed here was the average fee at the country-level. This does not account for within-country across-university differences which are of quite a lot of importance if the results from the NZ Model (Section 6.1) are any indication. Extending my model to other countries such as Australia, Canada, etcetera. seems like a natural avenue for expansion. This could combine the OECD and NZ Model to provide a global model of across-university differences or could be a standalone model of a certain country.

\subsection{Final Remarks}

This research has developed a model of the demand for international student places in New Zealand, and in 17 OECD countries. This contributes to two bodies of literature, the economics of education literature concerned with the impact of tuition fees on college enrolment, and the international migration literature concerned with the determinants of international mobility. The demand of international students intersects both of these topics with international students being both international in the mobility sense and students in the education sense.

I presented two models. My first model was a standalone New Zealand model, focusing on what explains variations in university demand within New Zealand. I found in my preferred specification Table 6.8 that a $1 \%$ increase in fees leads to a $0.4 \%$ decrease in the number of international EFTS within a country-subject-university group, but this effect is not statistically significant. This implies that the demand for New Zealand university is relatively inelastic. However, there is a large amount of heterogeneity in these results, with universities such as Otago and Auckland exhibiting positive demand elasticities and universities such as Lincoln and Waikato exhibiting slightly elastic ones.

My second model analysed the demand of international students destined for 17 OECD countries. Interestingly in the preferred specification 
Table 6.14, the effect of fees is quite similar to the New Zealand model with an elasticity of -0.42. Implying that the demand for international university education in OECD countries is also relatively inelastic.

It is clear that in general, the demand of international students is relatively inelastic. This implies that an increase in prices is likely to decrease the number of students, but this decrease in students is not proportionate to the increase in prices. It appears however, that tuition fees are not necessarily of a great importance to this market. More important, are factors such as university ranking and prestige. 


\section{References}

Abraham, K. G., \& Clark, M. A. (2006). Financial Aid and Students' College Decisions: Evidence from the District of Columbia Tuition Assistance Grant Program. The Journal of Human Resources, 41(3), 578-610. Retrieved from http://www.jstor.org/stable/40057270

Baxter, R. (2012). Sharing the private and public costs of tertriary education. Policy Quarterly, 8(2), 48-53. Retrieved 2017-07-13, from http:// ips.ac.nz/publications/files/4295b3c417c.pdf

Beine, M., Docquier, F., \& Rapoport, H. (2008, April). Brain Drain and Human Capital Formation in Developing Countries: Winners and Losers*. The Economic Journal, 118(528), 631-652. Retrieved 2017-03-09, from http://onlinelibrary.wiley.com.helicon.vuw .ac.nz/doi/10.1111/j.1468-0297.2008.02135.x/abstract doi: 10.1111/j.1468-0297.2008.02135.x

Beine, M., Noel, R., \& Ragot, L. (2012, June). The Determinants of International Mobility of Students (SSRN Scholarly Paper No. ID 2092662). Rochester, NY: Social Science Research Network. Retrieved 2017-0531, from https: //papers. ssrn. com/abstract $=2092662$

Beine, M., Noel, R., \& Ragot, L. (2014, August). Determinants of the international mobility of students. Economics of Education Review, 41, 40-54. Retrieved 2017-03-09, from http://www.sciencedirect .com/science/article/pii/S0272775714000338 doi: 10.1016/j .econedurev.2014.03.003

Bound, J., \& Turner, S. (2007). Cohort crowding: How resources affect collegiate attainment. Journal of public Economics, 91(5), 877-899. Retrieved 2017-05-31, from http://www.sciencedirect.com/science/ article/pii/S0047272706001137

Butcher, A. (2004). International Students in New Zealand: Needs and Responses. International Education Journal, 5(4), 540-551. Retrieved 2017-03-13, from https://eric.ed.gov/?id=EJ903877

Cameron, A. C., \& Miller, D. L. (2015). A practitioners guide to clusterrobust inference. Journal of Human Resources, 50(2), 317-372. 
Campbell, R., \& Siegel, B. N. (1967). The Demand for Higher Education in the United States, 1919-1964. The American Economic Review, 57(3), 482-494. Retrieved 2017-04-04, from http://www . jstor.org.helicon .vuw.ac.nz/stable/1812115

Dreher, A., \& Poutvaara, P. (2005). Student Flows and Migration: An Empirical Analysis (IZA Discussion Paper No. 1612). Institute for the Study of Labor (IZA). Retrieved 2017-03-09, from https://ideas .repec.org/p/iza/izadps/dp1612.html

Dwenger, N., Storck, J., \& Wrohlich, K. (2012, February). Do tuition fees affect the mobility of university applicants? Evidence from a natural experiment. Economics of Education Review, 31(1), 155-167. Retrieved 2017-04-04, from http://www.sciencedirect.com/science/ article/pii/S0272775711001713 doi: 10.1016/j.econedurev.2011.10 .004

Dynarski, S. M. (2003). Does Aid Matter? Measuring the Effect of Student Aid on College Attendance and Completion. The American Economic Review, 93(1), 279-288. Retrieved 2017-04-03, from http://www.jstor.org.helicon.vuw.ac.nz/stable/3132174

Education NZ. (2016a). The Economic Impact of International Education: 2015-2016 Education NZ.

Education NZ. (2016b). International Education Snapshot. Retrieved 2017-03-08, from https://www.enz.govt.nz/news-and-research/ research/international-education-snapshot-january-to -august-2/

Epple, D., Romano, R., \& Sieg, H. (2006, July). Admission, Tuition, and Financial Aid Policies in the Market for Higher Education. Econometrica, 74 (4), 885-928. Retrieved from http://onlinelibrary.wiley.com/ doi/10.1111/j.1468-0262.2006.00690.x/abstract doi: 10.1111/ j.1468-0262.2006.00690.x

European Commision. (2014). Press release - Another record-breaking year for Erasmus. Retrieved 2017-10-11, from http://europa.eu/

Heller, D. E. (1997). Student Price Response in Higher Education: An Update to Leslie and Brinkman. The Journal of Higher Education, 68(6), 624-659. Retrieved 2017-04-03, from http://www.jstor.org .helicon.vuw.ac.nz/stable/2959966 doi: 10.2307/2959966

Hsiao, C. (2005). Why panel data? The Singapore Economic Review, 50(02), $143-154$.

Hubner, M. (2012, December). Do tuition fees affect enrollment behavior? Evidence from a natural experiment in Germany. Economics of Education Review, 31(6), 949-960. Retrieved 2017-0403, from http://www.sciencedirect.com/science/article/pii/ 
S027277571200074X doi: 10.1016/j.econedurev.2012.06.006

Infometrics. (2008). The Economic Impact of Export Education (Tech. Rep.). Education Counts.

Kane, T. J. (2003, May). A Quasi-Experimental Estimate of the Impact of Financial Aid on College-Going (Working Paper No. 9703). National Bureau of Economic Research. Retrieved from http://www.nber .org/ papers/w9703 (DOI: 10.3386/w9703)

Keita, S. (2016, July). Bilateral real exchange rates and migration. Applied Economics, 48(31), 2937-2951. Retrieved 2017-05-19, from http://www.tandfonline.com/doi/full/10.1080/ 00036846.2015.1133893 doi: 10.1080/00036846.2015.1133893

King, R., Findlay, A., \& Ahrens, J. (2010). International student mobility literature review. Retrieved 2017-03-09, from http://sro.sussex.ac .uk/12011/

Leslie, L. L., \& Brinkman, P. T. (1987). Student Price Response in Higher Education: The Student Demand Studies. The Journal of Higher Education, 58(2), 181-204. Retrieved 2017-04-04, from http://www . jstor .org.helicon.vuw.ac.nz/stable/1981241 doi: 10.2307/1981241

Lewin, T. (2013). As interest fades in the humanities, colleges worry. The New York Times, 30.

Mclnnis, C., Peacock, R., Catherwood, V., Brown, J., New Zealand, Ministry of Education, \& PhilipsKPA. (2006). Internationalisation in New Zealand tertiary education organisations. Wellington, N.Z.: New Zealand, Ministry of Education. (OCLC: 156600935)

Ministry of Education. (2011). International Student Enrolments in New Zealand 2004-2010 (Tech. Rep.).

Ministry of Education. (2016). Export Education Levy Annual Report - 2016.

Mixon, F. G., \& Hsing, Y. (1994). The Determinants of Out-of-State Enrollments in Higher Education: A Tobit Analysis. Economics of Education Review, 13(4), 329-35.

Neill, C. (2009, October). Tuition fees and the demand for university places. Economics of Education Review, 28(5), 561-570. Retrieved 2017-04-03, from http://www.sciencedirect.com/science/ article/pii/S0272775709000211 doi: 10.1016/j.econedurev.2009.01 .002

New Zealand Gazette. (2017). The Tertiary Education (2018 Annual Maximum Fee Movement) Notice. Retrieved 2017-11-20, from https:// gazette.govt.nz/notice/id/2017-go2701

Nguyen, H. T., \& Duncan, A. S. (2017, March). Exchange rate fluctuations and immigrants' labour market outcomes: New evidence from Australian household panel data. Journal of International Economics, 
105, 174-186. Retrieved 2017-05-19, from http://www . sciencedirect .com/science/article/pii/S0022199616301702 doi: 10.1016/j .jinteco.2016.12.010

OECD. (2008). Education at a Glance 2008. Paris: Organisation for Economic Co-operation and Development. Retrieved from http:// www . oecd-ilibrary. org/content/book/eag-2008-en

OECD. (2009). Education at a Glance 2009. Paris: Organisation for Economic Co-operation and Development. Retrieved from http:// www. oecd-ilibrary.org/content/book/eag-2009-en

OECD. (2012). Education at a Glance 2012. Paris: Organisation for Economic Co-operation and Development. Retrieved from http:// www . oecd-ilibrary. org/content/book/eag-2012-en

OECD. (2014). Education at a Glance 2014. Paris: Organisation for Economic Co-operation and Development. Retrieved from http:// www . oecd-ilibrary. org/content/book/eag-2014-en

OECD. (2016). Education at a Glance 2016. Paris: Organisation for Economic Co-operation and Development. Retrieved from http:// www . oecd-ilibrary. org/content/book/eag-2016-en

OECD. (2017). Education at a Glance 201\%. Paris: Organisation for Economic Co-operation and Development. Retrieved from http:// www . oecd-ilibrary. org/content/book/eag-2017-en

Rogers, W. (1994). Regression standard errors in clustered samples. Stata technical bulletin, 3(13).

Rosenzweig, M. R. (2007, March). Global Wage Differences and International Student Flows. Brookings Trade Forum, $2006(1)$, 57-86. Retrieved 2017-03-09, from https://muse-jhu-edu.helicon.vuw.ac .nz/article/211316 doi: 10.1353/btf.2007.0011

Rosenzweig, M. R. (2008). Higher education and international migration in Asia: brain circulation. In Annual World Bank conference on development economics (pp. 59-100).

Sa, F. (2014, August). The Effect of Tuition Fees on University Applications and Attendance: Evidence from the UK (IZA Discussion Paper No. 8364). Institute for the Study of Labor (IZA). Retrieved 2017-04-03, from http://econpapers.repec.org/paper/izaizadps/ dp8364.htm

Schaffer, M. E. (2015). xtivreg2: Stata module to perform extended IV/2sls, GMM and AC/HAC, LIML and k-class regression for panel data models. Statistical Software Components.

Smart, W. (2014). The Performance of NZ Universities in International Rankings (Tech. Rep.). Ministry of Education.

Verbeek, M. (2008). A guide to modern econometrics. John Wiley \& Sons. 
Wei, H. (2013, July). An empirical study on the determinants of international student mobility: a global perspective. Higher Education, 66 (1), 105-122. Retrieved 2017-03-13, from https://link-springer-com .helicon.vuw.ac.nz/article/10.1007/s10734-012-9593-5 doi: $10.1007 / \mathrm{s} 10734-012-9593-5$

Wilkinson, A. (2010). Life after study: international students' settlement experiences in New Zealand. Wellington, N.Z.: Dept. of Labour. (OCLC: 708359471)

Wooldridge, J. M. (2010). Econometric analysis of cross section and panel data. MIT press.

Zuccollo, J., Maani, S., Kaye-Blake, B., Zeng, L., \& others. (2013). Private returns to tertiary education. How does New Zealand compare to the OECD (Tech. Rep.). New Zealand Treasury. 
Appendices 


\section{Appendix A}

\section{New Zealand Model}

\section{A.1 International EFTS by Country, (All Coun- tries)}

Figure A.1: International EFTS by Country: Afghanistan - Luxembourg

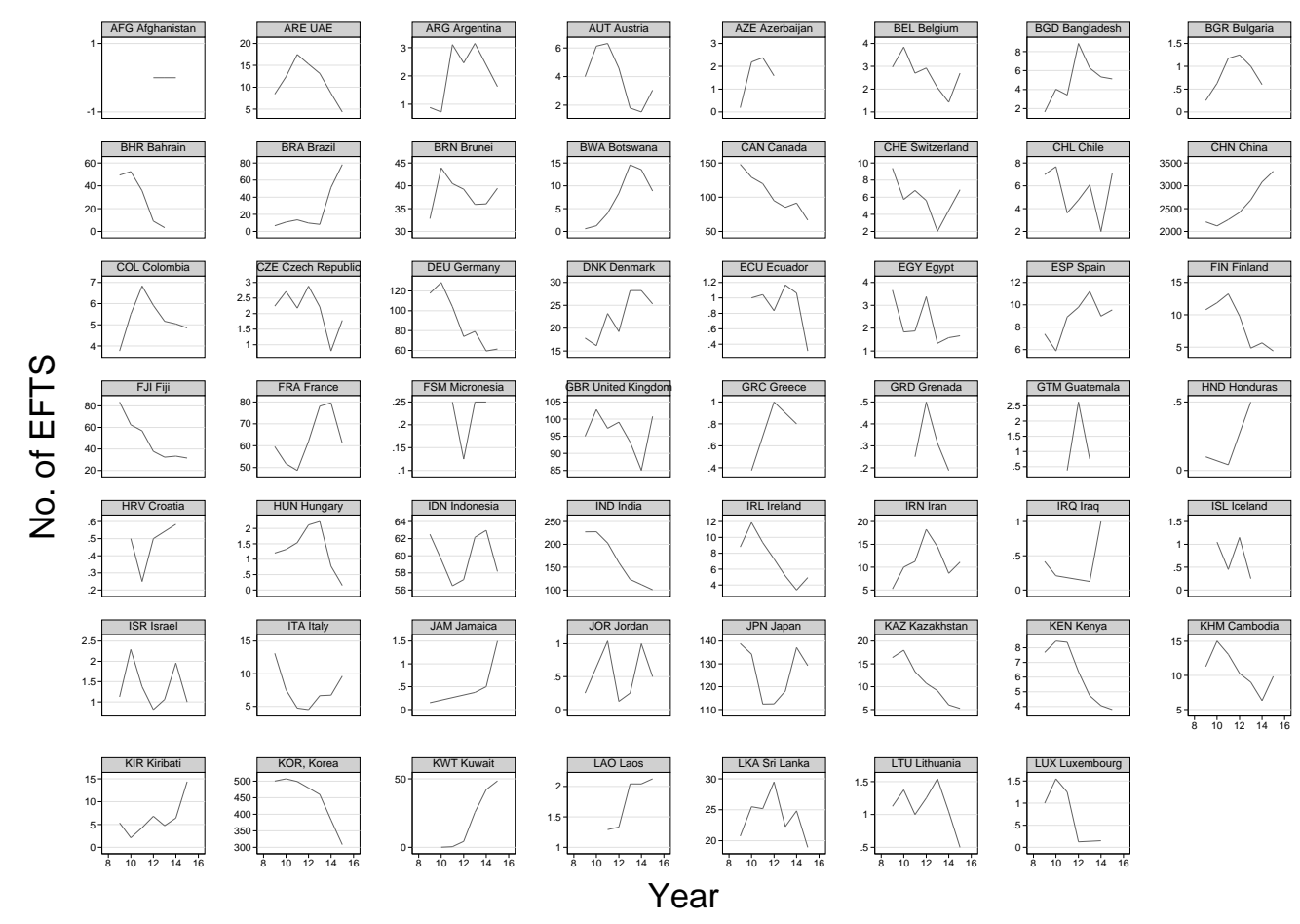


Figure A.2: International EFTS by Country: Morocco - Zimbabwe

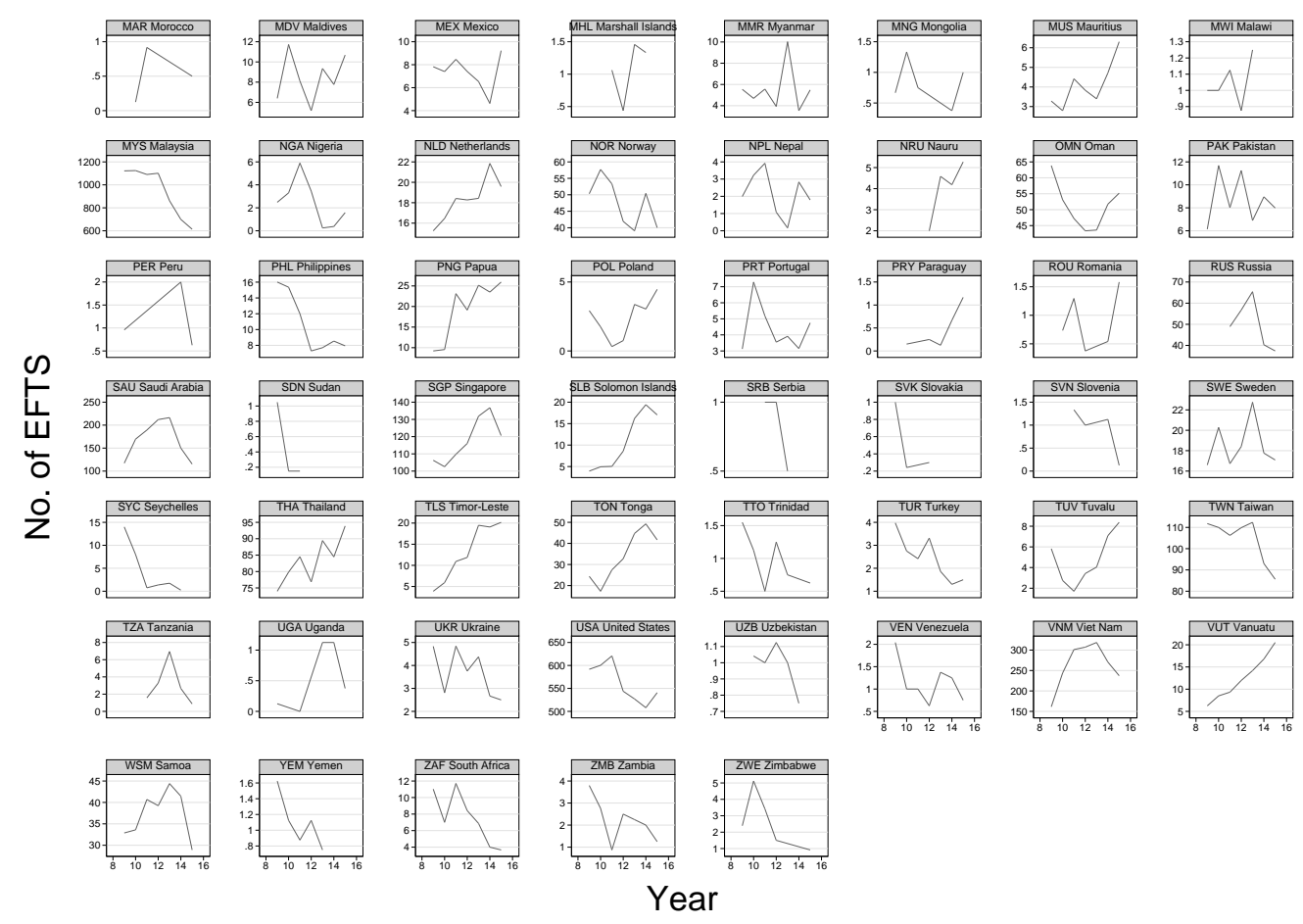

\section{A.2 EFTS by University for Selected Courses}

This appendix shows the international EFTS, by university, for four selected NZCED subjects: Commerce, Science, Health and Society and Culture (Humanities). 
Figure A.3: International EFTS by University: Commerce
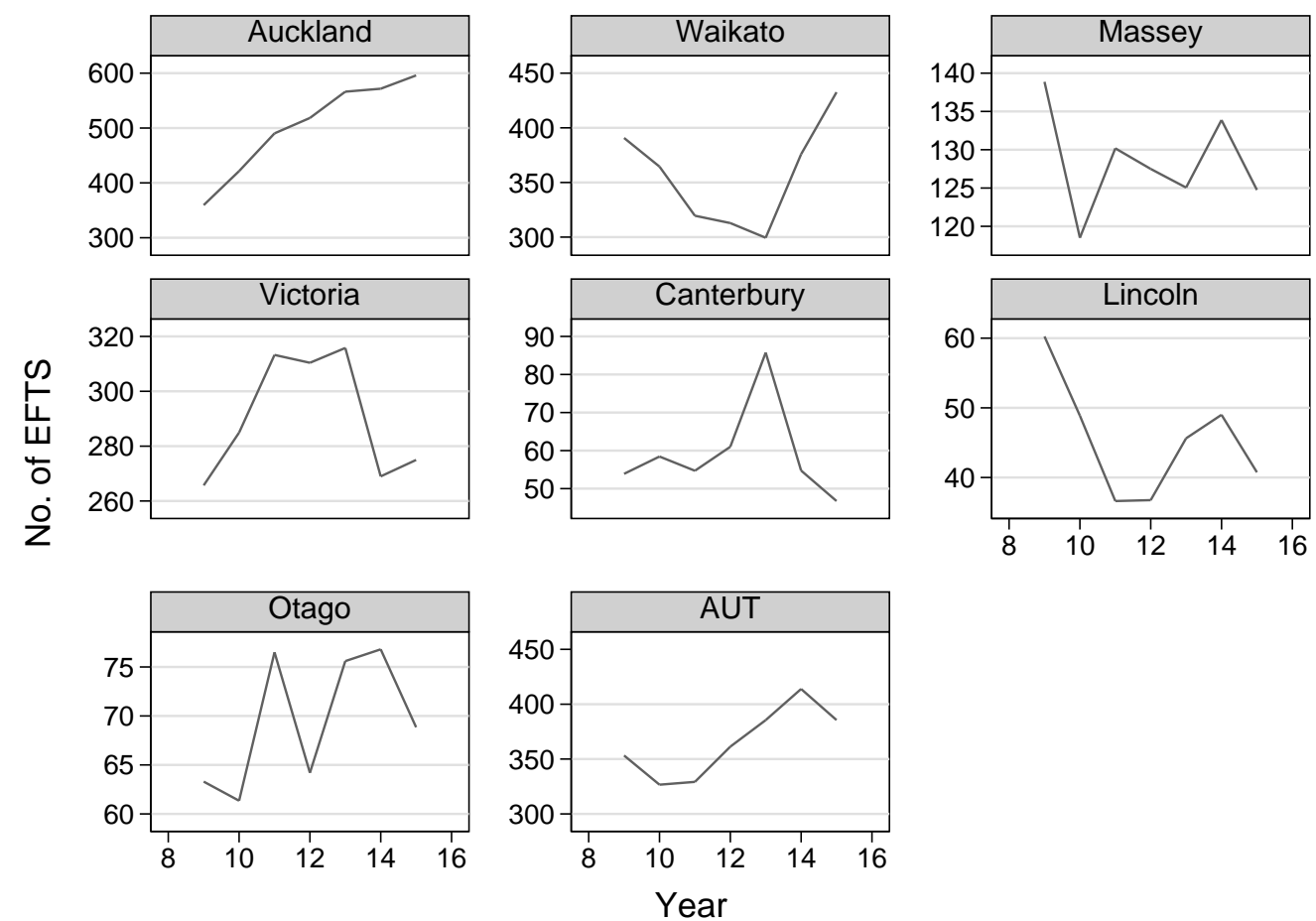
Figure A.4: International EFTS by University: Science
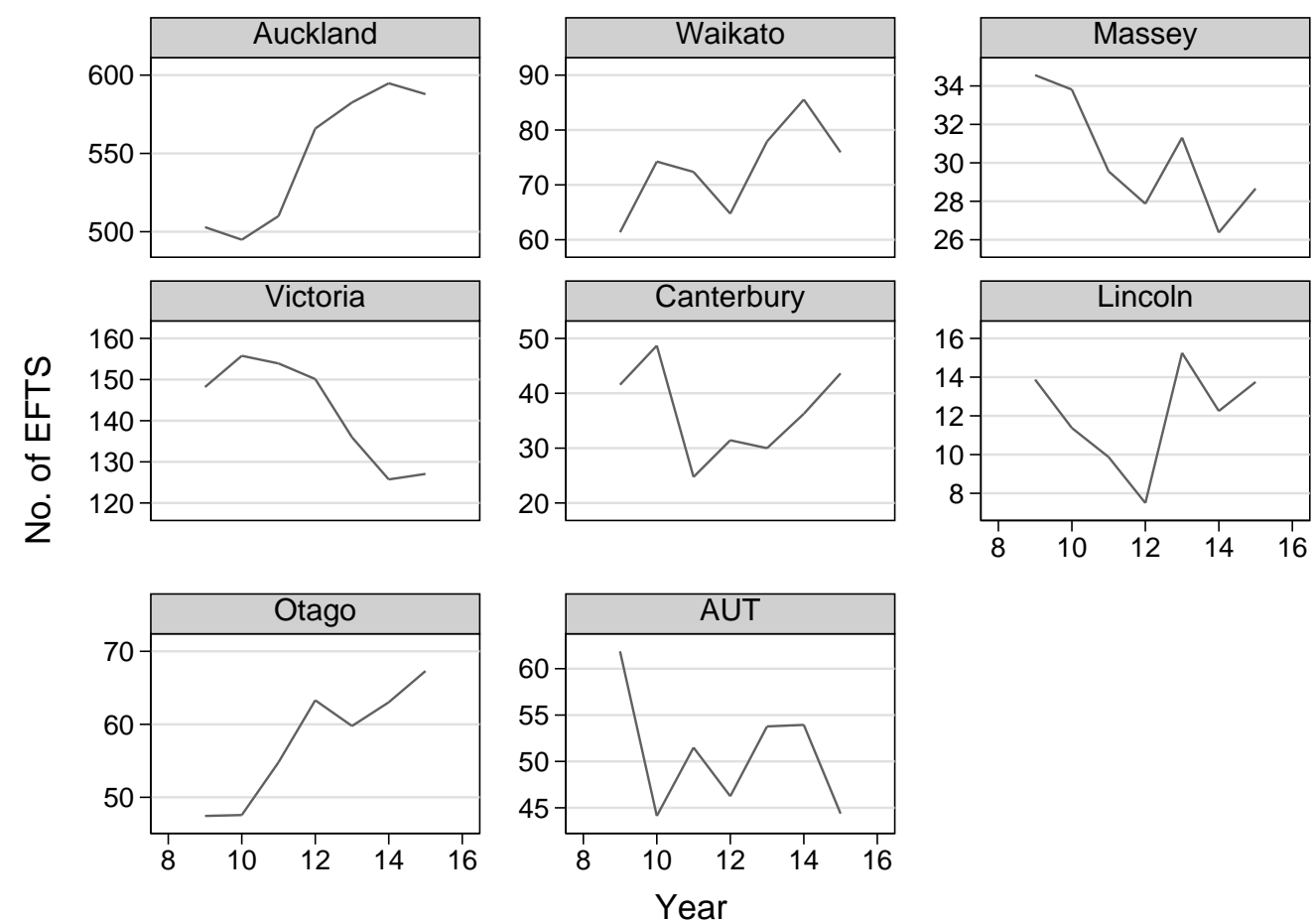
Figure A.5: International EFTS by University: Health
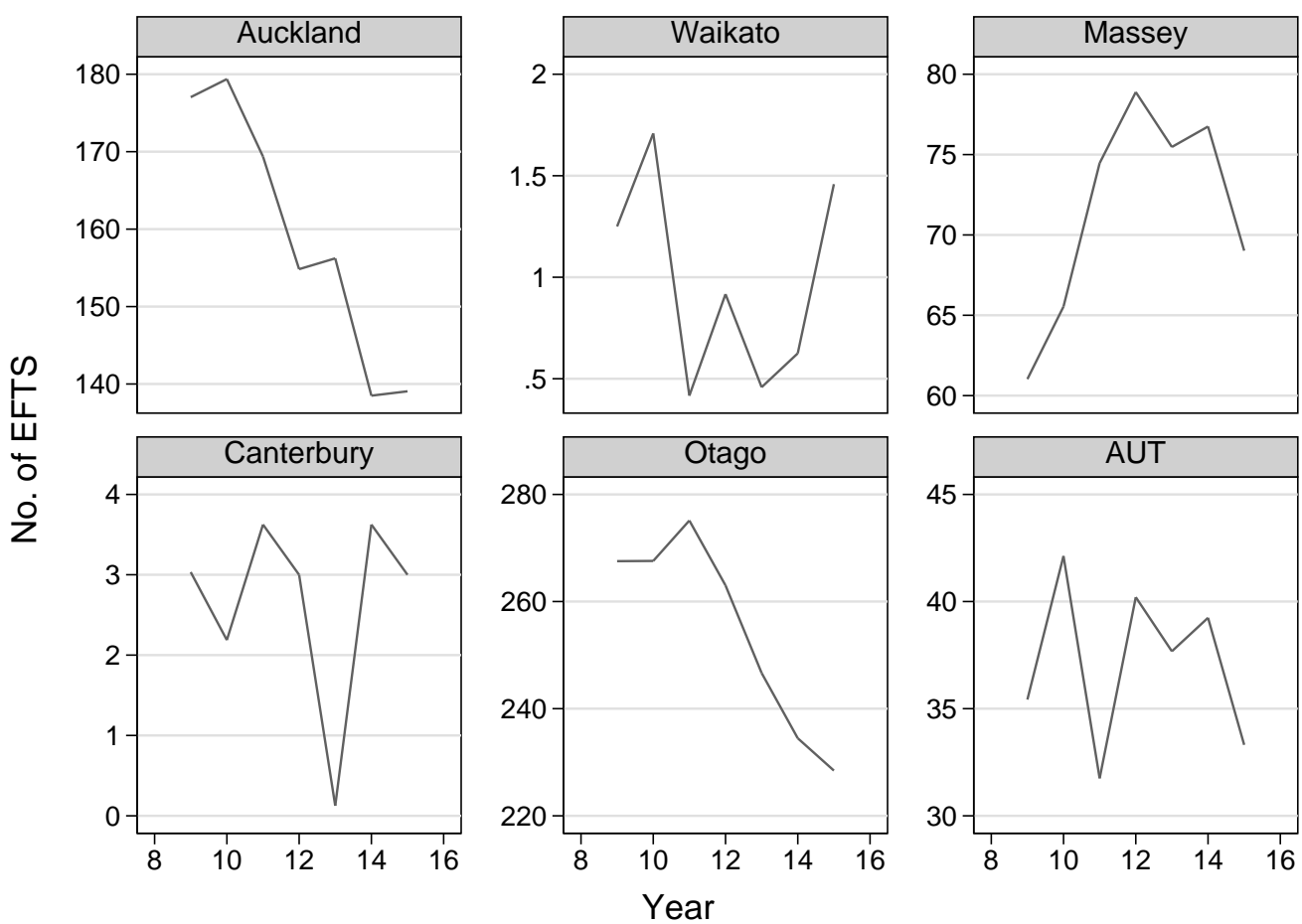
Figure A.6: International EFTS by University: Society and Culture
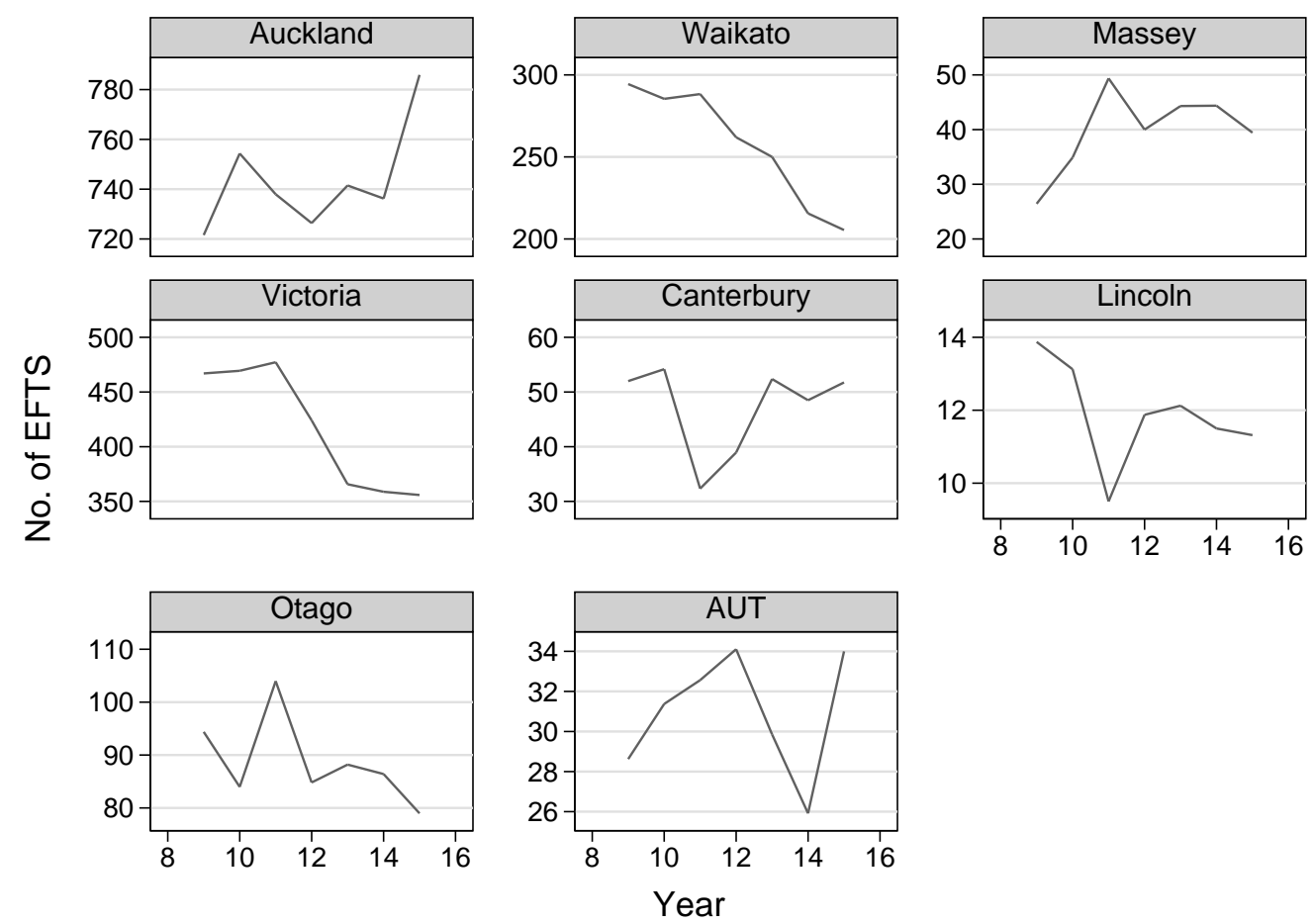

\section{A.3 University Fees by Course}

This appendix shows the average fee from Commerce, Science, Health and Humanities courses in each university (if they are offered) per year. These are the major courses that international students take in New Zealand (with the exception of general programmes). The majority of these follow the general trend of fees, i.e increasing continuously over the entirety of the sample. 
Figure A.7: Average Commerce Fee by Year
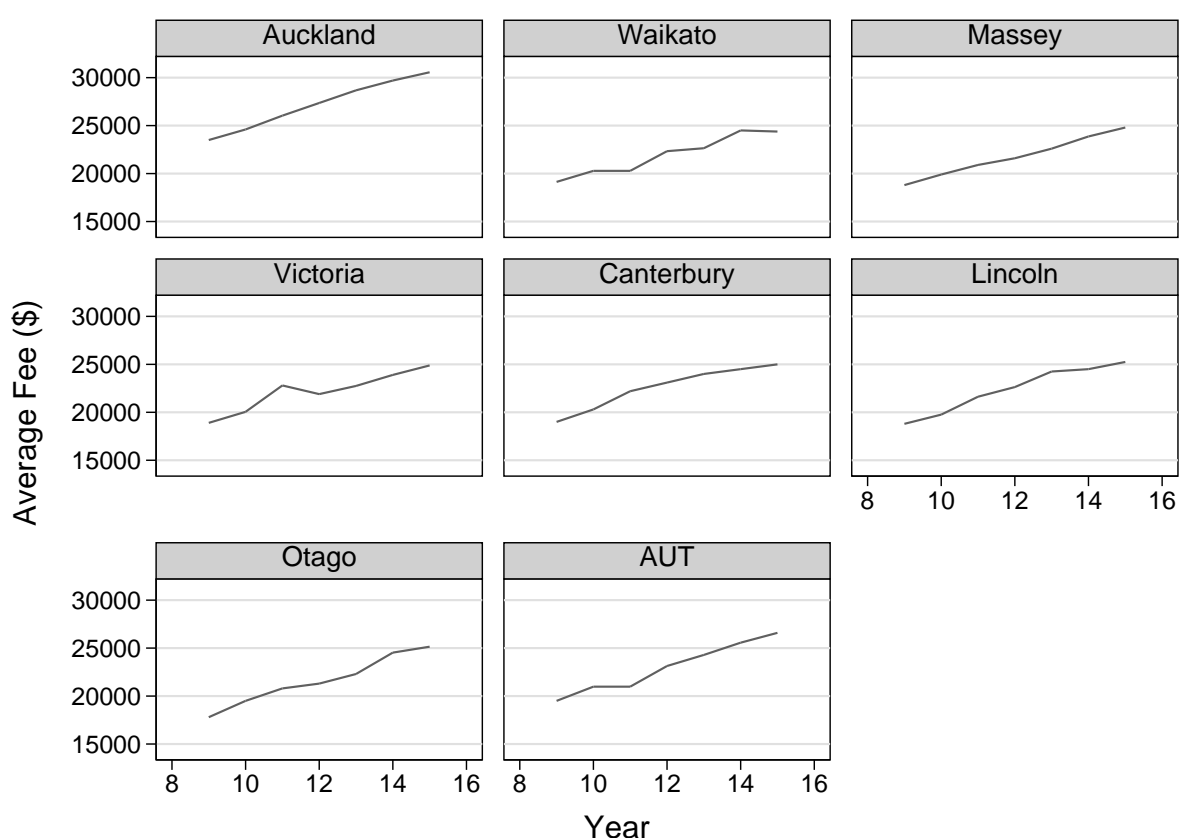

Figure A.8: Average Science Fee by Year
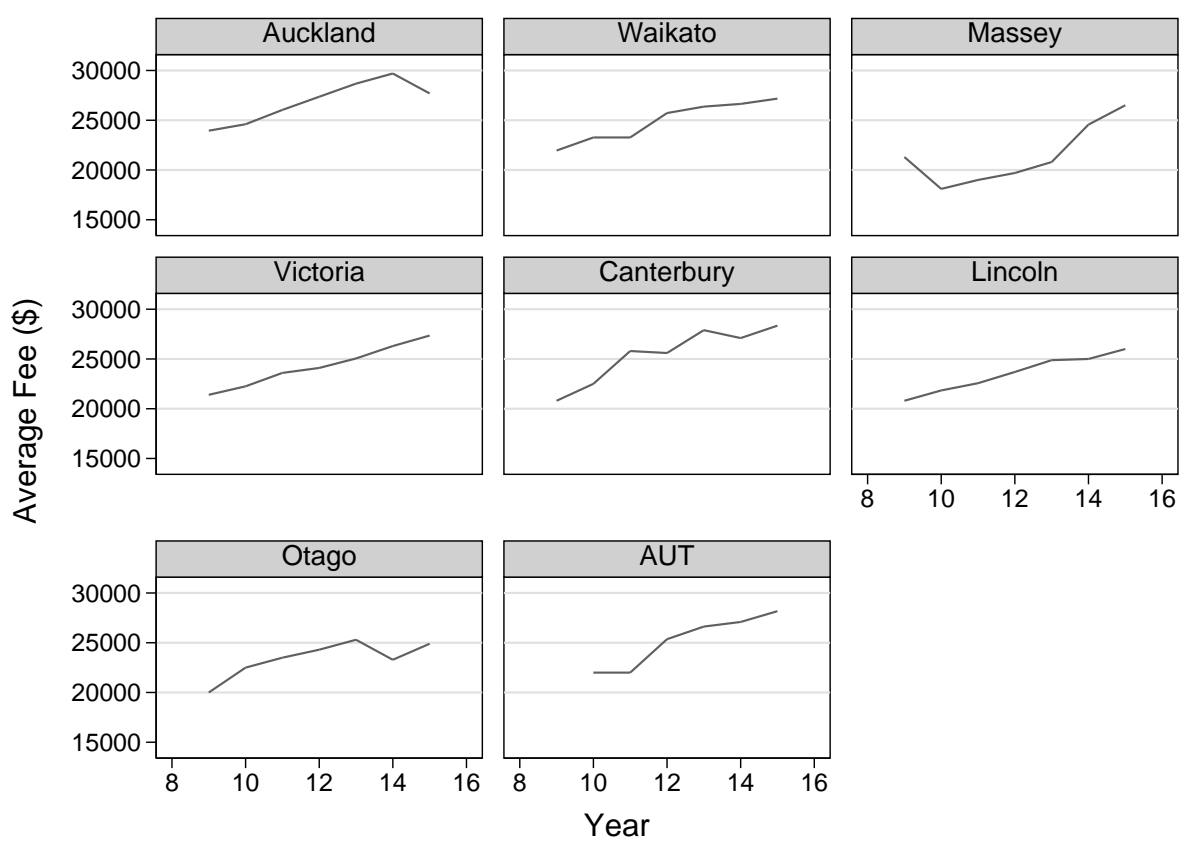
Figure A.9: Average Health Fee by Year
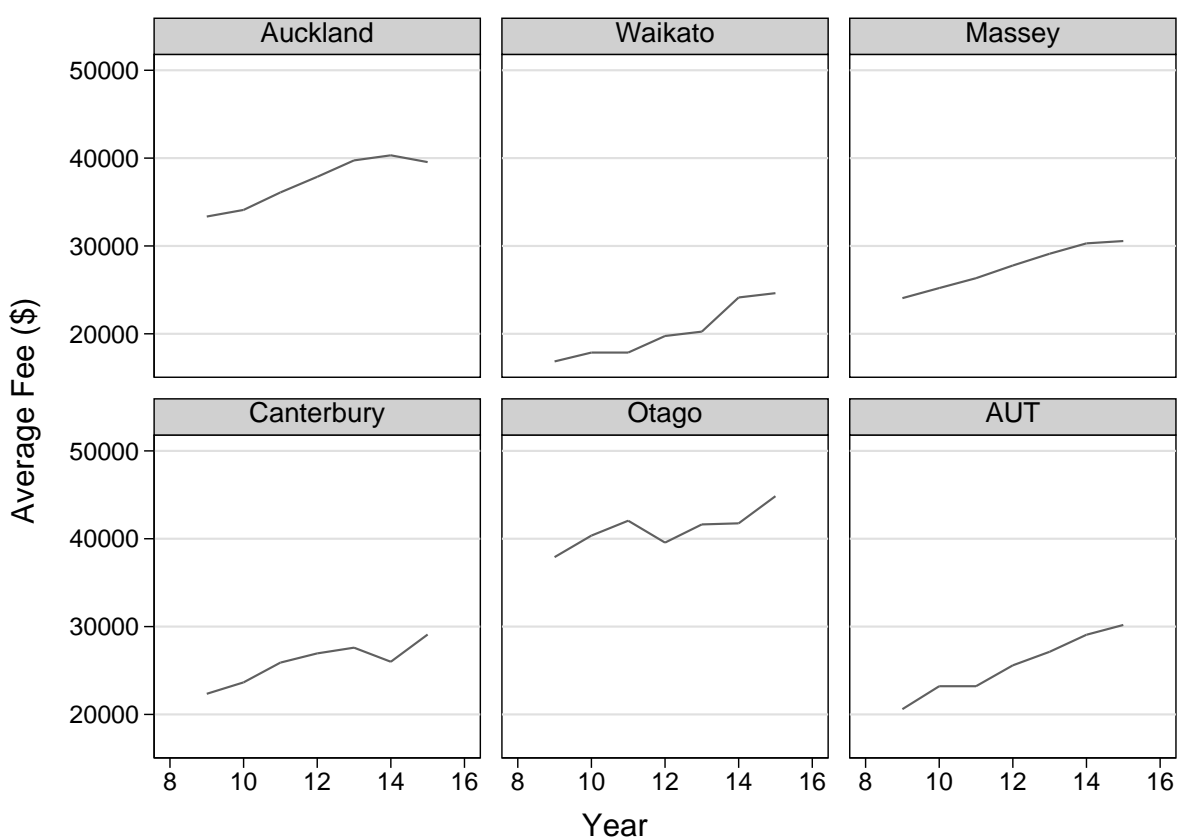

Figure A.10: Average 'Society and Culture' (Humanities) Fee by Year
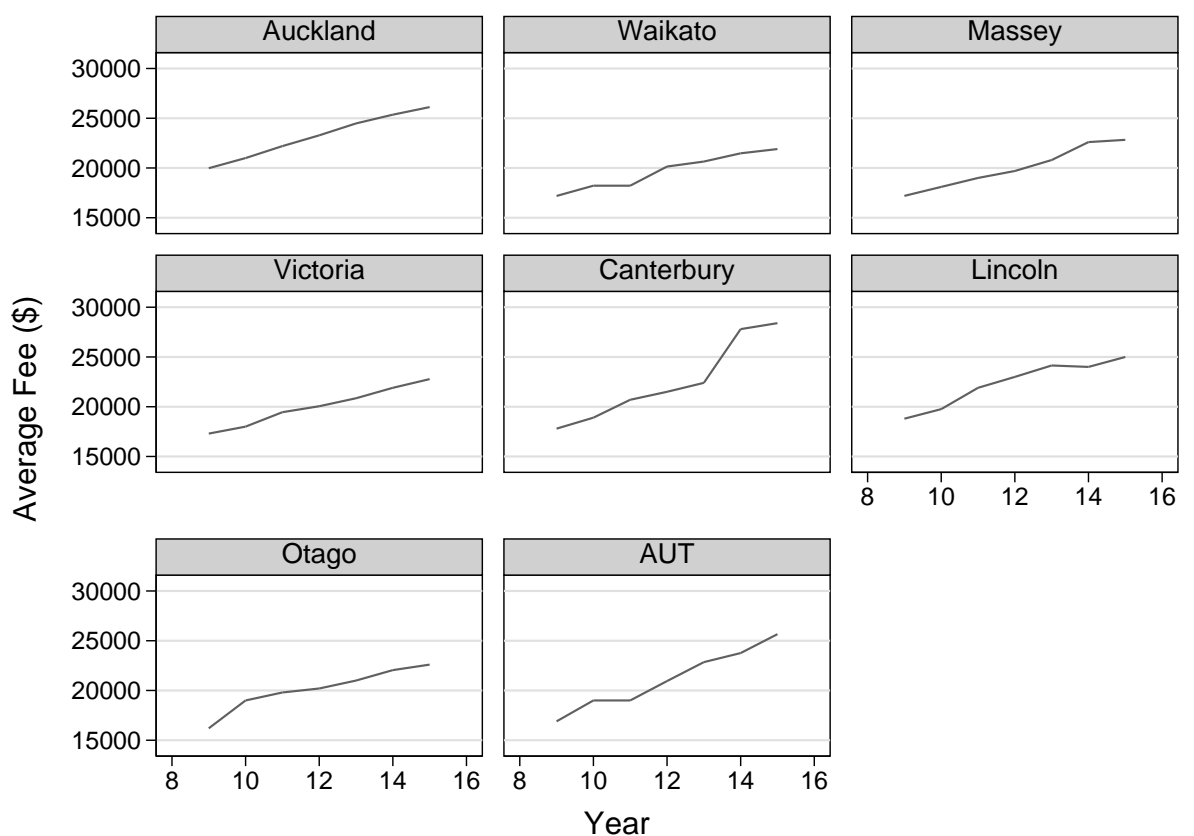


\section{Appendix B}

\section{OECD Model}

\section{B.1 Foreign Fees Assumptions}

The following graphs provide regression evidence for the assumptions made in the all countries model (Section 6.2) surrounding the plausibility of domestic fees as a proxy for international fees. Both regressions use the data from Section 6.2.

Table B.1: International Fees Versus Domestic Fees

$$
\begin{array}{cc}
\hline \text { VARIABLES } & \begin{array}{c}
(1) \\
\text { fees_foreign }
\end{array} \\
\hline \text { fees_domestic } & \begin{array}{c}
1.258143^{* * *} \\
(0.360516)
\end{array} \\
\hline * * * \mathrm{p}<0.01,{ }^{* *} \mathrm{p}<0.05,{ }^{*} \mathrm{p}<0.1
\end{array}
$$

Table B.1 regresses international fees on domestic fees in 2013 and 2015. We can see that international fees are positively correlated with domestic fees and this effect is statistically significant at the $1 \%$ level.

Table B.2: Change in International Fees Versus Domestic Fees

\begin{tabular}{cc}
\hline VARIABLES & $\begin{array}{c}(1) \\
\text { d_fees_foreign }\end{array}$ \\
\hline d_fees_domestic & 1.916692 \\
& $(3.561339)$ \\
\hline & \\
\hline$* * * \mathrm{p}<0.01,{ }^{* *} \mathrm{p}<0.05,{ }^{*} \mathrm{p}<0.1$
\end{tabular}


Table B.2 regress the change in international fees from 2013 to 2015 against the change in domestic fees from 2013 to 2015. This tests the assumption that changes in international fees are correlated with changes in domestic fees. We can see that changes in international fees are correlated with changes in domestic fees, although the effect is no longer significant. This due to an increase in standard errors from Table B.1 rather than a decrease in the magnitude of the effect. 


\section{B.2 Sending-Country International Students}

Figure B.1: Number of International Students at OECD Universities, by Sending Country (Afghanistan - Jamaica)

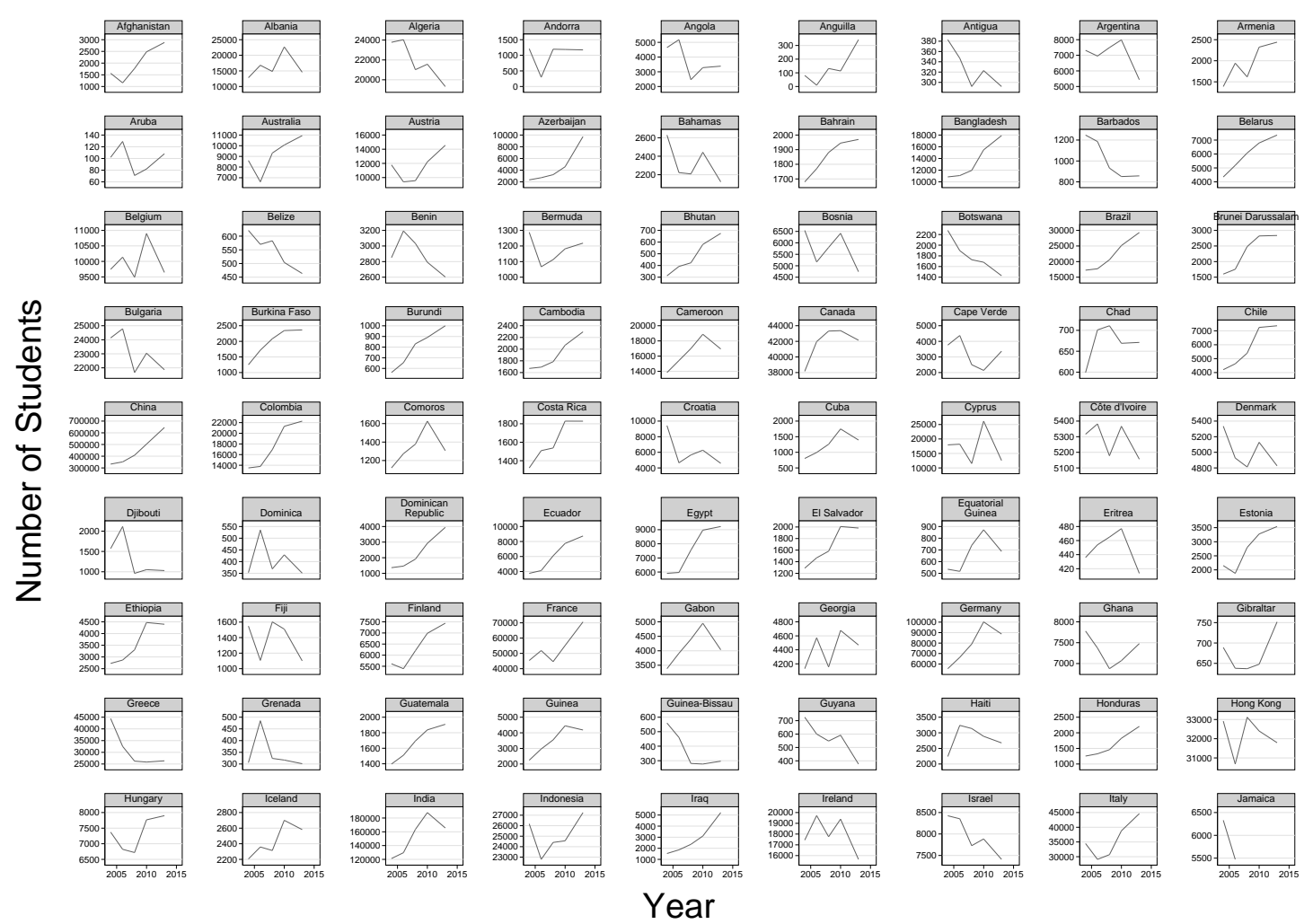


Figure B.2: Number of International Students at OECD Universities, by Sending Country (Jamaica - Timor-Leste)

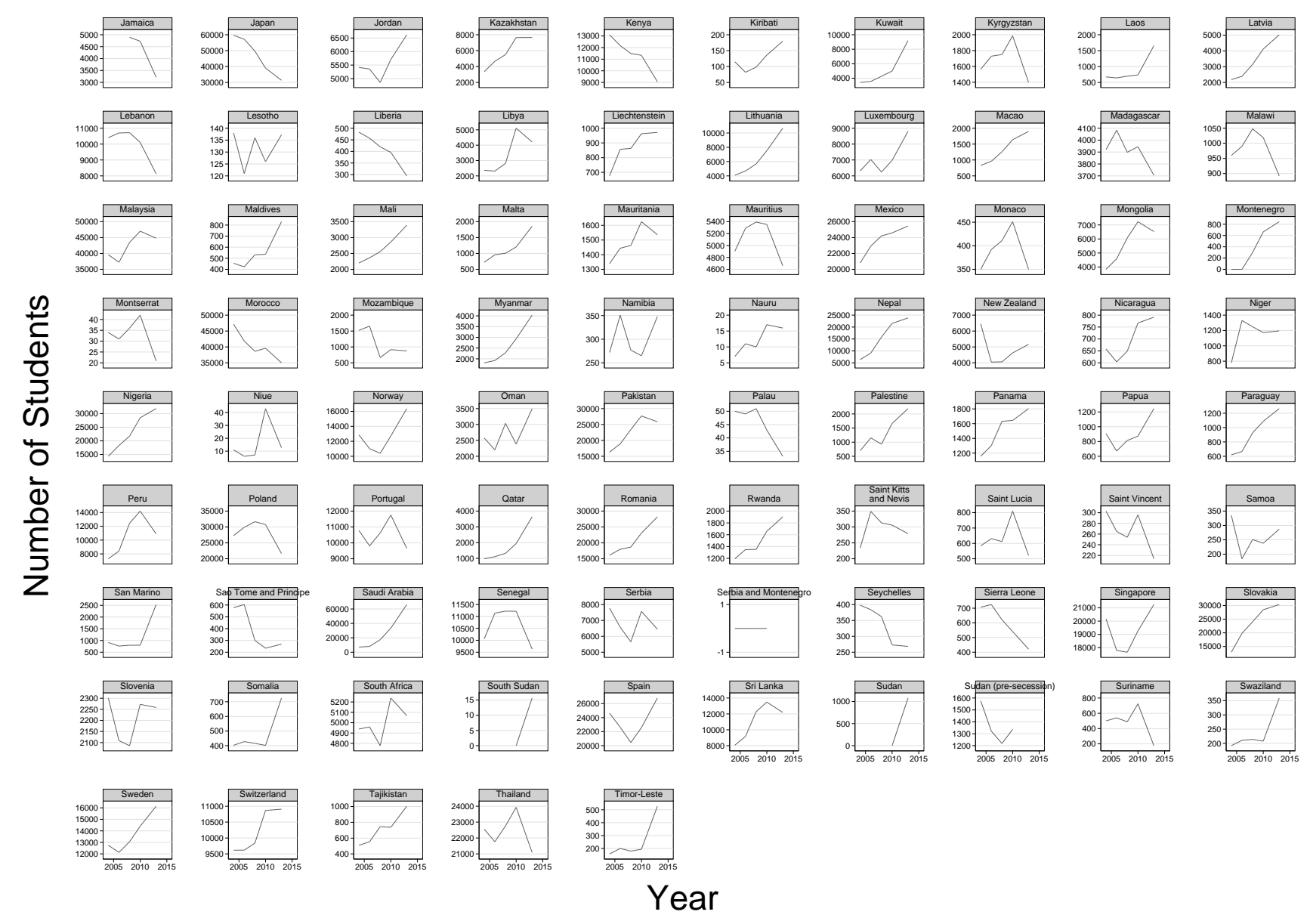


Figure B.3: Number of International Students at OECD Universities, by Sending Country (Togo - Macedonia)

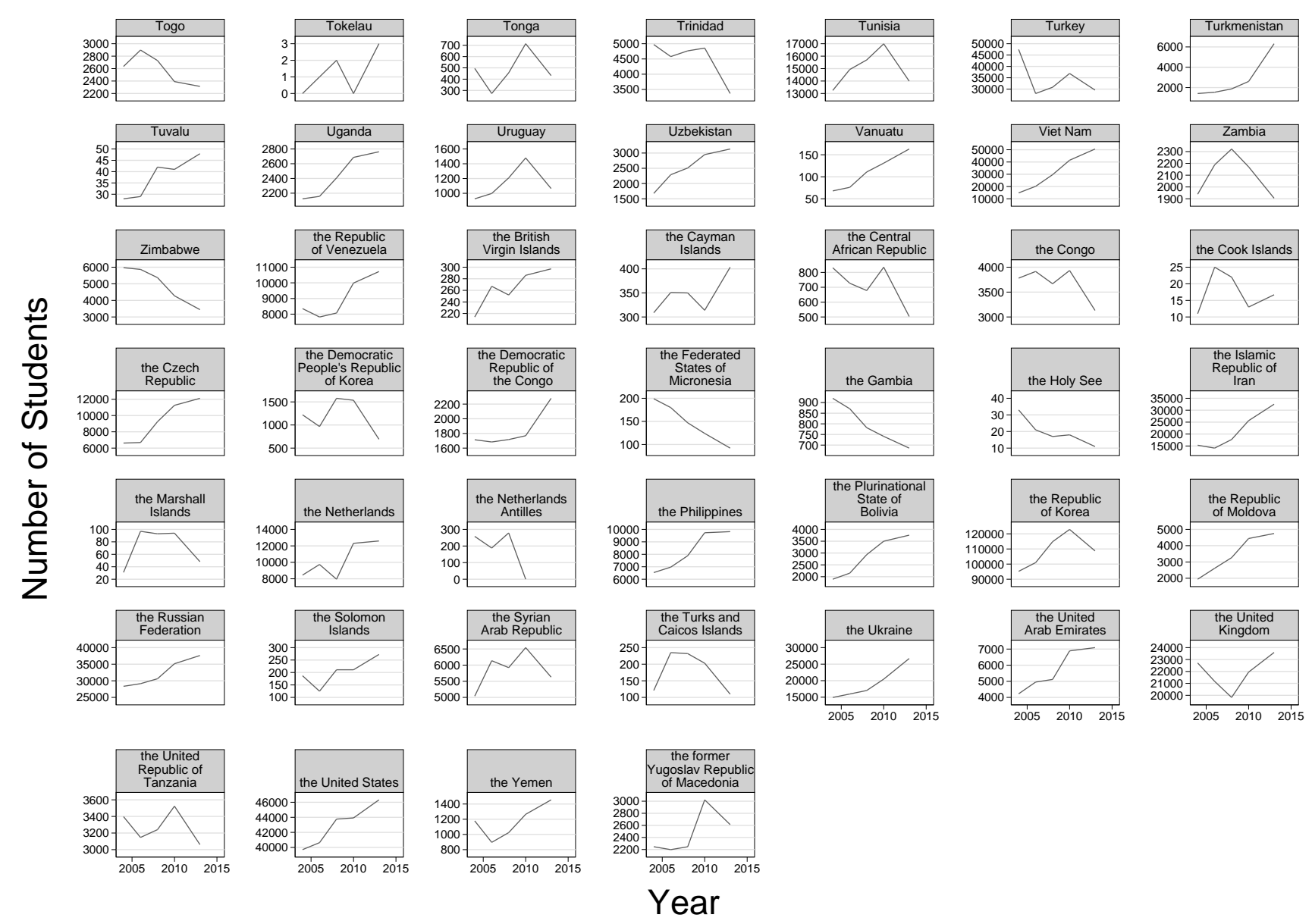

